\title{
WestVirginiaUniversity
}

THE RESEARCH REPOSITORY @ WVU

Graduate Theses, Dissertations, and Problem Reports

2003

\section{Recreational opportunities and health status in West Virginia}

\author{
Yoav Sneh \\ West Virginia University
}

Follow this and additional works at: https://researchrepository.wvu.edu/etd

\section{Recommended Citation}

Sneh, Yoav, "Recreational opportunities and health status in West Virginia" (2003). Graduate Theses,

Dissertations, and Problem Reports. 1727.

https://researchrepository.wvu.edu/etd/1727

This Thesis is protected by copyright and/or related rights. It has been brought to you by the The Research Repository @ WVU with permission from the rights-holder(s). You are free to use this Thesis in any way that is permitted by the copyright and related rights legislation that applies to your use. For other uses you must obtain permission from the rights-holder(s) directly, unless additional rights are indicated by a Creative Commons license in the record and/ or on the work itself. This Thesis has been accepted for inclusion in WVU Graduate Theses, Dissertations, and Problem Reports collection by an authorized administrator of The Research Repository @ WVU. For more information, please contact researchrepository@mail.wvu.edu. 


\title{
Recreational Opportunities and Health Status in West Virginia
}

\author{
Yoav Sneh \\ Thesis Submitted to the Davis College of \\ Agriculture, Forestry, and Consumer Sciences \\ at West Virginia University \\ in Partial Fulfillment of the Requirements \\ for the Degree of \\ Master of Science \\ In \\ Agricultural and Resource Economics \\ Randall S. Rosenberger, Ph.D., Chair \\ Tim T. Phipps, Ph.D. \\ Gerard E. D'Souza, Ph.D. \\ Department of Resource Economics
}

Morgantown, West Virginia

2003

Keywords: Recreational Supply, Health-Status, Physical Activity Copyright 2003 Yoav Sneh 


\section{ABSTRACT \\ Recreational Opportunities and Health Status in West Virginia Yoav Sneh}

Over half of all Americans are considered to be physically inactive and/or obese, leading to significant individual and societal costs. This study investigates the link between recreational supply and health status for West Virginia. Using spatial econometric techniques, this study provides solid evidence that the demand for health care is positively associated with physical inactivity rates, and that physical inactivity rates are inversely related to the supply of recreational opportunities. When promoting the importance of physical activity as preventative health care, policy makers should consider the provision of recreational opportunities as a means to overcome sedentary behaviors. 


\section{ACKNOWLEDGMENTS}

I greatly appreciate the help and support my committee members provided me upon completing this research. First, I would like to thank Dr. Rosenberger, who as a chairman of my committee and my main advisor, introduced me to this project and provided guidance, professional support, theoretical and practical input, and shared with me his valuable experience. Further, any time I approached him, Dr. Rosenberger was accessible and willing to help in a friendly fashion that encouraged me to pursue this research with enthusiasm and joy.

Thanks also go to Dr. Phipps and Dr. D'Souza for serving on my committee and for their insightful comments, support, and high academic standards that helped in making this research valuable and worthy. Dr. Phipps is also entitled to special thanks for helping me overcoming some of the spatial issues involved in this research.

Finally, I would like to thank the entire staff, faculty, and graduate students of the Division of Resource Management for making my time at West Virginia University educational, productive, and enjoyable. 


\section{TABLE OF CONTENTS}

CHAPTER ONE: INTRODUCTION ..................................................................... 1

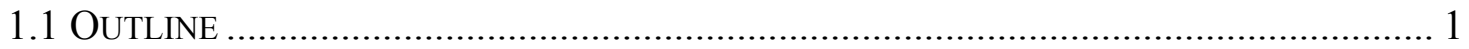

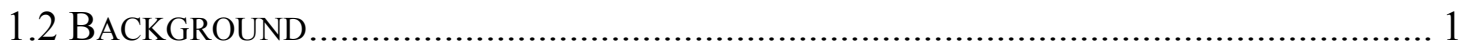

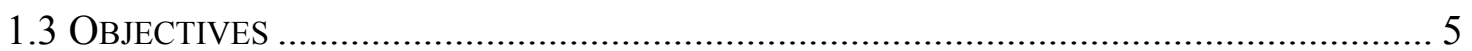

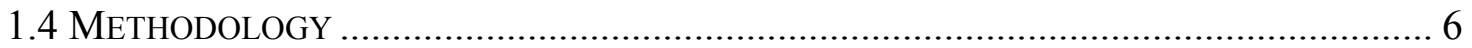

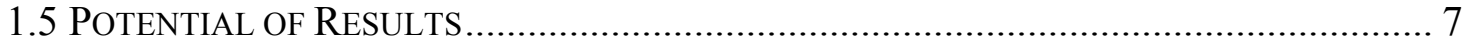

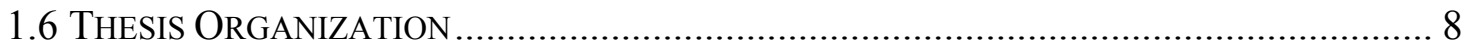

CHAPTER TWO: LITERATURE REVIEW ............................................................ 9

2.1 The IMPORTANCE OF LifESTYLES AND THEIR AsSOCIATION WITH HEALTH StATUS . 9

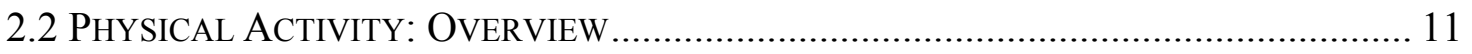

2.2.1 Health Benefits of Physical Activity ........................................................... 11

2.2.2 Economic Benefits of Physical Activity......................................................... 16

2.2.3 The Current State of Physical Activity in the United States ........................... 23

2.2.4 Determinants of Physical Activity.................................................................. 24

2.2.5 Analysis of the Current State of Physical Activity in the United States.......... 26

2.3 Recreation and Recreational Activities to Promote Physical ACtivity . 31

2.4 Policy Interventions to Promote Physical Activity .................................... 32

CHAPTER THREE: METHODOLOGY ........................................................ 34

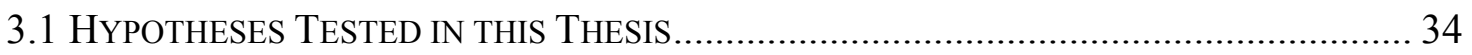

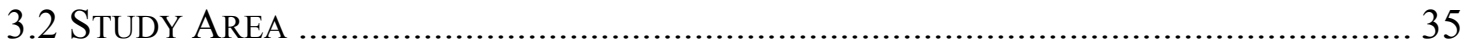

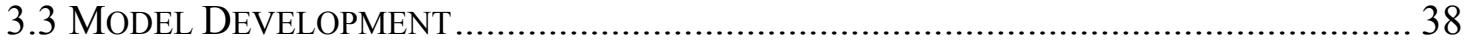

3.3.1 Spatial Analysis................................................................................. 41

3.3.2 Dependent Variables..................................................................................... 46

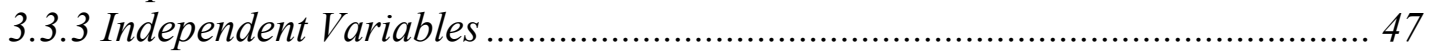

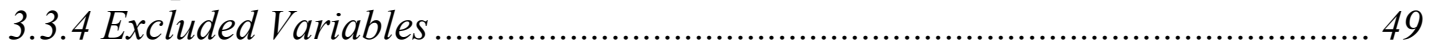

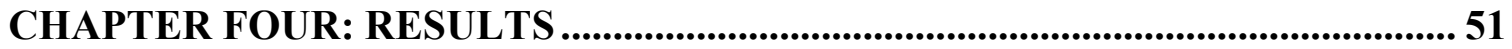

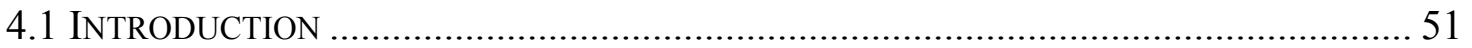

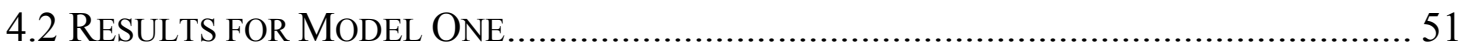

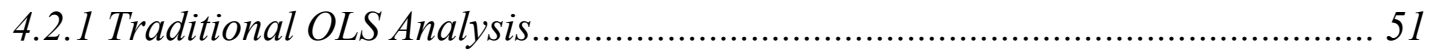

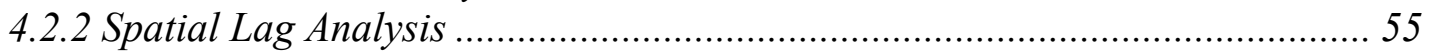

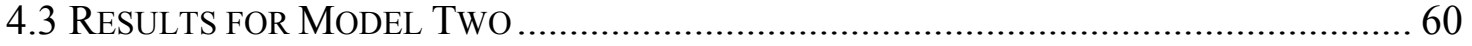

4.3.1 Specification of Simultaneous Equations for Model Two ............................. 61

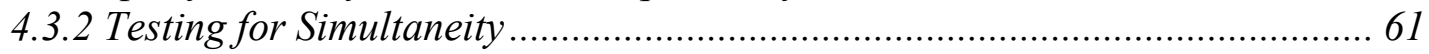

4.3.3 Two Stage Least Squares Spatial Durbin Model ......................................... 63

\section{CHAPTER FIVE: SUMMARY OF RESULTS, CONCLUSIONS AND POLICY} IMPLICATIONS, AND SUGGESTIONS FOR FUTURE STUDY ........................ 65

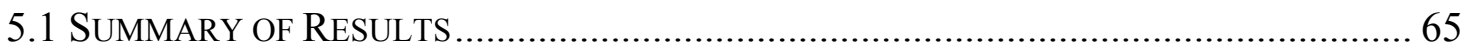

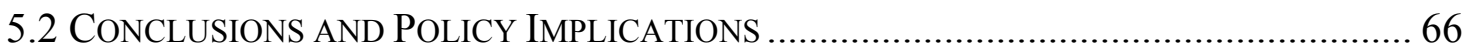

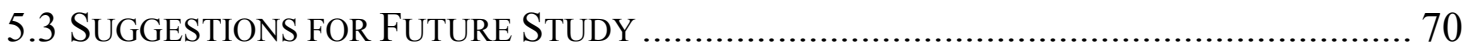

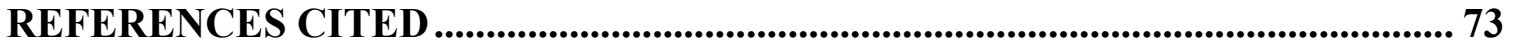




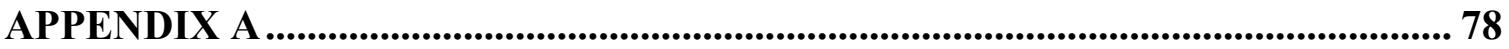

HEALTH VALUATION METHODS....................................................................... 78

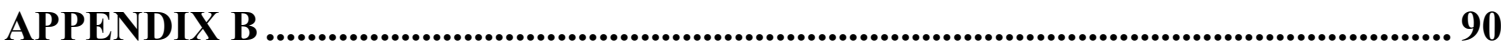

REGRESSION RESULTS (LIMDEP AND SPACESTAT OUTPUT) ..................... 90

Traditional OLS Analysis (LIMDEP) .............................................................. 90

SPACESTAT Regression Diagnostics for the Non-Spatial OLS Model.................... 90

First Order Spatial Lag Analysis (LIMDEP).................................................... 91

First Order Spatial Lag Analysis (SPACESTAT) ................................................ 91

Two Stage Least Squares Spatial Durbin Model: PHINAC97 (LIMDEP) .............. 92

Two Stage Least Squares Spatial Durbin Model: OBES97 (LIMDEP)................... 92

DESCRIPTIVE STATISTICS.................................................................................93

\section{LIST OF TABLES AND FIGURES}

Figure 2.1: The Relationship between Physical Activity Level and Health Outcomes....14

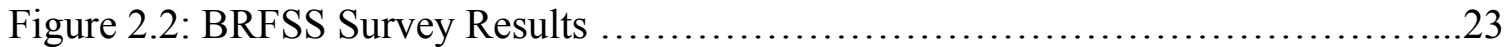

Figure 2.3: The Relationship between Physical Activity and Health Benefits ............30

Figure 2.4: No Leisure-Time Physical Activity among Adults .......................33

Figure 3.1: Comparison between West Virginia and the U.S. .......................... 35

Figure 3.2: Risk Factors and Preventive Services, West Virginia and the U.S. ............36

Figure 3.3: Per Capita Hospital Total Charges for Diseases and Disorders of the

Circulatory System 1999 .........................................................

Figure 3.4: Behavioral Prevalence - Physical Inactivity 1997 (\%) ......................42

Figure 3.5: Behavioral Prevalence - Obesity 1997 (\%)................................43

Table 3.1: Dependent Variables .................................................. 47

Table 3.2: Independent Variables ................................................... 48

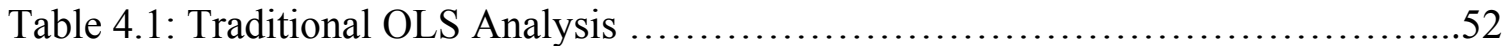

Table 4.2: SPACESTAT Regression Diagnostics …............................55

Figure 4.1: Distribution of the Residuals of an OLS Model ..........................55

Table 4.3: First Order Spatial Lag Analysis .......................................56

Figure 4.2: Distribution of the Residuals of a Spatial Lag Model .......................58

Table 4.4: Results of Hausman Specification Test for Simultaneity ...................62

Table 4.5: Two Stage Least Squares Spatial Durbin Models ............................63 


\section{CHAPTER ONE: INTRODUCTION}

\subsection{Outline}

There are numerous benefits inherent in physically active lifestyles. Health benefits, economic benefits, and social benefits are a few. Policy makers are aware of these benefits and try to promote more physically active lifestyles. Yet, more than $50 \%$ of Americans are defined as physically inactive. Investing in recreational facilities might provide the necessary opportunities and options for increasing physical activity rates. This thesis will examine the relationships between physical inactivity levels, measures of physical activity related health status, and the supply and provision of recreational opportunities across the counties of West Virginia.

\subsection{Background}

Over the last couple of decades, a powerful movement, commonly referred to as "the health revolution", has emerged in the United States. Americans today are well aware of the risks associated with unhealthy lifestyles, professions, and behaviors. Americans also acknowledge the benefits, which are associated with healthy and active lifestyles. These benefits are not solely health benefits that are consistent with higher life expectancy; rather they are related to a large array of benefits as improved quality of life, greater well being, economic and social benefits, and so forth.

The reason that health, healthy lifestyles, health promotion, and other healthoriented issues are gaining so much of the public's attention nowadays is straightforward. Most diseases that affect Americans today are chronic diseases, such as cardiovascular diseases, cancer, and diabetes mellitus. These chronic diseases account for the most deaths in the United States. Therefore, Americans have started to realize that the health system, as progressive as it is, might not be as effective against these chronic diseases as lifestyle changes can be. Hence, the notion people are getting is that in order to prevent and battle modern diseases effectively, some behaviors associated with sedentary lifestyles should be abandoned and replaced by behaviors associated with healthy, active lifestyles.

Clearly, our health status is a function of multiple factors. Heredity is obviously a key factor in one's health status. However, we cannot control the genetic makeup we 
inherit from our parents. Nevertheless, there are other factors that influence our health that we can control and modify. Health status is also a function of our physical and social environment, socio-demographic characteristics, accessibility to health care, and lifestyles. Recently, the issue of lifestyles is gaining so much attention because it turns out that the major causes for morbidity and mortality in the United States, such as heart diseases, cancer etc. are strongly associated with lifestyle behaviors, including smoking, improper diet, and a lack of exercise (Levy et al., 1988). Lifestyles can be altered and behaviors can be modified, thus, as more and more people become aware today that their quality of life, health, and well being are, in part, dependent on choices, health promotion will continue to increase.

Physical activity has long been regarded as an important component of a healthy lifestyle. Physical activity is associated with the prevention and control of numerous medical conditions including cardiovascular diseases, obesity, types of cancer, mental health problems, premature death, and more. Many of these medical conditions, especially Coronary Heart Disease (CHD), are the leading causes of morbidity and mortality in the United States (Harris et al., 1989). In addition, not only does physical activity improves one's endurance, flexibility, and muscle strength, but it is also associated with improvements in psychological functioning. Evidence from health literature shows that active persons are more likely to be better adjusted, perform better on tests of cognitive functioning, exhibit reduced cardiovascular response to stress, and report fewer symptoms of anxiety and depression. Further, there is solid evidence that physical activity has an important role in improving one's self-confidence, self-esteem, and an increased feeling of well being (Fletcher et al., 1996).

Physical activity also provides significant economic benefits both for the individual participant, his family, and the general public (see appendix A for an overview of health evaluation methods). Generally, the economic costs attributable to a certain disease can be defined in terms of direct and indirect costs. Direct costs are associated with providing medical care to patients (e.g. hospitalization, physician and nursing services, medications, etc.). Indirect costs are associated with lost productivity resulting from morbidity or premature mortality. 
Clearly, the costs associated with various health conditions can be identified and calculated. However, there is no formula for determining and capturing the entire economic value of neither a "good" health status nor the benefits to a health status that are attributable to physical activity (e.g. reduced health costs, higher productivity due to less absenteeism, better quality of life, higher self-esteem, etc.). Nonetheless, the vast majority of studies conclude that the economic value of health benefits derived from a certain physical activity outweigh the costs of participation in such activity and therefore provide net economic benefits (Jones and Eaton, 1994). Moreover, these studies tend to underestimate these benefits by not capturing intangible benefits associated with physical activity such as better quality of life and overall well being.

This research doesn't attempt to calculate the economic benefits of physical activities or healthier lifestyles. Rather, the goal of this research is to provide empirical evidence that more active people spend less on hospital charges and that recreational opportunities are positively correlated with healthier, more active lifestyles. This is an exploratory cross sectional study. It doesn't claim to establish a cause-effect relationship between supply of recreational opportunities and improved health status. However, it does highlight the direct and indirect relationships between levels of behavioral risk factors, recreational supply indices, and healthcare expenditures.

Quality of life issues, along with recognition of the health benefits of physical activity, are among the major factors behind a recent shift in health care policy. In the past couple of years, health care policy is becoming more proactive toward preventing or reducing the risks and incidences of morbidity and mortality episodes. Health care professionals, insurance companies, educators, and policy makers call for increased participation in physical activities in order to improve people's quality of life. In fact, policy makers, while trying to improve and increase the years of healthy life for all Americans, have issued several programs to promote and encourage public health (e.g. Healthy People 2000, Healthy people 2010). One of their top priorities is to encourage and promote physical activity (Healthy People 2000, n.d.)

Success in promoting the importance of a physically active lifestyles, especially among people who engage in sedentary lifestyles will pay dividends to both individuals who become healthier and the general public who will not need to bear the health burden 
associated with a sedentary society. However, despite the understanding of the importance of healthier lifestyles, the United States is still a predominantly sedentary society. According to the Behavioral Risk Factors Surveillance System (BRFSS) nearly $60 \%$ of American adults engage in little or no leisure time physical activity at all, more than half of all Americans are classified as sedentary, and more than $60 \%$ of Americans are overweight (MMWR, 1993).

There are many reasons why Americans do not engage regularly in physical activities. These reasons, defined in the literature as "barriers to participate", include two prime categories. The first category of "barriers to participate" includes actual or physical barriers, such as the lack of facilities, lack of time, physical disabilities, or poor accessibility. The second category of "barriers to participate" includes perceptual barriers. Many Americans do not engage in ongoing physical activities because they believe exercise has to be difficult, boring, and not enjoyable. The issue of perceptual barriers captures a large array of excuses and reasons for not engaging in leisure time physical activities. However, since recreational activities are perceived as fun and enjoyable activities, they can appeal to people and have the potential to attract people to become less sedentary. Recreational activities are versatile and can create opportunities for engaging in a variety of physical activities and improving one's health and well being.

The way to overcome the aforementioned barriers is by improving the availability and accessibility of recreational opportunities and options, and marketing and promoting them effectively. As a result of an increase in the supply of recreational opportunities, people will have the freedom to choose from a variety of recreational activities, according to their preferences. Thus, for the reason that recreational activities are associated with fun, leisure, and pleasure, there is a basis to believe that many people will adhere to these activities, substitute sedentary behaviors for them, and consequently gain health benefits and improve their health status.

This research will focus on West Virginia. West Virginia's rates for obesity, physical inactivity, and smoking are among the highest in the nation. In fact, according to the Centers for Disease Control and Prevention (CDC), West Virginia ranks in the top five states for all of these risk factors. Consistent with empirical research that documents the relationship between these behavioral risk factors and chronic diseases, mainly 
cardiovascular related illnesses and episodes, West Virginians suffer a higher rate of heart disease mortality than the national average. Because of the significant economic implications of a poor health status, there is an increasing concern, among West Virginia's legislators “to begin addressing obesity and laziness because the state can't afford the costs associated with unhealthy lifestyles" (Bundy, 2002). As West Virginia's legislatures are about to embark on a program to improve the health status of the state, and as a follow-up to previous policy makers recommendations of developing new recreational opportunities in West Virginia in order to enhance a more active lifestyle activities (Keith and Althouse, 1999), this research aims to provide an original empirical analysis as well as additional food for thought about the relationship between counties' health status indices in West Virginia and the recreational opportunities they possess.

\subsection{Objectives}

There are many studies that have documented the importance of physical activity for improved health and quality of life. Likewise, there is mounting evidence that link the supply of recreational opportunities and changes in usage rates. However, very little research has been conducted that combines these two issues. In other words, there is little empirical evidence on the relationship between the availability of recreational opportunities and health status. This project is therefore an exploratory study that examines the relationship between recreational supply and health status. The logic that underlies this research is as follows:

- Physical activity is a key factor for preventing cardiovascular diseases and improving one's well being and quality of life.

- More than half of all Americans do not engage in leisure time physical activities.

- The reasons for not engaging in leisure time physical activities are defined in the literature as "barriers to participate". These include actual barriers, such as unavailability of recreational facilities or poor accessibility and maintenance along with perceptual barriers, such as lack of fun and enjoyment.

- Recreational activities are perceived as fun and enjoyable activities, with many of them involving physical activities. 
- Availability of recreational opportunities can encourage people to become more active and therefore, indirectly improve their health status.

This research will tackle the issue of health care policy and promoting physical activities from an original angle. It aims to empirically test whether the provision and availability of recreational opportunities in West Virginia's counties is associated with the health status of these counties. Results from this research will be used to answer the policy question of whether or not policy makers should be encouraged to invest more in recreational opportunities in order to promote health status.

The hypotheses tested in this research are:

1) Physical inactivity leads to higher health care costs.

2) The supply of recreational opportunities is positively related to physical activity levels.

3) Physical activity and obesity are endogenously related.

\subsection{Methodology}

This research provides a comparative analysis of West Virginia's 55 counties. The comprehensive data collection includes variables, such as behavioral risk factors (e.g. physical inactivity, obesity, and cigarette smoking), socio-demographics, number and type of existing recreational facilities, recreational supply indices, land designation patterns, and measures of total deaths and hospital residents' charges for health care. These data were obtained mainly from the Behavioral Risk Factor Surveillance System (BRFSS), West Virginia Department of Health and Human Resources (WVDHHR), West Virginia Bureau of Employment Programs, The National Outdoor Recreation Supply Information System (NORSIS), and the U.S. Census Bureau.

One of the unique features of this research is the incorporation of spatial analysis tools. In order to look for general patterns and spatial issues, several variables are mapped using ArcView GIS software, and are overlayed onto various environmental maps. ArcView GIS is an effective tool for identifying patterns among different sets of attributes as well as a powerful tool for displaying and analyzing the findings (Carlin, S., 2001). As the maps (displayed in chapter three) show, this research deals with spatially distributed data. Observable patterns in the distribution of the variables are due to two 
main reasons: First, the prevalence of the behavioral risk factors in some of the southern counties in West Virginia is very high, a phenomenon that has cultural and economic reasons. Secondly, the issues of recreational supply and healthcare consumption are spatial in nature because people consume recreation and healthcare not only in their residential counties but also in other counties. Hence, in order to deal with these spatial patterns, Geographic Information System (GIS) software is employed and weighted variables that account for county location are introduced and analyzed.

The above hypotheses are tested using regression analyses. First, an Ordinary Least Squares (OLS) approach is employed to estimate for the marginal effects of factors associated with recreation supply on physical inactivity levels and variables that approximate health status. Then, a spatial regression approach is introduced due to the spatial distribution of several variables.

More specifically, the hypotheses are tested using the following procedures. The first hypothesis is tested using OLS by fitting a spatially-sensitive regression model. The dependent variable is hospital charges, by county, and explanatory variables include socio-demographics, health care availability, and physical inactivity levels. The second and third hypotheses are tested by specifying a two-stage least squares model that accounts for the potential simultaneity and endogeneity between physical inactivity and obesity rates. The explanatory variables include measures of recreation supply, sociodemographics, and land designation patterns. A sub-theme of this approach includes accounting for spatial factors in the regression models as previously identified.

\subsection{Potential of Results}

This research addresses an issue of significant importance. Not only is the issue of public health critical but also, despite a great call for promoting physical activity and healthy lifestyles, the compliance rates are not satisfactory. In addition, there is little scientific evidence that directly addresses this issue. Thus, a goal of this project is to pave the way and build a solid foundation for future efforts that will expand the scope of this research, employ new techniques, and draw additional conclusions to make our society more healthy and functional. 
This research also has significant policy implications. Policy makers have the means to significantly affect the supply of recreational facilities, opportunities and options for physical activity including budget allocation and promoting better health. The results of this research might aid policy makers in advocating healthier lifestyles by providing them with a framework that links resource management, physical inactivity and health status.

\subsection{Thesis Organization}

The remainder of this thesis will be organized in the following fashion. Chapter two includes an extensive literature review that describes the importance of physical activity to improved health, research that links the behavioral risk factors and lifestyles to health status, recreational activities and their implications, and an overview of the linkage between policy interventions and physical activity. Chapter three presents the data, models, and software used in the analyses as well as an overview of the study area, West Virginia. Chapter four contains the results of the analyses, and discussion of the models described in chapter three. Chapter five provides a summary of results, conclusions, policy implications, and suggestions for future study. Appendix A includes a survey of the most common health evaluation methods. Appendix B includes models outputs and statistical summaries of the variables used in the models. 


\section{CHAPTER TWO: LITERATURE REVIEW}

\subsection{The Importance of Lifestyles and their Association with Health Status}

As mentioned in the preceding chapter, most diseases that affect Americans today are chronic such as heart diseases, cancer, diabetes, etc. Yet, despite a modern health care industry, sophisticated drugs, state of the art hospitals, and new surgical procedures, chronic diseases are the leading causes for mortality in the United States. In fact, according to the CDC's National Center for Health Statistics, more than 50\% of death incidents in 1999 in the United States were attributed to heart diseases and cancer.

Heredity is a key factor affecting one's health status. However, one cannot control the genetic makeup he inherited from one's parents and therefore, this component of his health status is presently not modifiable ${ }^{1}$. Nevertheless, there are other factors that greatly influence one's health, including lifestyle, physical and social environment, social and socio-demographic characteristics, access to health-care, nutrition, and so forth. Lifestyle is a primary factor affecting health status. Behavioral choices have been identified as the leading contributors to overall mortality in the United States, accounting for about a third of all deaths (MMWR, 2001). Accordingly, in the past couple of decades, a consensus that lifestyle is a key determinant of health status has been established (Levy et al., 1988).

Today's top killers are, to a certain extent, attributed to human choices. They are highly correlated with such lifestyle behaviors as physical inactivity, alcohol abuse, cigarette smoking, and improper diets. Lifestyle is modifiable, and therefore a great number of deaths could have been prevented should people refrain from or minimize certain behaviors associated with sedentary lifestyle, and instead modify, adopt, or increase behaviors associated with a healthy lifestyle. In doing so, people will be able to achieve a higher quality of life, health, and sense of well being.

Health as defined by the World Health Organization (WHO) is "a state of complete physical, mental, and social well being and not merely the absence of disease or infirmity"(World Health Organization, n.d.). Obviously, this definition is broad and general. Health is a relative term for a dynamic quality of life that changes every day and therefore has various interpretations. Because of the nature of its definition, there aren't

\footnotetext{
${ }^{1}$ An emphasis of medical research in the areas of gene modification and stem cell technology is attempting to remove this constraint. However, the technology is controversial and not currently available.
} 
definitive standards to evaluate health, and thus throughout this thesis when the term health is mentioned, the meaning is of the state of well being, the ability to live comfortably, a feeling of vitality, and the capability to function and operate at peak performance. These interchangeable terms for health are direct functions of lifestyle choices and behaviors.

Many extensive studies provide solid evidence that people who incorporate specific behaviors in their lifestyle have a lower probability of developing chronic diseases and can expect to live longer. The most common health enhancing behaviors are: exercising regularly, not smoking, drinking alcohol moderately if at all, proper nutrition, maintaining normal weight, and sleeping about seven hours per night. Lifestyle, therefore, is the single most important modifiable factor influencing health (Levy et al., 1988).

This thesis emphasizes the role of physical activity and its importance to one's health status. Physical activity has a crucial part in preventing, or at least reducing rates of morbidity and mortality due to chronic diseases. Physical activity is negatively correlated with most behavioral risk factors such as inadequate sleeping and eating habits, smoking, hypertension, alcohol consumption, and obesity. In addition, recent studies document that from all behavioral risk factors, physical activity has the greatest impact on health status and that physical inactivity is the best predictor of mortality. In fact, a cross sectional and longitudinal analysis conducted by Johansson and Sundquist concludes that "physical activity was important to health status regardless of the patients body mass index (BMI) or smoking habits". The major clinical implications of this analysis are the long standing benefits of physical activity and their protection against poor health, irrespective of an increased BMI and smoking (Johansson and Sundquist, 1999). Another study, conducted to evaluate which risk factor was the best predictor of death from cardiovascular diseases, concludes that "exercise capacity is a more powerful predictor of mortality among men than other established risk factors for cardiovascular disease" (Myers et al., 2002). In other words, this study shows that poor physical activity is a better predictor of death than other risk factors such as hypertension, smoking, and diabetes. The study also confirms that high exercise capacity is a protection against poor health status even with the presence of other risk factors. 
Physical activity provides not only major health benefits, it also contributes significantly to one's feeling of well being, confidence, and self-esteem. For these reasons, physical activity is praised and recommended by health professional, educators, and policy and decision makers. The following sections describe more thoroughly the importance of physical activity, the benefits it provides, the current state of physical activity in the United States, and other topics associated with it.

\subsection{Physical Activity: Overview}

There is a consensus among the scientific community and an understanding among the general public about the importance of physical activity to a healthier life and a better quality of life. The notion that regular physical activity may be a key ingredient for optimal health has been receiving increasing attention, and is supported by mounting evidence in both medical and lay literature. Physical activity has been associated with the prevention and control of numerous medical conditions, such as heart diseases, types of cancer, obesity, mental health problems, premature death, and so forth.

Furthermore, as previously mentioned, physical activity is the single most influential factor of health status and the best predictor of mortality. Clearly, there are multiple components for a healthy lifestyle other than physical activity. Cigarette smoking, obesity, stress, sleep disorders, and inappropriate nutrition, all have negative affects on one's health, look, functionality, quality of life, and feeling of well being. Nonetheless, physical activity can decrease the negative impacts of other factors on one's health status and accordingly physical activity contributes both directly and indirectly to our health condition.

\subsubsection{Health Benefits of Physical Activity}

Physical activity can be defined as "any bodily movement produced by skeletal muscles that results in energy expenditure". Physical activity is closely related to terms such as exercise and physical fitness. The distinctions between these terms are as follows: exercise is a subset of physical activity that can be defined as "a planned and structured bodily movement done to improve physical fitness" where physical fitness is a set of attributes that relates to the ability of people to perform physical activity (Russell et al., 
1995). Since this thesis surveys the health benefits of physical activity in general, these terms are used interchangeably.

Regular physical activity has long been regarded as a key component of a healthy lifestyle. Epidemiological studies provide solid evidence that link regular physical activity to a wide array of physical and mental health benefits. The notion that regular physical activity improves one's endurance, flexibility, and muscle strength is straightforward. Physical activity is also associated with improvements in various indices of psychological functioning. Cross-sectional studies, for instance, show that active people are more likely to be better adjusted, perform better on tests of cognitive functioning, exhibit reduced cardiovascular response to stress, and report fewer symptoms of anxiety and depression. Furthermore, longitudinal studies have documented that physical activity has an important role in improving one's self-confidence, selfesteem, and increased feeling of well being (Fletcher et al., 1996). All of these benefits are familiar to everyone who engages in some sort of regular physical activity. Once one regularly participates in physical activity, whether it is in short or long-term training sessions, done in an amateur manner or professionally, all of these benefits come into play instantly and have a direct influence on his or her physical and mental condition. When physical activity is done on a regular basis and meets several criteria, it substantially contributes to long-run health benefits.

Physical activity has gained increasing importance in the past couple of decades mainly because epidemiological studies concluded that it has been associated with the prevention and control of numerous medical conditions, such as Coronary Heart Disease (CHD), hypertension, osteoporosis, colon cancer, obesity, mental health problems, diabetes, premature death, etc. Many of these medical conditions, especially CHD, are the leading causes of morbidity and mortality in the United States (Harris et al., 1989). This association is supported by experimental studies that provide evidence that exercise training reduces CHD risk factors, and improves blood lipid profile, body composition, resting blood pressure in borderline hypertensives, cardiovascular functional capacity, bone density, immune function, among other physical benefits. Physical activity also decreases myocardial oxygen demands for the same level of external work performed, enhances the beneficial effect of a low-saturated fat and low-cholesterol diet on blood 
lipoprotein levels, has effects on adipose tissue distribution which is important in reducing cardiovascular risks, has a significant effect on insulin sensitivity, and takes a significant role in the prevention and treatment of osteoporosis and colon cancer. Furthermore, increased exercise capacity has been also associated with beneficial changes in homodynamic, hormonal, metabolic, neurological and respiratory functions (Russell et al., 1995; Fletcher et al., 1996).

The bulk of studies that link physical activity and health benefits are related to diseases of the heart and the cardiovascular system. The prime reason for emphasizing medical research on the relationship between physical activity and cardiovascular and heart diseases is that these diseases are the top causes of morbidity and mortality in the United States. In addition, epidemiological criteria used to establish causal relationships between physical activity and cardiovascular and heart diseases can be applied in these studies. The epidemiological criteria are based on a set of principles that define causal relationships between events and their consequences, and distinguish between observed association and causation. When observations show a clear-cut association between two variables according to the following aspects, causation between them can be concluded. The aspects are: strength, consistency, specificity, temporality, biological gradient (doseresponse curve), plausibility, coherence, experiment, and analogy (Hill A.B., 1965). The criteria for causality appear to have been met when applying these concepts to the association between physical activity and CHD, as shown next:

Consistency - there is a strong association between physical inactivity and risk of CHD. In fact, there is a direct relationship between physical inactivity and rates of heart disease mortality.

Strength - the relative risk of CHD in association with physical inactivity is high compared to other risk factors.

Temporal sequencing - the observation of physical inactivity predates a diagnosis of CHD.

Dose response - most studies demonstrate an inverse relationship between CHD and physical activity.

Plausibility and coherence - physical activity reduces the risk of CHD through a number of physiological and metabolic mechanisms (Russell et al., 1995). 
These aspects establish a causal relationship between physical activity and CHD. Moreover, the aspects not only emphasize the importance of physically active lifestyle in preventing illnesses, in particular heart diseases, they also stress the role of physical inactivity as a risk factor of numerous illnesses.

Yet, despite enormous research effort and the formation of a causal relationship between physical activity and CHD, there is yet to be developed an explicit, specific dose-response function that enables the precise determination of the incremental tradeoffs between physical activity and subsequent health benefits or between physical inactivity and subsequent health risks.

In an attempt to further clarify the complex interrelationship between physical activity and health outcomes, the world's best exercise scientists have participated in two international conferences, during which they reviewed the current state-of-knowledge on this subject in order to form a consensus. Their consensus is that there is a dose-response relationship between physical activity and health outcomes. More specifically, the experts concluded that there is solid evidence for a dose-response relationship between the volume of physical activity and all-cause mortality rates. The slope of this dose-response function is not clearly defined, but in most studies it appears to be linear. The expert panel also reached an agreement that "there is a consistent inverse dose-response relationship between physical activity and both the incidences and mortality rates from all cardiovascular and coronary heart disease". This inverse relationship is generally linear as shown in figure 2.1 (Kesaniemi et al., 2001).

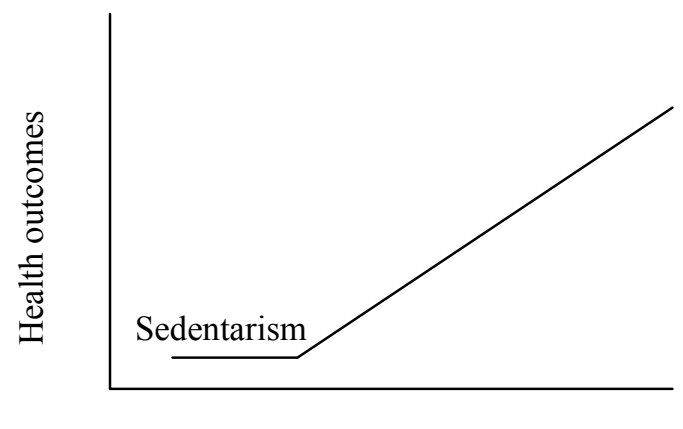

Duration and level of physical activity

Figure 2.1: The Relationship between Physical Activity Level and Health Outcomes

The implication of this relationship is that if someone embarks on an active lifestyle, once he passes a certain sedentarism level, his risk of all-cause mortality and 
heart disease incidence and mortality diminishes in a linear proportion to the duration and level of physical activity he engages in.

Despite the absence of a universally accepted, specified dose-response function between physical activity level and health outcomes, health professionals agree that it will depend upon many individual characteristics such as demographics (e.g. gender, age, race, etc.), health history, initial level of health, initial level of physical activity, and so forth, along with the exercise program characteristics such as intensity, frequency, and duration.

Obviously, physical inactivity is neither the only risk factor nor the mere reason associated with the aforementioned health impairments, in particular CHD. Other leading risk factors are increased systolic blood pressure, cigarette smoking, and elevated serum cholesterol. Nevertheless, results from longitudinal studies support the role of physical inactivity as a strong and independent risk factor for CHD. For example, estimates of population-attributable risk for CHD mortality associated with physical inactivity among a selected group of men from 1977 through 1985 was 14\%. In comparison, the associated risk for hypertension was $20 \%$, for cigarette smoking was $13 \%$, and for a positive family history of premature parental death was $20 \%$. Further, an analysis based on published studies and death rates in the United States, geared to estimate the number of deaths attributed to several risk factors for nine chronic diseases indicates that in 1986, for instance, a total of 205,254 deaths associated with CHD were attributed to the 'no' or 'very low' levels of physical activity. This estimate exceeds estimates for smoking, obesity, and hypertension, but is similar to estimates for elevated serum cholesterol (MMWR, 1993).

These findings stress the role of physical activity in improving health conditions and as a preventative factor, primarily due to the fact that physical activity is a controllable and modifiable behavior that can yield substantial benefits with relatively small effort. The mechanism behind the contribution of physical activity to better health is as follows: regular physical activity increases the ability of the human body to use oxygen and derive energy. Exercise training increases maximum ventilatory oxygen uptake by increasing both maximum cardiac output (e.g. the volume of blood ejected by the heart per minute which determines the amount of blood to be delivered to the 
muscles) and the ability of the muscles to extract and utilize oxygen from the blood. People can improve exercise performance through training. Training results in an increase in cardiovascular functional capacity and a decrease in myocardial oxygen demanded at any level of physical activity. These effects, nevertheless, can be maintained only by regular physical activity.

\subsubsection{Economic Benefits of Physical Activity}

Despite the broad acceptance and understanding of the health benefits of physical activity, little economic research has been conducted that quantifies its economic value. The absence of a well-defined dose-response function that reflects the relationship between physical activity and health outcomes makes it very difficult to estimate the monetary value of a specific activity. Nonetheless, the following studies provide evidence on the economic value of physical activity. It is important, though, to keep in mind the heterogeneous nature of health benefits gained by different people. Most studies that estimate the economic value of physical activity have focused on either a specific type of activity or a specific experimental group. Thus, current literature does not address the economic implications of popular forms of exercise for the general population (Jones and Eaton, 1994).

Health economic researchers do support the notion that the economic benefits of physical activity outweigh its costs. However, quantifying the health benefits achieved through physical activity by attaching a price on human health and the prevention or reduction of morbidity and mortality is a complex process that leads to controversial outcomes. An overview of some of the methods that could be used to estimate the economic value of physical activity is presented in appendix A.

Physical activity provides economic benefits. Typically, physically active people spend less on medical care, while at the same time their work productivity is higher than their sedentary peers. Some of the economic benefits gained through physical activity can be directly calculated. However, physical activity also provides intangible benefits that can't be calculated that easily. Physical activity provides a number of psychological benefits that influence self-confidence, self-esteem, and the feeling of well being, not to mention the pain and suffering from avoidable illnesses that might be eliminated or 
reduced. These benefits have a significant, yet difficult to quantify, impact on health condition, productivity at work, and quality of life.

Low to moderate intensities of physical activity, done regularly, can help prevent numerous diseases, which impose a substantial economic burden on individuals and society. Generally, the economic costs attributable to a certain disease can be defined in terms of direct and indirect costs where direct costs are associated with providing medical care to patients (e.g. hospitalization, physician, nursing services, medicines etc.) and indirect costs are associated with lost productivity resulting from morbidity or mortality. For example, according to the American Heart Association (AHA) 2001 heart and stroke statistical report, the total costs of CHD in the United States in 2001 are estimated at $\$ 100.8$ billion. The break-down of these costs is as follows: $\$ 39.1$ billion for hospitalization and nursing homes, $\$ 8$ billion for physicians and other professionals, $\$ 5$ billion for drugs and other medical durables, $\$ 1.3$ billion for home health care, and $\$ 47.4$ billion for lost of productivity due to morbidity or mortality.

The following review presents studies that examined the economic implications of physical activity and physical inactivity. These studies show that the economic value of health benefits attributable to physical activity (e.g. reduced health costs, higher productivity due to less absenteeism, etc.) outweigh the costs of participation in such activity, and therefore provide net economic benefits to individuals and the public alike.

The studies below demonstrate the estimated costs of CHD, and the economic benefits derived from multiple types of physical activities:

- CHD is the leading cause of mortality in the United States. CHD is newly diagnosed in approximately 1.5 million people each year and accounts for an estimated $\$ 50$ billion in direct health-care costs. Physical inactivity is considered as a strong and independent risk factor for CHD. Based on 1989 cost estimates for CHD, the extrapolated cost attributable to physical inactivity is about $\$ 5.7$ billion, more than the extrapolated cost associated with other risk factors such as obesity, smoking, and hypertension (MMWR, 1993).

- An analysis of an on-site facility fitness program for salaried employees in Toronto, Canada, shows some of the economic benefits of physical activity. The fitness program was comprised of 2-3 physical activity classes a week for 30-45 minutes a 
session. The gains in health as a result from the program can be calculated from the differential in medical insurance claims between the experimental group and the control group as obtained one year prior to the program and the year following the introduction of the program. The net one-year benefit from the fitness program was equivalent to about three medical consultations and a higher hospital bed usage for control subjects, amounting to a difference of $\$ 110$ per person (1990 Canadian dollars)(Shephard, 1992).

- Another study examined the costs and benefits associated with walking to prevent CHD. It was conducted among hypothetical cohorts of sedentary men and women aged 35-74. This study takes into account the cost of exercise and injuries. The cost of exercise included the cost of shoes, physician physical check-ups, and other costs (e.g., time). A time cost valued at half of their average hourly wage was assigned to people who disliked exercise. Costs of injuries were assigned based on average physician charges for an intermediate visit. According to the results of this study, \$5.6 billion would be saved annually to the United States economy if $10 \%$ of sedentary adults began a regular walking program. This study concludes that despite the significant gender and age differences in the economic benefits of walking to prevent heart disease, a substantial savings is predicted from encouraging sedentary individuals to participate regularly in walking programs (Jones and Eaton, 1994).

- A study targeted at deriving estimates of the relative risk, of the major disease groups for which there is good evidence that the disease can be prevented or ameliorated by exercise (CHD, stroke, diabetes etc.) was conducted in the UK. The study compared individuals who exercised regularly with those that did not. The results show that for adults over the age of 45 , the estimated medical care costs avoided by the diseaseprevention effects of exercise greatly outweigh the costs that would be incurred as a result of regular participation in physical activity. This particular study, which addressed only the direct costs and benefits of exercise, concludes that there are strong economic arguments in favor of exercise in adults over the age of 45 (Nichol et al., 1994).

- A cost-effectiveness analysis was conducted in order to estimate the economic implication of a physical activity program in preventing CHD. The study involved 
two hypothetical cohorts of 1000 men aged 35, where one cohort was physically active and the other was physically inactive. The researchers used jogging as an example of physical activity and therefore calculated the costs, both direct and indirect, injury rates, adherence to an exercise program, and the value of time associated with this specific activity. The results, based on 30 years of observations, show that physical activity is associated with 78 fewer CHD events and 1138 qualityadjusted life years gained during this time period. In addition, the cost per qualityadjusted life year gained due to jogging was $\$ 11,313$, a favorable figure when compared with other preventive interventions for CHD. However, under the base case assumptions that include indirect costs such as time spent in exercise, this research concludes that exercise doesn't produce economic savings. Nevertheless, it turns out that the value of time spent exercising is a crucial factor, influencing whether exercise is a cost-saving activity. An alternative model that examined only cohorts members who either liked or were neutral about exercising reinforces the importance of the value of time in determining the success of an intervention because the alternative model showed not only a reduction in mortality, but it also produced net economic savings (Hatziandreu et al., 1988).

Another group of studies focused on measuring the costs of physical inactivity and its adverse health outcomes:

- A cross sectional analysis of the direct medical expenditures among United States civilian men and women was conducted. The results show that inactive people spend more, on average, on medical care than active people do. The results were consistent across age group and by gender. Not surprisingly, the study has found that the consumption of medical care (hospitalization, physician visits, and medications) was also lower for physically active people than for inactive people. The conclusion of this analysis suggests that if all inactive Americans over the age of 15 participate in a moderate level of physical activity, the national medical costs will be reduced by as much as $\$ 76.6$ billion (Pratt et al., 2000).

- A study aiming to estimate the "costs of couch potatoes" was conducted in North Carolina, United States. The study took place in North Carolina because it has been found that sedentary lifestyles are particularly prevalent in rural areas in the southern 
states. In fact, according to the CDC about $70 \%$ of North Carolina adults are physically inactive. The study showed that physical inactivity costs the state of North Carolina approximately \$231 million in circulatory-based medical claims alone, outdistancing the second highest risk factor, obesity, by nearly a 3:2 margin. In addition, it has been found that musculoskeletal claims (strongly related to physical inactivity) cost North Carolina approximately $\$ 159$ millions. These costs exclude loss of productivity due to illness and inefficiency of replacing workers that can be estimated conservatively at over a billion dollars (Chenoweth and Pfohl, 2000).

- A study, based on a cross sectional stratified analysis of the 1987 National Medical Expenditures Survey, focused on describing the direct medical expenditures associated with physical inactivity. The results showed that regularly physically active adults spend, on average, $\$ 1019$ on direct medical costs compared to $\$ 1349$ spent by adults who reported being inactive. The results were consistent across age groups and by gender and led to the conclusion that the mean net annual benefit of physical activity was $\$ 330$ per person in 1987 dollars. The researchers suggest that increasing participation in regular moderate physical activity among those who were reported being inactive might reduce the annual national medical costs by approximately \$29.2 billion in 1987 dollars (Pratt et al., 2000).

This latter group of studies reinforces, although from another angle, the vital role of physical activity in preventing or reducing morbidity and mortality from cardiovascular diseases as well as from many other sorts of diseases, and that physical inactivity and its associated health impairments impose enormous economic burdens on individuals as well as on society.

The majority of studies that tried to evaluate the economic benefits of physical activity in terms of productivity, absenteeism, and turnover rates refer to specific worksite fitness programs. Although most of these studies relate to white-collar workers in non-union companies, with a history of good industrial relations, similar or larger effects are anticipated to be observed in other working sectors. These studies indicate that participation in a worksite fitness program induces a more positive attitude for work, develops better leadership, communications, and interpersonal skills, and also reduces stress and tension. Indeed, the nature of white-collar industries, where no end product is 
produced, makes it tough to measure changes in output. However, the general perception is that the operation of fitness programs is linked to small gains in both the quality and quantity of production. The literature provides evidence of improved productivity in variety of tasks after the introduction of a fitness program. In particular, it has been shown that in types of jobs where heavy physical effort is required, a fitness program increased working capacity. Moreover, fitness programs are highly correlated with increases in worker satisfaction, relief of boredom, and improvement in positive attitude toward work. In terms of absenteeism, the majority of reports suggest some impact of the fitness programs on absenteeism, particularly on the short term uncertified type of absenteeism (Shephard, 1989 and 1992).

For example, a Canadian company offered an on-site gym at a down town office with about 1200 employees. The gym was 250 square meters in size where the employees could participate in 2-3, 30-45 minute exercise sessions per week led by professional fitness instructors at a time of their choosing. This study shows that after 6 months of program operation, absenteeism was reduced significantly $(22 \%)$ when frequent program participants were compared with other members of the same company or with workers at the matched control company. Subsequent follow-ups showed that low absenteeism was linked to the program participation and although a causal relationship wasn't established, it could be argued that the low absenteeism and the high program participation rates reflected a mutual dependence upon good health. In terms of productivity, an assessment was very difficult since the company didn't produce end products. Yet, a $2.7 \%$ differential in production in favor of the experimental company compared to the control company was estimated. This gain can be attributed to employee satisfaction from the worksite fitness program and less absenteeism (Shephard, 1992).

As mentioned and shown in the preceding examples, active lifestyle contributes to a better health status and may prevent numerous diseases. Comprehensive research has shown that physical activity is associated with better quality of life, less risk of CHD and other chronic diseases, and economic gains. These economic gains are due to a decrease in the costs for medical care, medical treatment, and medical insurance, and increases in businesses' financial status due to increased productivity, less absenteeism and fewer employee turnovers. 
Indeed, some of these studies' results are subject to controversy because of the differences in the research methods used and study design (e.g. specific physical activity, a specific work place, and so forth). However, the common denominator of all studies is that an increase in the number of sedentary individuals who trade an hour "on the couch" at home for physical activity will result in substantial economic benefits for these individuals, their families, their employer, and society as a whole.

It is important to underscore that studies that employed benefit-cost analyses to evaluate a specific physical activity depended on the value of time devoted to physical activity, and therefore, their results are sensitive to the value of time spent on performing the activity. Generally, the value of time assigned to physical activity varies and depends on one's attitude towards the specific activity. In most studies, the "cost" of exercise ranges on a scale of zero for those who enjoy exercise to an hourly wage for those who dislike it. Since the value of time is a crucial factor in determining the economic profitability of physical activity programs, it is clear that greater supply, better accessibility, and better promotion to encourage positive attitudes toward exercise will make physical activity even more worthwhile. Furthermore, if the time spent on physical activity is referred to as a 'cost' than it implies that this time is strictly an input into a production of something valuable such as physical fitness or improved health. However, if physical activity is enjoyable, like recreation, than the time spent on it may be interpreted as a benefit that one directly enter to his or hers utility function. That is, when one enjoys recreating, than the time spent on it is a value, not only cost.

Another factor that influences the "cost" side of the profitability equation is injuries. While vigorous physical activities may cause injuries, recreational activities, which are mostly associated with low-moderate type of activities, are associated with a minimum rate of injuries.

In summary, physical activity is a key factor for deriving economic benefits due to a better health condition. Physical activity helps not only in preventing and reducing morbidity and mortality from chronic diseases, which are associated with great direct and indirect costs, but it also provides economic benefits in terms of enhanced productivity, reduction in employee absenteeism, and better feeling of well being. 


\subsubsection{The Current State of Physical Activity in the United States}

Participation in regular physical activity gradually increased during the 1960s, 1970s, and early 1980s, but seems to have plateaued in recent years. Despite the general understanding about the health benefits associated with physical activity, recent data show that only about $22 \%$ of American adults are active at the recommended level for health benefits (e.g. engage regularly in light to moderate physical activity that last for 30 minutes on most days of the week). Fifty-four percent are reported to be somewhat active but do not meet the recommended level for health benefits, and $24 \%$ do not engage in any leisure time physical activity at all (Russell et al., 1995).

In fact, a CDC analysis of the 1991 BRFSS survey (see figure 2.2), which was conducted in order to assess the prevalence of sedentary lifestyle and identify groups characterized by a high prevalence of physical inactivity, reveals the following findings (MMWR, 1993):

About $60 \%$ of respondents were classified as sedentary, where $30 \%$ reported no leisure-time activities.

$>$ The crude prevalence of sedentary lifestyle didn't differ by gender.

$>$ The prevalence of sedentary lifestyle was higher for other races than for non-Hispanic whites, particularly for women of other races.

$>$ The prevalence of a sedentary lifestyle increased steadily with age.

$>$ The prevalence of a sedentary lifestyle was inversely related to income.

$>$ The prevalence of a sedentary lifestyle was inversely related to education.

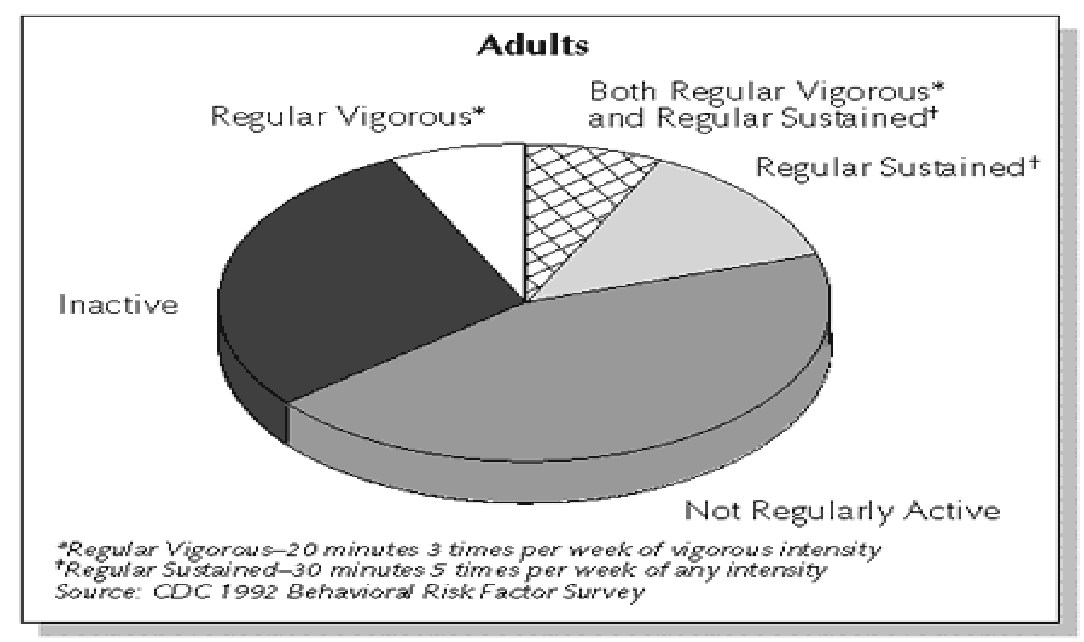

Figure 2.2: BRFSS Survey Results (Source: Centers for Disease Control and Prevention) 
Additional findings from a CDC report that was published in April 2002 are:

$>$ Overall, only $22.9 \%$ of adults engage in some strengthening activity.

$>$ Men are more likely than women to engage in some leisure-time physical activity.

Married men and women were more likely than men and women in any other marital status to engage in some sort of leisure time physical activity.

> Adults living in the West were most likely to engage in leisure time physical activity, and adults living in the South were least likely to engage in leisure time physical activity.

$>$ Adults who live in the suburbs are more likely to engage in physical activity than adults who live in rural or urban areas (Schoenborn and Barnes, 2002).

It seems that people are not responding to information about the health benefits of physical activity, as evidenced by the number of sedentary people. This information includes the epidemiological evidence that stresses the importance of habitual physically active lifestyle in preventing illness problems, and the estimation that approximately $12 \%$ of all death in the United States is attributable to a lack of regular physical activity (Russell et al., 1995). Why are we faced with physical inactivity epidemic? The next section describes the determinants of physical activity.

\subsubsection{Determinants of Physical Activity}

The abovementioned CDC findings provide a general outlook of the current state of physical activity in the United States. The determinants of physical activity are as follows (King et al., 1992; Dishman et al., 1985):

\section{Socio-demographics:}

- There isn't a significant difference between men or women with respect to lightmoderate levels of regular physical activity.

- Physical activity level among adults is inversely correlated with age.

- Black women are found to be less active than white women; the results for men are variable.

- The relationship between occupation and leisure-time physical activity is unclear.

- There is remarkable evidence that the level of education is positively associated with leisure-time physical activity. 
- Unlike popular opinion, the relationship between cigarette smoking levels and physical activity levels is relatively modest. While some studies show no correlation, others show weak negative correlations.

- The relationship between income level and leisure-time physical activity is modest.

- There is a modest to moderate family aggregation of physical activity levels.

- Healthy people are more active than persons with medical problems.

Knowledge, attitudes, perceptions, and beliefs:

- Understanding and believing in the health benefits of physical activity has been associated with the adoption of an exercise program and the level of physical activity, but their relationship with adherence to the program has been inconsistent.

- Perceptions of being in poor health and lack of knowledge of the benefits of physical activity are associated with reduced levels of physical activity.

- Intentions toward physical activity fail to predict subsequent participation.

- The confidence in the ability to successfully perform an activity is associated with physical activity levels.

- Perceived access to facilities is an important factor influencing physical activity levels.

- Lack of time is the number one reported reason for not engaging in physical activity or for dropping out of exercise programs.

- The perception of exercise as an enjoyable activity predicts higher levels of physical activities and adherence to exercise programs.

Self-motivation and skills:

- Self-motivation as a product of psychological and behavioral attributes and traits is consistently correlated with physical activity levels.

- Skills as effective goal setting, self-monitoring of progress, and self-reinforcement, along with previous success in being able to participate in physical activity have been found positively correlated with physical activity levels.

Exercise program/ regimen factors:

- Complexity of the program, characteristics of the exercise program, cost of participation in a specific activity, and the exercise regimen structure and flexibility, may all influence exercise levels. 
Social factors:

- Family participation and support are strong predictors of exercise maintenance.

- The influence of friends' support was found to be a predictor for a vigorous physical activity.

Environmental factors:

- The distance and accessibility to exercise facilities is a consistent predictor of exercise participation.

- Environmental prompts or cues might increase physical activity levels.

- Weather is a determinant of types and level of physical activity.

\subsubsection{Analysis of the Current State of Physical Activity in the United States}

Although Americans today know more than ever before about the benefits of physical activity, health risks associated with physical inactivity are on the rise. This contradiction is not comprehensible, rather it reveals a gap between people's knowledge and understanding of the subject matter and their ability to modify their habits. This gap, in essence, is a manifestation of a phenomenon called cognitive dissonance. Even tough people recognize that certain behaviors lead to unfavorable outcomes, they do nothing to change these behaviors. Some bad habits, which are based on psychological needs, are to a certain degree addictions (smoking, overeating, etc.). In contrast, physical inactivity is a cognitive choice. Yet, although most people understand that physical inactivity is a risk factor, most of them choose to remain physically inactive.

Surprisingly, the relationship between regular participation in physical activity and intentions to exercise and the awareness of the benefits of physical activity is weak. In fact, it looks like the role of a habit with regard to a regular physically active lifestyle is the prime determinant of exercise behavior. An intention to engage in physical activity is also an important predictor of activity levels, which is directly influenced by habits and attitudes. However, in situations when decisions involve changing or adopting an active lifestyle over a previous sedentary lifestyle, the influence of intentions becomes relatively minor (King et al., 1992). Consequently, the decision to continue exercising for an individual who already has a well-established habit of exercise requires much less "will" than of an individual who has to resist the forces of old habits and establish new ones 
(switching from a sedentary lifestyle to a regularly active lifestyle) (Godin et al., 1987). These findings imply that in order to promote physically active lifestyles, acknowledgment of the health benefits of physical activity might not be a sufficient incentive for people to start exercising and maintain an active lifestyle. Rather, the emphasis should be on developing exercise habits and a positive attitude toward it, not only because they both correlate with intentions, but also due to the fact that when exercise becomes an enjoyable habit, the odds of maintaining an active lifestyle increase dramatically.

The explanations for the inconsistency between the awareness of the benefits associated with physical activity and the low percentage of American adults who engage regularly in these activities are multi-dimensional. As there are physical, behavioral, and psychological benefits of physical activity, these same variables provide also the causes for physical inactivity. People realize the importance of a healthy lifestyle, but, at the same time, they can find reasons and excuses for not participating regularly in physical activity. These reasons and excuses, which often are due to misperceptions, are defined as "barriers to participate" in physical activity. Each individual has his own barriers to participation, which depend on a variety of variables. The most common barrier to participate in regular physical activity is lack of time. If the recommended duration of exercise to gain health benefits is about 30 minutes a day, almost every day, then the net weekly amount of time devoted to physical activity has to be approximately 3.5 hours a week while the gross amount of time is generally larger. Additionally, lack of time is among the top reasons for dropping out of exercise programs.

Other barriers to an active lifestyle are: 1) lack of confidence in the ability to be physically active, 2) accessibility to and maintenance of sports/recreational facilities, 3) environmental factors such as: lack of designated trails for bicycling and walking, distance from traffic, inclement weather, and unsafe neighborhoods, 4) social factors: people need to have a role model or somebody to talk to during and after the activity, and 5) a lack of enjoyment. The last barrier, lack of enjoyment, seems to be the most important barrier because it captures any kind of excuses for not engaging in physical activity. In other words, if physical activity is perceived as a non-enjoyable activity, it would be easier to put the blame for that on a lack of time, lack of company, the bad 
weather, etc. Moreover, a non-enjoyable activity will not become a habit, in most cases, and thus will not be continuously maintained. In fact, King et al. (1992) stated that for many people the lack of time simply reflects a lack of interest or commitment to physical activity. They also raised the suspicion that the use of factors such as lack of time and inconvenient location are excuses for poor adherence to exercise programs.

Even when people decide to take part in physical activities and overcome their barriers to participate, it still doesn't imply that they will gain significant health benefits. These people may quit practicing after a short period of time. Most of the long-run health benefits can be derived only from a sustained physically active lifestyle.

Another factor associated with the general public's misinterpretation and misperception of the health benefits derived from physical activity is that promotion campaigns geared toward promoting physical activity fail to deliver the right message to their target audience. The low rate of participation in exercise is in part due to the fact that people believe that they have to be vigorously active in a continuous exercise program in order to achieve any health benefits. People sometimes decline physical activities because they inappropriately connect sports stars and professional athletes to a great health condition. This linkage is flawed because scientific evidence clearly demonstrates that regular, low-moderate intensity of physical activity provides substantial long-term health benefits. This linkage might also induce discouragement and feelings of inferiority and unattainable goals that result in a withdrawal from exercise programs (Russell et al., 1995; Fletcher et al., 1996).

The typical recommendations for gaining optimal health benefits is to accumulate at least 30 minutes or more of moderate-intensity physical activity on most, preferably all, days of the week. Thirty minutes of moderate-intensity physical activity is equivalent to expending approximately 200 calories, which can be achieved by a brisk walk of 2 miles. However, recently the $\mathrm{CDC}$ and the American College of Sports Medicine (ACSM) expanded and updated the traditional recommendations.

The updated recommendations state that the duration of physical activity can be accumulated in several short periods of activity, in contrast to the previous recommendation that encouraged continuous formal exercise for 20-60 minutes. This adjustment allows people to exercise intermittently during a day and still gain health 
benefits as long as their total exercise time accumulates to 30 minutes or more (Russell et al., 1995). To qualify, people can walk up the stairs instead of taking the elevator; they can walk short distances instead of driving the car, and so forth as long as the intensity of the activity is similar to a brisk walk and that they accumulate at least 30 minutes of whichever activity a day. More vigorous activities such as running, cycling, ball games and other recreational activities provide the same if not more health benefits. However the emphasis on the low-moderate level activities is important to reduce or prevent the risk of injuries.

Once people start engaging in physical activity and overcome the initial barrier of actually exercising they encounter three options:

i. They can quit. Despite the positive physical and mental health benefits of exercise, long-term adherence to exercise programs is problematic. About $50 \%$ of all people who initiate an exercise program will drop out of it within six months (Fletcher et al., 1996). The issue of low adherence is particularly important because one can gain all the benefits derived from physical activity only if it is sustained. A short period of activity can provide a flavor of some of the health benefits, but gaining all the longrun health benefits requires sustaining an active lifestyle. The main reasons associated with a withdrawal from exercise programs are cigarette smoking, obesity, engaging in high-intensity activities, and lack of self-regulatory skills such as goal setting, selfmonitoring, and self reinforcement. Injuries are also common reasons for stopping regular physical activity. Fortunately, most injuries do not occur while engaging in low-moderate activities and if they occur they are usually mild (Russell et al., 1995).

ii. People can keep a healthy lifestyle that includes at least 30 minutes of low-moderate intensity physical activity on most days of the week. P

iii. People can advance and take part in more vigorous activities like running, swimming, cycling, ball games etc.

The health benefits derived from physical activity are contingent upon the initial condition of the participant. The relationship between the initial level of activity to the health benefits associated with physical activity at the recommended level can be illustrated by a concave dose-response function that exhibits diminishing health benefits derived from an improved activity status (see figure 2.3). This function shows that 
individuals with sedentary lifestyles are expected to have the most benefits from increasing their activity to the recommended level. In fact, studies show that the greatest potential for reduced mortality is when sedentary people become moderately active. People who remain sedentary have the highest risk for all-cause and cardiovascular diseases mortality (Blair et al., 1995). This relationship also implies that people who engage in some sort of exercise, but below the recommended level, will gain some health benefits. However, they will gain fewer benefits than sedentary people who become moderately active or active people who exceed the recommended level of physical activity (Russell et al., 1995).

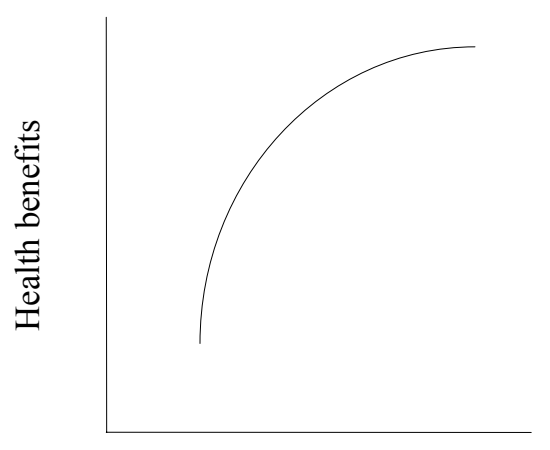

Baseline activity status

Figure 2.3: The Relationship between Physical Activity and Health Benefits

The new recommendations of the CDC and the ACSM are important because they extend the traditional exercise-fitness model to a broader paradigm. The new recommendations indicate that health benefits derived from physical activity are primarily associated with the total amount of physical activity performed. In other words, the traditional variables (e.g. mode, frequency, intensity, and duration of the activity) that have had a prime importance in the past take now a minor part. Today, the most important parameter is the total time of the activity. The new recommendations stress two core elements: First, they emphasize the important role of low-moderate intensity physical activities outside of formal exercises programs in gaining most of the health benefits that were previously associated with moderate-high intensity endurance exercise performed more than 3 times a week for 20-60 minutes. Thus, activities like walking for pleasure, gardening, yard work, housework, and a lot of leisure-time activities can result 
in significant health benefits. Second, the new recommendations point out that accumulation of physical activities in intermittent short bouts is a legitimate approach for gaining health benefits (Russell et al., 1995).

To sum, based on the most recent data the CDC and the American College of Sports Medicine conclude that:

$>$ Caloric expenditure and total amount of time of physical activity are associated with substantial health benefits.

$>$ There is a dose-response relationship between health benefits and base line activity status.

$>$ Regular low-moderate physical activity provides significant health benefits

$>$ Intermittent bouts of physical activity, totaling 30 minutes or more on most days of the week, provide beneficial health and fitness effects.

The interpretation of these conclusions is straightforward. Americans are challenged to adopt a more active lifestyle. This challenge refers especially to those Americans who maintain sedentary lifestyle because they have the highest risk for allcause and cardiovascular disease mortality, and have the most to benefit from changing their lifestyles.

\subsection{Recreation and Recreational Activities to Promote Physical Activity}

Indoor and outdoor recreational opportunities and options can attract people to engage in different sorts of activities because recreational activities are associated with movement, space, and fun. They can provide people with a convenient, enjoyable, and fairly priced (if at all) substitutes to other activities, that are associated with sedentary lifestyle. Recreational activities can create the opportunity for engaging in a variety of physical activities such as walking, running, skating, swimming, roller-blading, etc. that can be performed for different periods of time, individually or as part of a group, in low intensity or vigorously and so forth. Moreover, recreational activities, especially outdoors, is associated with leisure, nature, and freedom that have a greater contribution to one's satisfaction, happiness in life and feeling of well being than regimented health club activities. The underlying logic of developing recreational opportunities and options is that recreational opportunities may directly lead to some form of physical activity, and 
thus indirectly enable its participants to attain a better health condition. Or, as stated by Ruskin in a paper presented in an European Leisure and Recreation Association (ELRA) congress: "leisure can be used directly or indirectly to affect positively health and wellness as well as prevent negative health status and even cure" (Ruskin, 1999).

Therefore recreational activities can be used as tools to overcome the barriers to participate. Yet, in order to overcome the barriers to participate, some actions have to be taken. Recreational facilities have to be available, accessible, functional, well maintained, and well marketed. These actions are, in part, policy issues, and thus policy interventions to promote physical activity are essential.

\subsection{Policy Interventions to Promote Physical Activity}

One of the top priorities of policy makers is to promote physical activity, especially among people who engage in sedentary lifestyles. Policy makers have been aware of the significance of physical activity and its contribution to better health and quality of life. This awareness came into play in several ways, especially in health care policy that has experienced a shift of emphasis recently. As the role of physical activity in preventing and reducing morbidity and mortality was established, a new trend that viewed physical activity as a preventative factor for many illnesses has developed. This makes concurrent healthcare policy proactive instead of reactive, as it has been (Nicholl et al., 1994; Harris et al., 1989).

Additionally, in an effort to promote public health and encourage physical activity, national programs have set objectives and goals for healthcare policy (e.g. Healthy People 2000, Healthy People 2010). These programs are basically a statement of national health objectives designed to identify the most significant preventable threats to health and to establish national goals to reduce these threats by the end of the decade. The programs were developed through a broad consultation process, built on the best scientific knowledge and designed to evaluate the programs over time. The concept of "Healthy People" programs is to provide a road map to better health, which can be used by many different people, states, communities, professional organizations, etc. Healthy People 2010 incorporates partners from all sectors, including federal agencies, the Secretary's Council advisory group, the Healthy People Consortium (which consists of 
more than 400 national organizations), all State and territorial health departments, and key national associations of State health officials.

Healthy People 2010 established leading health indicators to measure the health of the nation over the next decade. As a group, the leading health indicators reflect the major health concerns in the United States at the beginning of the $21^{\text {st }}$ century. The top indicator is physical activity. The Healthy People program sets national targets in order to assess its progress and goals. A target of $15 \%$ was set for the proportion of the total population aged 18 and older who engage in no leisure-time physical activity. However, no progress can be reported in this category regardless of substantial efforts, and the proportion of American adults who engage in no leisure-time physical activity remained fairly stable at around 23-24 percent from 1985 to 1995 (see figure 2.4).

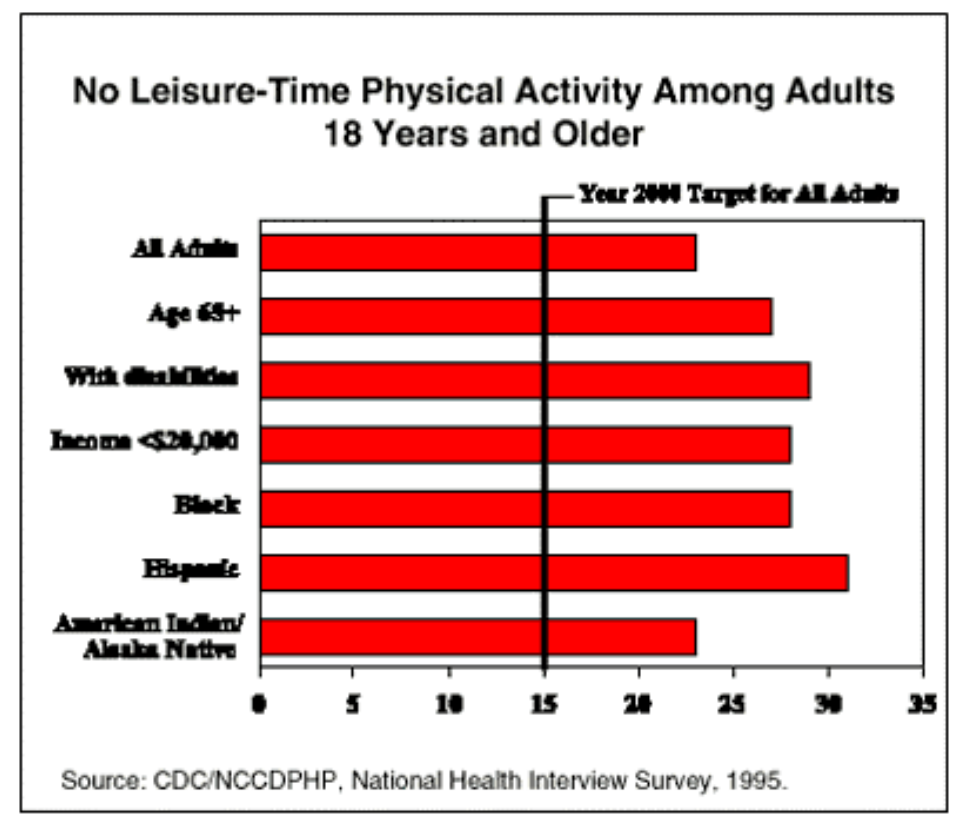

Figure 2.4: No Leisure-Time Physical Activity Among Adults (Source: Healthy People 2000 Progress Review, 1998)

Healthy People 2010 is not a mandatory program, rather individuals, groups, and organizations are encouraged to integrate its contents into their current programs. In fact, to date most States have developed their own Healthy People plans using the national plan as a guideline. A 1993 National Association of County and City Health Officials survey showed that 70 percent of local health departments use Healthy People 2000 objectives (Healthy People Progress Review, 1998; Healthy people 2000, n.d.; Healthy People 2010, n.d.). 


\section{CHAPTER THREE: METHODOLOGY}

\subsection{Hypotheses Tested in this Thesis}

Given the exploratory nature of this project and the lack of previous work in this area, relying on previous research for guidance was very limited. Instead, this project adopted a pioneer approach in an attempt to formulate a valid relationship between recreation supply and health status using physical activity as a link.

The main purpose of this thesis is to test a set of hypotheses concerning the linkage between recreation supply, physical activity levels, and healthcare expenditures by using cross-sectional analysis based on pre-existing, county-level data.

As described in the preceding chapter, physical activity is considered as a key preventive factor for cardiovascular and heart diseases. In addition, both physical activity and physical inactivity have associated economic values. Therefore, the first hypothesis examines whether more physically active counties have lower health care burdens. This hypothesis is tested by regressing rates of physical inactivity on per capita hospital charges in treatments of diseases and disorders of the circulatory system, while controlling for related medical care availability. Physical inactivity is an indicator of health status. Hospital charges due to diseases and disorders of the circulatory system are an outcome of health status. Therefore, this hypothesis establishes a direct relationship between physical inactivity and healthcare expenditures. This hypothesis examines primarily if there is a significant relationship between the main indicator of health status to health outcome, and then whether or not the relationship is of the expected sign. The expected sign of the coefficient on physical inactivity is positive $(+)$, indicating that physical inactivity is positively associated with heart disorder healthcare costs.

Formally, the first model can be expressed by:

$\mathrm{H}_{0}: \beta_{\text {physical inactivity }}=0$ vs. $\mathrm{H}_{1}: \beta_{\text {physical inactivity }} \neq 0$.

The second hypothesis examines whether lower levels of physical inactivity are related to the supply of recreational opportunities and options. Specifically, it tests for the marginal effects of recreation supply such as proportion of a county in public ownership, proportion of recreational designated land in a county, and other recreational supply indices, on rates of physical inactivity while controlling for socio-demographic 
differences. This hypothesis is tested by regressing recreation supply and sociodemographic variables on rates of physical inactivity. By establishing a direct link between recreation supply and an indicator of health status, an indirect link is also established between recreation supply and healthcare burdens. The second hypothesis examines primarily for a significant relationship between recreation supply and rates of physical inactivity, and then whether or not this relationship is of the expected sign. The expected sign of the coefficients on variables associated with recreational opportunities is negative (-), indicating that recreational supply is negatively associated with physical inactivity levels. Formally, $\mathrm{H}_{0}: \beta_{\text {recreation supply }}=0$ vs. $\mathrm{H}_{1}: \beta_{\text {recreation supply }} \neq 0$.

\subsection{Study Area}

The study area for this research project is West Virginia. West Virginia's rates for behavioral risk factors, including obesity, physical inactivity, and smoking, are among the highest in the United States. Consistent with empirical research that documents the relationship between these risk factors and chronic diseases, especially cardiovascular related illnesses and episodes, West Virginians suffer a higher rate of heart disease mortality than the national average. In fact, West Virginia is ranked second in the nation for age-adjusted rates of heart disease deaths (see figure 3.1).

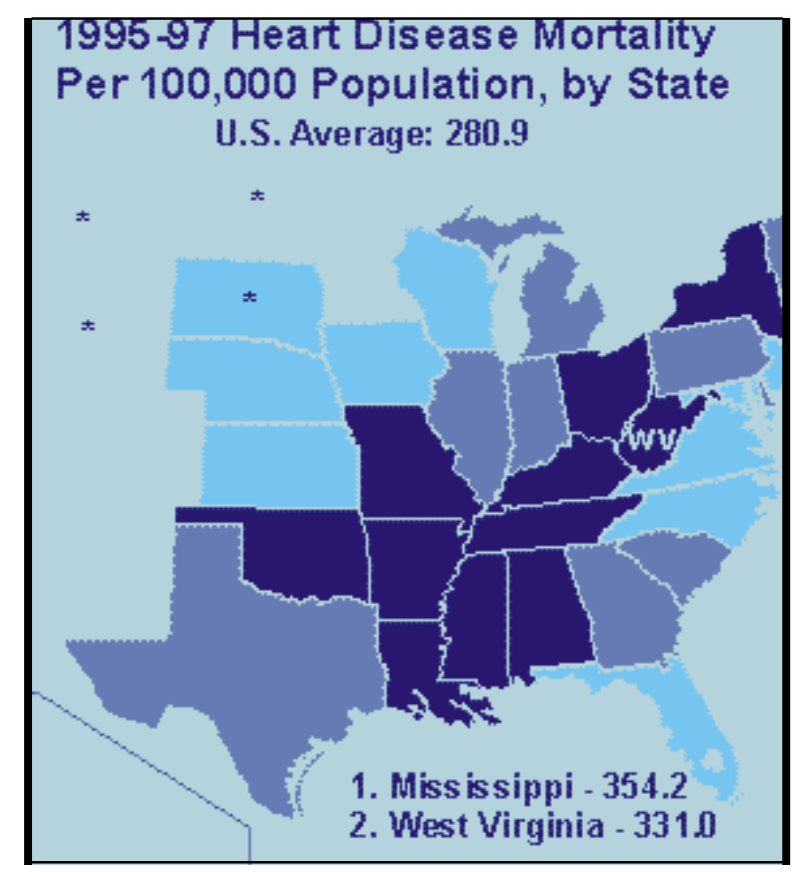

Figure3.1: Comparison between West Virginia and the U.S. (Source: Centers for Disease Control and prevention) 
Cardiovascular disease (CVD) is the number one cause of mortality in West Virginia accounting for about $40 \%$ of all deaths. CVD is the leading cause of death for both men and women and among all races and ethnicities, all income and educational levels. West Virginians have higher prevalence of all CVD risk factors that include physical inactivity, cigarette smoking, hypertension, high cholesterol levels, obesity, diabetes, and periodontal disease, than the rest of the United States. For instance, 43.7\% of West Virginia's adults reported being physically inactive in 1998, compared with the United States average of $27.7 \%$. In 1999 West Virginia's adults were $25 \%$ more likely to be obese than their peers nationwide, and the prevalence of cigarette smoking, hypertension, high cholesterol levels, and diabetes was higher in West Virginia than the United States' average as well. Another important factor in the fight against cardiovascular disease is access to health care. In 1999, 18.1\% of West Virginia's adults lacked health care coverage, compared to the U.S. median of $12.4 \%$, and a shortage of quality medical care services, especially the type geared for cardiovascular disease, existed in West Virginia (A report by the Office of Epidemiology and Health Promotion (OEHP), 2002). A BRFSS recent comparison of risk factors and preventive services between West Virginia and the United States is presented in figure 3.2.

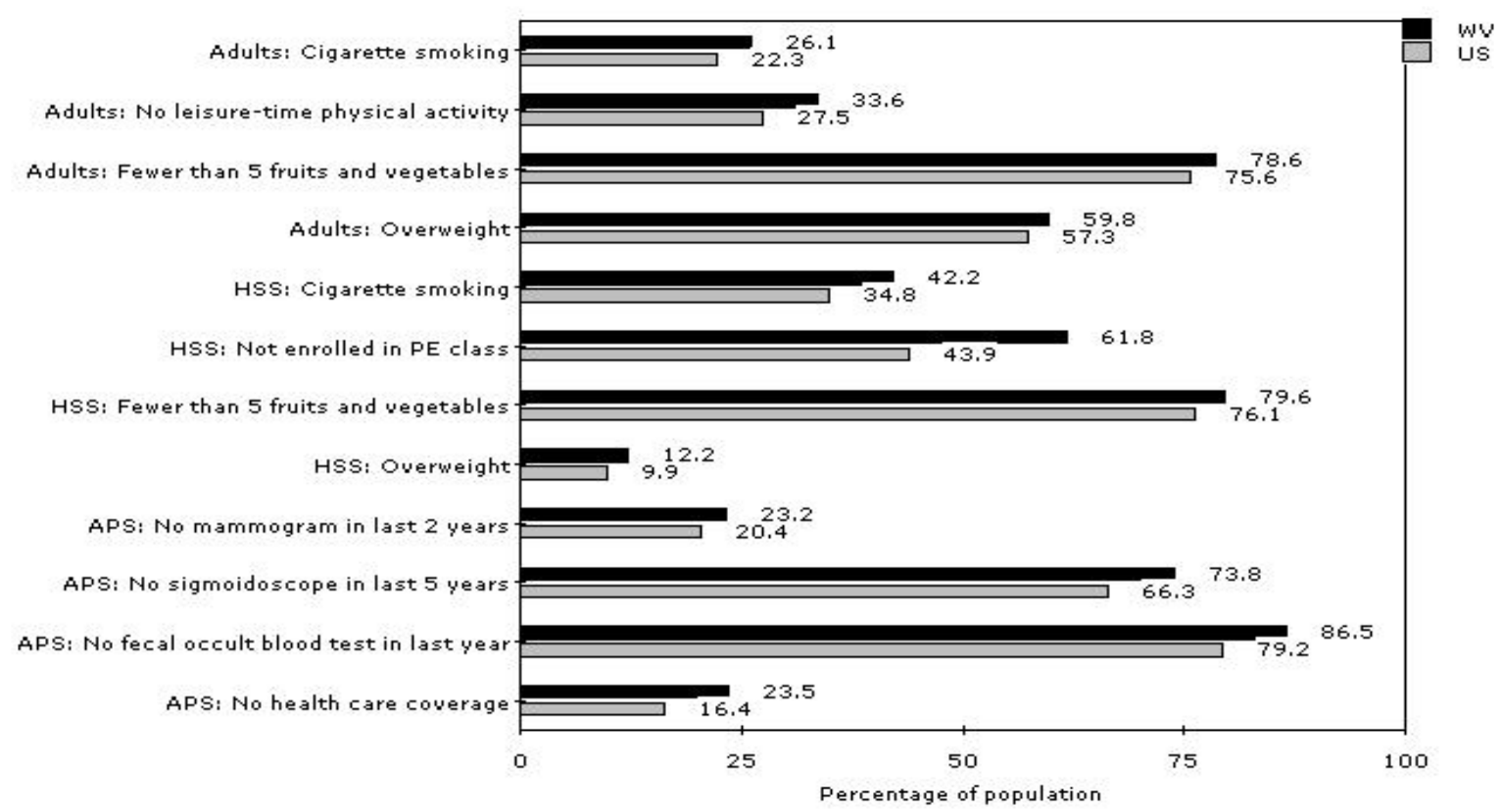

Figure 3.2: Risk Factors and Preventive Services, West Virginia Compared with United States (HSS: High School Students, APS: Adult Preventive Service). (Source: Centers for Disease Control and Prevention) 
Appalachia is particularly vulnerable to CVD and other chronic diseases because of its history of economic underdevelopment. High rates of unemployment, poverty, disability, and low levels of education are among the factors of this vulnerability. Geographically, higher rates of CVD mortality were concentrated in the central counties of Appalachia including the southern counties of West Virginia. Those counties are characterized by low per-capita personal income, and high rates of unemployment. Additionally, high rates of CVD mortality are found in non-metropolitan counties, in which the local economy is not diversified and is historically dependent on the mining industry.

Medical care resources that have a vital role in reducing CVD fatality are distributed unevenly across Appalachia, thus rural counties experience accessibility and availability problems with regard to cardiovascular specialty physicians, coronary care units, and cardiac rehabilitation facilities.

Economic improvements in the past couple decades have had an impact on the health status of West Virginia. Yet, these improvements have not benefited all the communities equally. Thus, many rural counties in West Virginia continue to experience adverse social and economic conditions that have negative impacts on public health (Barnett et al., 1998).

A recent Social Indicators Survey found that many West Virginians want to regularly engage in physical activity, mainly walking, jogging, roller-blading, skating, horseback riding, and cycling. Another finding was that West Virginians do not regularly exercise because of poor infrastructure and unavailability of places to exercise and recreate, and problems associated with accessibility to those facilities (Keith and Althouse, 1999).

This thesis was written as the issue of healthy lifestyles was gaining increasing attention in West Virginia. Obesity, inactivity, and sedentary lifestyles are so prevalent in West Virginia that it has become a significant burden on the state's economy. West Virginia's policy makers are concerned about the state's health profile and currently emphasize the need to "begin addressing obesity and laziness because the state can't afford the costs associated with unhealthy lifestyles" (Bundy 2002). 


\subsection{Model Development}

This thesis presents a comparative analysis of West Virginia's 55 counties to test the aforementioned hypotheses on a county-level scale, and establish a relationship between recreation supply and health status.

The models employed in this thesis to test those hypotheses are as follows. The first model investigates the relationship between hospital charges for treatments of diseases and disorders of the circulatory system incurred by county residents at West Virginia's hospitals, and rates of physical inactivity in those counties.

Formally, the model is:

1. $\quad \$ \mathrm{CH}=\mathrm{f}(\mathrm{PI}, \mathrm{SD}, \mathrm{HF})$,

where $\$ \mathrm{CH}$ are per capita hospital charges for treatments of diseases and disorders of the circulatory system from point of residence in 1999. PI is the proportion of the adult population considered being physically inactive in 1997. SD are socio-demographic characteristics. HF is availability of health care facilities. More specifically, the sociodemographic explanatory variables include age, level of education, and whether or not the county is classified as a metro county, while the availability of health care facilities variables include information on specific cardiac oriented services such as the existence of a CVD physician and the existence of cardiac rehabilitation units. Clearly, there are other variables that can potentially affect healthcare costs. However, for the purposes of increasing the efficiency of this model while maintaining a consistent theme of the relationships between exercise, recreation supply, and health outcome, some variables were excluded from the model. These variables are listed in section 3.3.4.

The second model investigates the relationship between rates of physical inactivity and the provision of recreational opportunities. This model takes into account the potential endogeneity and simultaneity of physical inactivity levels and rates of obesity in a county because physical inactivity tends to promote obesity, and obesity tends to promote physical inactivity ${ }^{2}$. Thus, for this model there is a need to specify a simultaneous equations model of the form:

\footnotetext{
${ }^{2}$ Measurement of cigarette smoking was considered for this model. However, rates of smoking weren't highly correlated with either physical activity or obesity measures. This measurement is omitted from the final analysis because it is unclear what causal relationship exists between prevalence for smoking and prevalence for physical inactivity and/or obesity (King et al., 1992).
} 
1). $P I=f\left(O B, S_{1}, R S_{1}\right)$
2). $O B=f\left(P I, D_{2}, R S_{2}\right)$,

where $O B$ is the proportion of the adult population considered being obese in 1997, $R S$ are measures of recreational supply, and the other variables are as previously defined. In order to deal with the endogeniety of the variables, a two-stage least squares model is incorporated. A two-stage least squares model is suitable in cases where some of the variables change simultaneously, and thus its results are more consistent. The second model incorporates some socio-demographic variables that explain some of the variation of the dependent variable, along with land designation oriented variables associated with dispersed recreation supply such as: density of the population in the county, proportion of public land in the county. $R S$ are recreation supply indices that have been especially developed for this analysis.

The background and logic for forming these recreational supply indices is as follows: Although data about number and specific types of recreational facilities were collected, any analysis of that data was flawed because the data were incommensurable. For example, how do you compare out-door tennis courts and in-door swimming pools, a country club and a high school gym, etc. Additional questions that arose were, how to compare two miles of trail and twenty miles of trail, and how to make the number of trails commensurate with playgrounds, acres of public land, whitewater river miles and so forth. To overcome these problems and in order to create meaning for measures of recreational opportunities, a method of principal components or factor analysis was employed (English et al. 2000). A principal component is a method of reducing the number of variables and detecting structure in the relationship between variables. In other words, it is a method of reducing related variables into a single manifest variable. These manifest variables are essentially linear combinations of the latent variations in the original variables. This method has proven to be effective when dealing with the development of recreation supply indices for disparate recreation opportunities measures (Deller et al. 2001; English et al. 2000). For instance, Deller et al. constructed five indices designed to capture specific amenity and quality of life characteristics using fifty-four separate indicators. Another example is a research conducted by English et al., where the researchers had too many resource attributes to include in a regression analysis. Thus, 
they employed the method of principal components to reduce the resource array into four groups that represent specific types of opportunities for recreation and tourism.

Data for constructing the recreational supply indices, used in this study, was retrieved from the National Outdoor Recreation Supply Information System (NORSIS) 1997 data set. NORSIS is a county-level database of outdoor recreation resources in the United States, developed and maintained by the USDA Forest Service's Wilderness Assessment Unit, Southern Research Station, Athens, Georgia. The NORSIS data set contains over 200 separate variables including facilities, businesses, and resources that support recreational activities. The NORSIS database contains 14 recreation supply indices. These indices where constructed by selecting 51 individual recreation resource variables from a set of over 200 such variables. Variables were than classified according to whether they were related to developed facilities, land, water, or winter recreation resource bases. To condense those blocks of variables to single measures, the method of principal components was employed. After following the convention of retaining factors with eigenvalues greater than one, out of the 51 pre-selected variables, only 14 were retained. Then, to summarize the relative availability of resources for a factor in a specific county, factor scores were calculated for each factor for each county.

However, because NORSIS is a national data set, and this thesis focuses on West Virginia, a reproduction of the factor analysis process was appropriate in order to obtain results for West Virginia's counties only. Four broad categories of recreation supply, including developed recreation, dispersed land-based recreation, water-based recreation, and winter-based recreation, were developed. In total, 13 factors were identified. However, in specification tests of the model, only three of these factors were retained: FURB1, FLD2, and FWT2. Table 3.2 provides a description of the variables underlying these factors. These three recreation factors are unit-less measures of recreation supply and can be positive or negative, with the more positive the value, the higher the supply of recreation opportunities. 


\subsubsection{Spatial Analysis}

The geographical dispersion of the variables as well as the natural interrelation between some of them indicates a potential for spatial patterns in the data as shown in figures $3.3,3.4$, and 3.5

\section{Per Capita Hospital Total Charges for Diseases and Disorders of the Circulatory System 1999 (\$)}

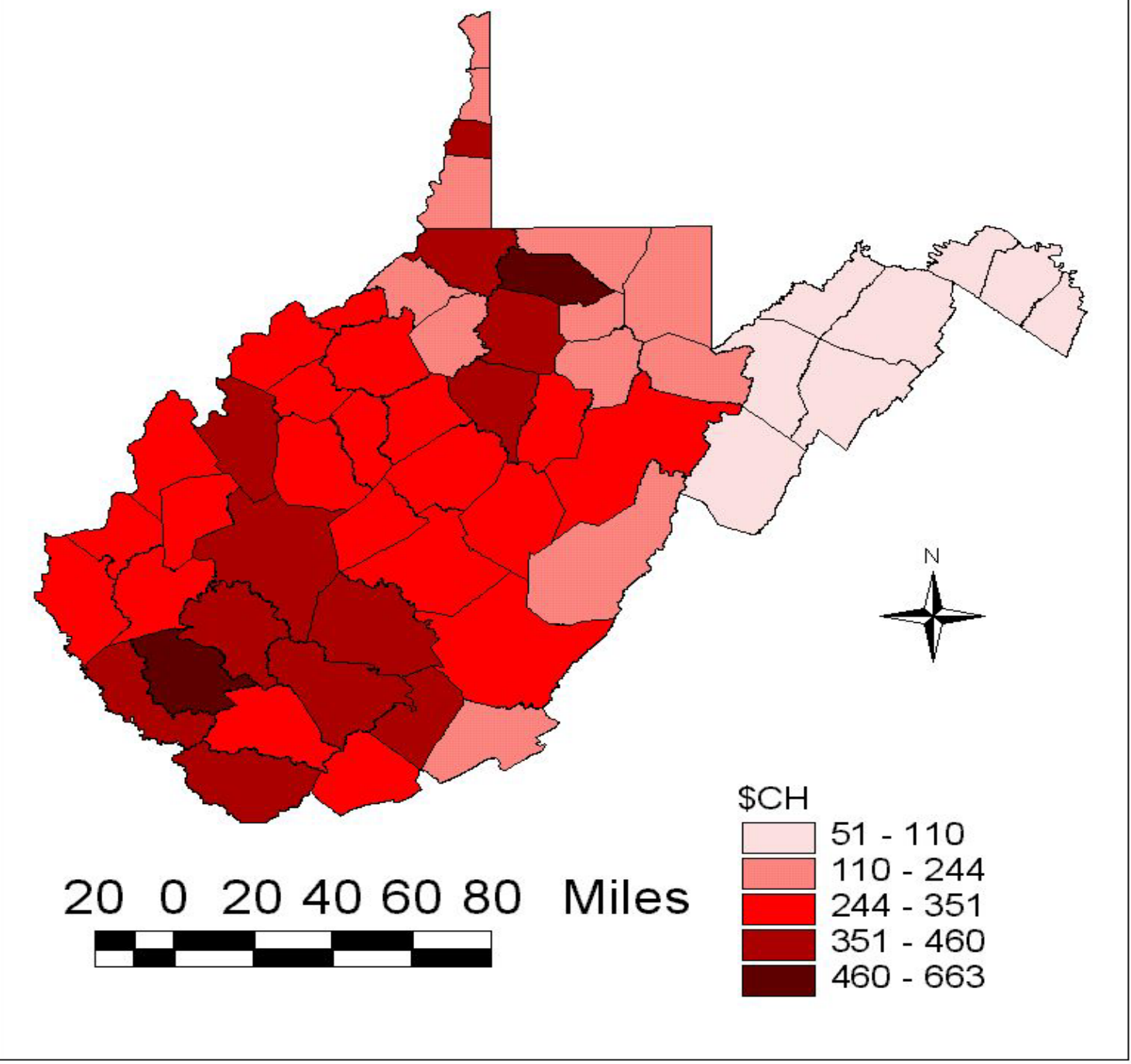

Figure 3.3: Per Capita Hospital Total Charges for Diseases and Disorders of the Circulatory System 1999 


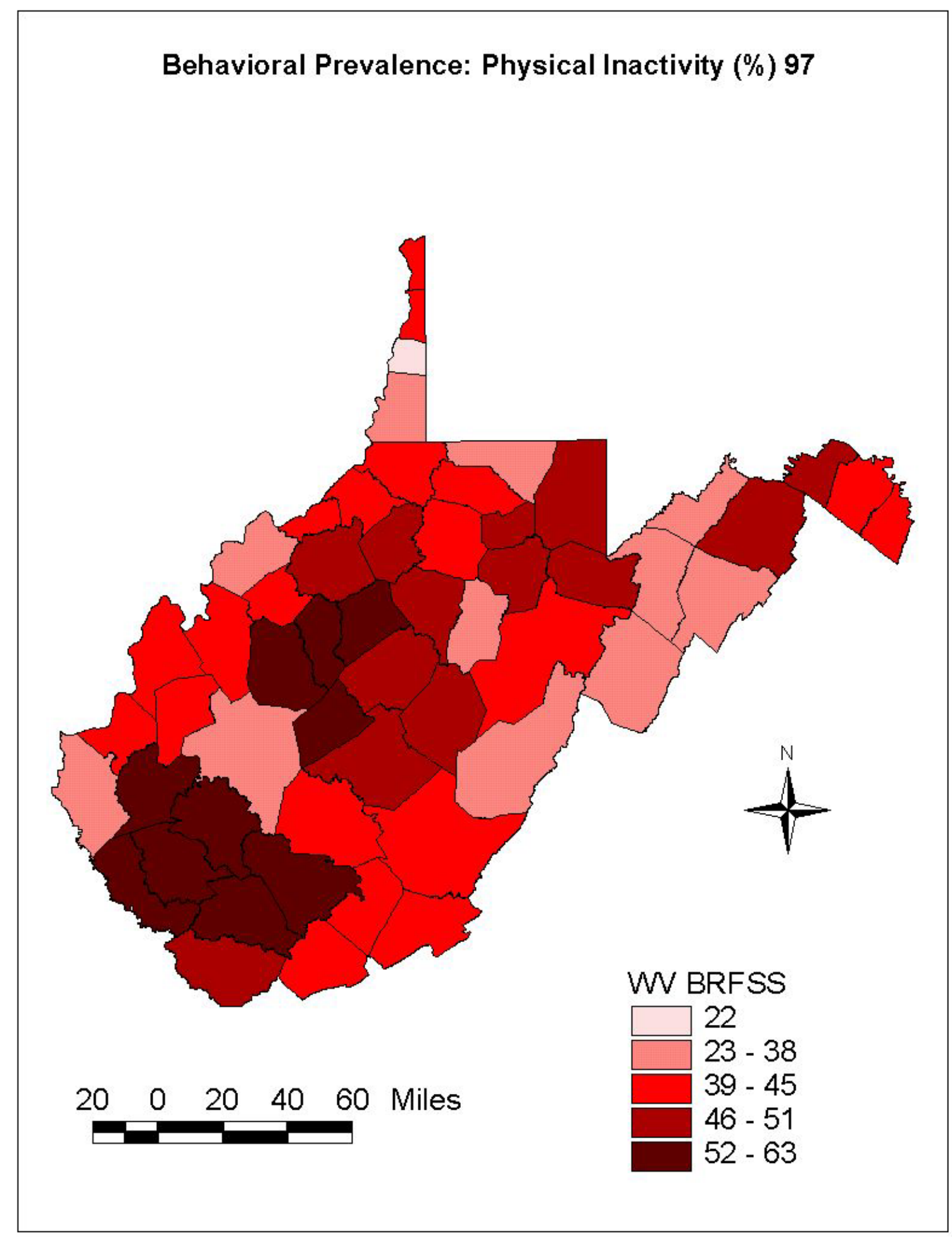

Figure 3.4: Behavioral Prevalence- Physical Inactivity 1997 (\%) 


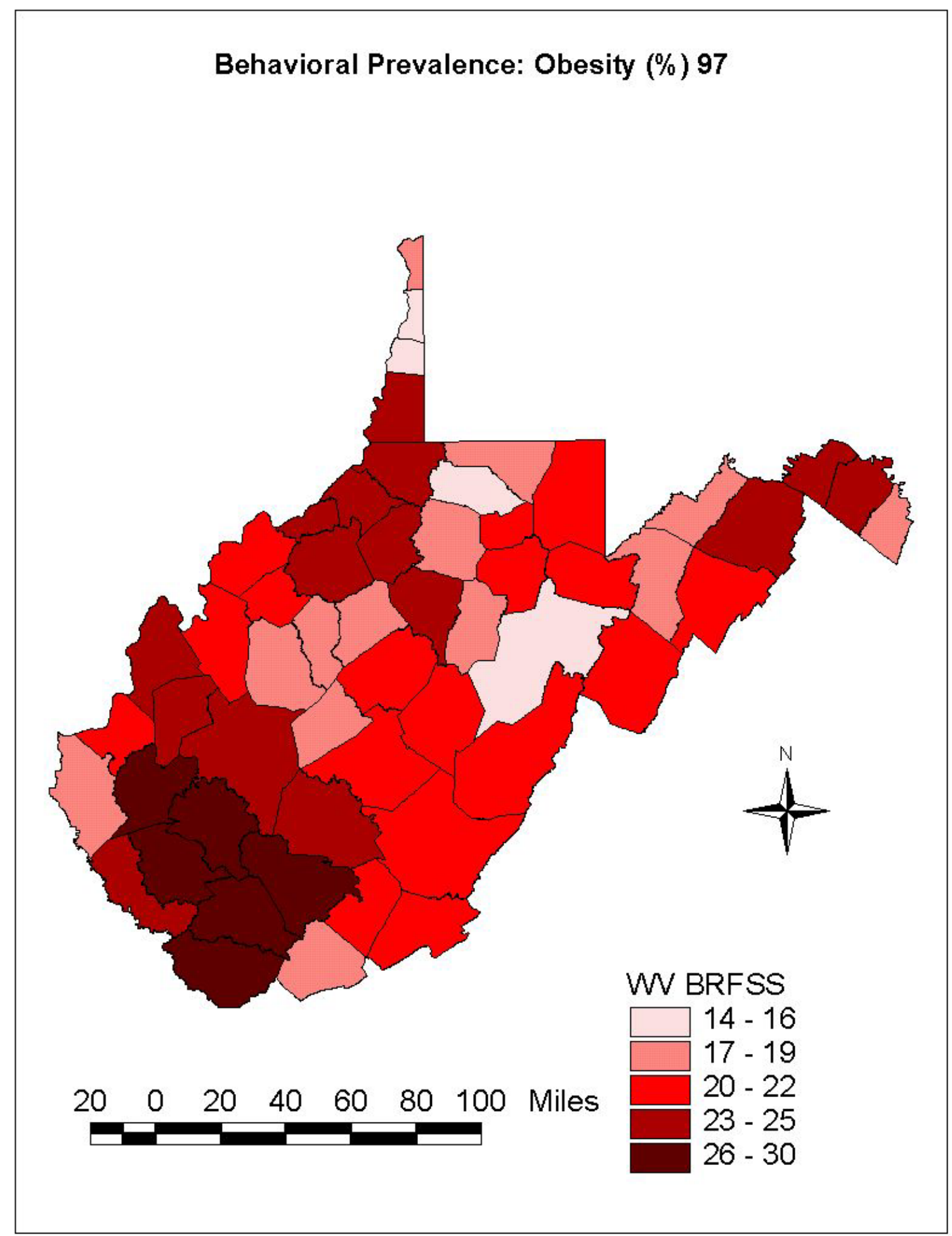

Figure 3.5: Behavioral Prevalence- Obesity 1997 (\%)

As shown in the figures, there tends to be a clustering of high hospital charges down at the southern part of the state, and low hospital charges up at the eastern 
panhandle counties. Additionally, the spatial distribution of physical inactivity rates and other risk factors is unequal across the state. There are pockets of counties, mainly in the southern part of West Virginia, that have higher rates of physical inactivity and obesity than other regions of the state. Accounting for spatiality in the data is important to strengthen any regression analysis because the spatial component can improve the results by capturing and accounting for some of the variation of the dependent variables. By not accounting for spatial autocorrelation, least squares regressions are biased and inconsistent if the correlation is among the explanatory variables, or inefficient if the correlation is with the error term. In this research, as shown in the maps, accounting for spatiality is crucial given that 1) people can seek health care outside of their county of residence, 2) residents of a county can participate in recreation activities outside of their county of residence, and 3) it is a way to capture some of the cultural factors affecting communities. Consequently, a traditional OLS regression will not be sufficient for a valid analysis, and thus, a couple of spatial analysis techniques are incorporated in testing the models, in order to improve the results, reduce bias and inconsistency in the presence of spatial lags, and increase the efficiency of the models.

Hence, in order to reduce spatial bias in the first model, a generic Spatial Autoregressive model ${ }^{3}$ is specified (LeSage 1999):

3. $\$ \mathrm{CH}_{\mathrm{i}}=\rho \mathbf{w} \$ \mathrm{CH}_{\mathrm{i}-1}+\beta \mathrm{X}_{\mathrm{i}}+\mu_{\mathrm{i}}$,

$$
\mu_{\mathrm{i}}=\lambda \mu_{\mathrm{i}-1}+\varepsilon_{\mathrm{i}}
$$

where $\rho \boldsymbol{w} \$ C H_{i-1}$ is the first-order spatially weighted $\$ C H$ for counties contiguous to county $\mathrm{i}, X_{i}$ is a matrix of non-spatial explanatory variables for county $\mathrm{i}, \mu_{\mathrm{i}}$ is the autocorrelated error component with $\varepsilon_{\mathrm{i}}$ being the i.i.d. stochastic component. Rho $(\rho)$ on the weighted dependent variable $\left(\boldsymbol{w} \$ C \mathrm{H}_{i-1}\right)$ is the first-order coefficient of lagged spatial autocorrelation and $\lambda$ is the first-order coefficient of the error spatial autocorrelation. The $\boldsymbol{w}$ represents the spatial weight matrix and is developed using the queen definition of first-order county contiguity. In other words, $\boldsymbol{w}$ implies that due to the spatial distribution

\footnotetext{
${ }^{3}$ Two important classes of spatial econometric models may be formed from the generic model. If $\rho=0$ we have the spatial error model, and if $\lambda=0$ we have the spatial lag model. All diagnostic tests for this spatial model favored the spatial lag formulation. See Anselin (1989) for details.
} 
of the variables, a county's measurement is also a function of measurements of its adjacent counties.

In order to account for the spatial distributions of the endogenous and exogenous variables, a Spatial Durbin model is used for the second model. The primary difference between a Spatial Autoregressive model and a Spatial Durbin model is that the latter model introduces additional spatially lagged exogenous variables. This is important because residents of a county can participate in, or consume recreation activities outside of their county of residence ("sleep-in" counties or "bedroom" communities). The same weight matrix, $\boldsymbol{w}$, is be applied to the Spatial Durbin model and the model is restricted to first-order contiguity.

This thesis provides a multi-step analysis, broken down to the following steps:

- Step one - a traditional OLS analysis using LIMDEP software. Model number one checks for the marginal effects of several variables, including physical inactivity, on healthcare expenditures. Model one establishes a relationship between physical inactivity and healthcare expenditures. However, model one doesn't account for spatiality within the data set and therefore is biased, and inefficient in the presence of spatial autocorrelation.

- Step two - due to structural spatial autocorrelation in the data set, weighted variables based on a spatial weight matrix, are introduced to model one. A spatial lag analysis is performed using both LIMDEP and SPACESTAT software. A spatial lag OLS analysis is compared to a spatial lag Maximum Likelihood Estimation (MLE) analysis, and outputs of the two statistical packages are presented.

- Step three - due to the fact that the second model consist of two endogenous behavioral risk factors (physical inactivity and obesity) that tend to influence each other, a Hausman specification test is performed to check for simultaneity between these variables. Then, a two stage least squares spatial Durbin model is performed to investigate the marginal effects variables associated with recreation supply on physical inactivity levels. 


\subsubsection{Dependent Variables}

The dependent variables in this thesis are per capita total hospital charges due to diseases and disorders in the circulatory system, physical inactivity levels, and obesity levels.

- Total hospital charges due to diseases and disorders of the circulatory system - data were retrieved from the West Virginia Health Care Authority's web site. All West Virginia's hospitals are required to submit copies of a Uniform Bill (UB) for every patient discharged, regardless of the expected source of payment. Therefore, the database includes information on patients covered by commercial carriers, Blue Cross, the Public Employees Insurance Agency, Medicaid and Medicare as well as for those patients who have no insurance coverage. The data used in this project were collected based on the International Classification of Diseases, 9th Edition (Clinical Modification) (ICD-9-CM) - which is a listing of diagnoses and identifying codes used by physicians for reporting diagnoses. The coding and terminology provide a uniform language that can accurately designate primary and secondary diagnoses and provide for reliable, consistent communication on claim forms. The diagnosis description chosen for this project was "principal diseases and disorders of the circulatory system". As a subset criterion, data on diseases and disorders of the circulatory system were broken down based on the patients' county of residence. In order to obtain per capita measures, each county sum of total charges for principal diseases and disorders of the circulatory system was divided by the county's population of the year 2000 .

- Physical inactivity and obesity levels for 1997 - data were retrieved from the "West Virginia County Health Profile 2000" report, released by the WV Office of Epidemiology and Health Promotion, in 2001. County prevalences for both physical inactivity and obesity for 1997 represent aggregated data from 1995 through 1999. The following are the classifications for these behavioral risk factors based on BRFSS $^{4}$ definitions:

\footnotetext{
${ }^{4}$ The BRFSS, the world's largest telephone survey, tracks health risks in the U.S. The BRFSS is a cross-sectional, population based, and random-digit-dial telephone survey of adults (18 years of age or older) conducted by the CDC and state health departments. The BRFSS is a very expansive system. However, for this thesis, the information used is about the proportion of adults that are regarded as physically inactive (PI) or obese (OB) in each county.
} 
$\Rightarrow$ Persons are classified as inactive if they report no physical activity outside of their occupation during the month preceding the survey.

$\Rightarrow$ Persons are classified as obese if they have a Body Mass Index (BMI) of 30 or more. Body Mass Index is defined as a measure of an adult weight in relation to height. Specifically, it is the adult's weight in kilograms divided by the square of his or her height in meters.

Table 3.1 contains additional information on the dependent variables.

\begin{tabular}{|c|l|l|l|}
\hline \multicolumn{5}{|c|}{$\begin{array}{c}\text { TABLE 3.1: DEPENDENT VARIABLES } \\
\text { Code }\end{array}$} & \multicolumn{1}{|c|}{ Description } & \multicolumn{1}{c|}{ Source } \\
\hline PCHOCH99 & $\begin{array}{l}\text { Per capita hospital } \\
\text { total charges for } \\
\text { diseases and disorders } \\
\text { of the circulatory } \\
\text { system 1999 }\end{array}$ & $\begin{array}{l}\text { West Virginia Health care Authority } \\
\text { http://www.hcawv.org }\end{array}$ \\
\hline PHINAC97 & $\begin{array}{l}\text { Behavioral prevalence } \\
\text { physical inactivity 97 } \\
(\%)\end{array}$ & $\begin{array}{l}\text { "West Virginia County Health Profile 2000". A } \\
\text { publication by the WVDHHR, Bureau of Public Health, } \\
\text { and Office of Epidemiology and Health Promotion }\end{array}$ \\
\hline OBES97 & $\begin{array}{l}\text { Behavioral prevalence } \\
\text { obesity 97 (\%) }\end{array}$ & $\begin{array}{l}\text { "West Virginia County Health Profile 2000". A } \\
\text { publication by the WVDHHR, Bureau of Public Health, } \\
\text { and Office of Epidemiology and Health Promotion }\end{array}$ \\
\hline
\end{tabular}

\subsubsection{Independent Variables}

Table 3.2 contains a description of the independent variables. Most of the variables presented in table 3.2 were chosen based on literature review as described in the preceding chapter. However, since this is an exploratory study, some of the variables were selected based on logic and common sense. 


\begin{tabular}{|c|c|c|}
\hline $\begin{array}{l}\text { Variable's } \\
\text { Code }\end{array}$ & Description & Source \\
\hline WPCH99A & Weighted PCHOCH99 & $\begin{array}{l}\text { West Virginia Health care Authority } \\
\mathrm{http}: / / \text { www.hcawv.org }\end{array}$ \\
\hline WPHYSA & Weighted PHINAC97 & $\begin{array}{l}\text { "West Virginia County Health Profile 2000". A } \\
\text { publication by the WVDHHR, Bureau of Public } \\
\text { Health, and Office of Epidemiology and Health } \\
\text { Promotion }\end{array}$ \\
\hline WOBES97A & Weighted OBES97 & $\begin{array}{l}\text { "West Virginia County Health Profile 2000". A } \\
\text { publication by the WVDHHR, Bureau of Public } \\
\text { Health, and Office of Epidemiology and Health } \\
\text { Promotion }\end{array}$ \\
\hline POPOV65 & $\begin{array}{l}\text { County's percentage of population } \\
\text { over the age of } 65(2000)\end{array}$ & U.S. Census Bureau \\
\hline CVDPHY90 & $\begin{array}{l}\text { A dummy variable: Existence of a } \\
\text { CVD physician (1990) }\end{array}$ & $\begin{array}{l}\text { "Heart Disease in Appalachia". An Atlas of County } \\
\text { Economic Conditions, Mortality, and Medical Care } \\
\text { Resources }\end{array}$ \\
\hline REHAB93 & $\begin{array}{l}\text { A dummy variable: Existence of } \\
\text { cardiac rehabilitation units (1993) }\end{array}$ & $\begin{array}{l}\text { "Heart Disease in Appalachia". An Atlas of County } \\
\text { Economic Conditions, Mortality, and Medical Care } \\
\text { Resources }\end{array}$ \\
\hline EDU2 & $\begin{array}{l}\text { Percentage of county's residents, age } \\
25 \text { and over who are at least high } \\
\text { school graduates }\end{array}$ & U.S. Census Bureau \\
\hline METRO & A dummy variable: metro county & $\begin{array}{l}\text { The National Outdoor Recreation } \\
\text { Information System (NORSIS) (1997) }\end{array}$ \\
\hline POPDEN00 & $\begin{array}{l}\text { Population density (2000): county's } \\
\text { population divided by its square miles }\end{array}$ & $\begin{array}{l}\text { U.S. Census Bureau } \\
\text { NORSIS (1997) }\end{array}$ \\
\hline PUBLANP & $\begin{array}{l}\text { Proportion of public land of county } \\
\text { total land }\end{array}$ & NORSIS (1997) \\
\hline WPULANPA & Weighted PUBLANP & NORSIS (1997) \\
\hline FURB1 & $\begin{array}{l}\text { Recreation supply index: developed } \\
\text { local facilities, closely tied to } \\
\text { population growth. Associated with } \\
\text { local park and recreation departments. }\end{array}$ & NORSIS (1997) \\
\hline FLD2 & $\begin{array}{l}\text { Recreation supply index: wildlife land, } \\
\text { primary owned by Fish and Wildlife } \\
\text { Service and The Nature Conservancy. }\end{array}$ & NORSIS (1997) \\
\hline FWT2 & $\begin{array}{l}\text { Recreation supply index: associated } \\
\text { with wild, scenic, and whitewater river } \\
\text { opportunities. }\end{array}$ & NORSIS (1997) \\
\hline
\end{tabular}




\subsubsection{Excluded Variables}

Due to the fact that this is an exploratory study, a large array of variables were collected and considered, but eventually excluded from the final models, because of irrelevance, insignificance, and/or correlation with other variables:

- A division of the county population to rural and urban residents was excluded due to its representation of numerous underlying factors in the analysis, and therefore, this exclusion should prevent multicollinearity complexities. However, the dummy variable METRO, which has been mentioned in the literature as a determinant of physical activity, is used in the analysis to provide information about the residential structure in a county.

- Race is mentioned in the literature as a determinant of physical activity and health status. However, this variable was tested and dropped from the models due to the fact that the population in West Virginia is predominantly white (95\%).

- Data on income level were collected but is directly correlated with data on educational level. A level of education was a preferable measure based on previous research about the determinants of physical activity.

- Other socio-demographic data were collected and considered. For example, type of household, gender etc. At this scope of analysis these data were found to be insignificant.

- Data on temperatures, level of precipitation, and snowfall were collected. Yet, because of the relatively small differences of these variables across the state of West Virginia, they are excluded from the final analysis

- The total number of deaths were considered and calculated. Yet, for the scope of this thesis, a dependent variable that is quantified in monetary terms was preferable.

- Data on other behavioral risk factors such as cigarette smoking and hypertension were collected. However, due to multicollinearity issues between some of the risk factors, the unclear relationships between smoking and both physical inactivity and obesity levels (see footnote 2), and the focus of this research on physical activity, smoking and hypertension were omitted from the final analysis. This is also supported by the medical literature that provides evidence that not only praise the importance of 
physical activity as the most important risk factor, but also concludes that physical activity is crucial to health status regardless of smoking habits.

- The variables "existence of a CVD physician" and "existence of cardiac rehabilitation centers" were selected to represent availability of and accessibility to health care. Data on number of hospitals, number of hospital beds, and existence of dieticians were collected as well, but the two selected variables match the best with heart diseases prevention. Thus, the inclusion of other healthcare variables would impose both over-specification problems and multi-collinearity issues with variables that explain population density and status of a county, in terms of whether or not the county is defined as a metro county.

- As mentioned before, data on specific types of recreational facilities (e.g. ballparks, basketball courts, country clubs, golf courses, tennis courts, parks, etc.) were collected. However, these variables were not significant in early specifications of the models. One primary reason for this is that there isn't a common metric for the different recreational opportunities. Additionally, because these variables are incommensurable (a trail is measured as one trail regardless of its length, a park is measured as one park regardless of its size etc.), analysis based on them would be subject to flaws and inaccuracies.

- Data on the number and types of businesses and services associated with recreation was collected as well based on the linkage between demand and supply for recreational activities. Nevertheless, these variables were not significant in the analysis. In addition, many of these businesses serve non-residents and may not benefit the county's residents.

- Data on more specific land patterns were collected. However, in preliminary analyses any introduction of more specific land pattern variables, such as recreation land to its types, was found to be insignificant and provided no contribution to this research. 


\section{CHAPTER FOUR: RESULTS}

\subsection{Introduction}

This chapter presents the main estimations of the models presented in the previous chapter. The output for all models, as well as the descriptive statistics of all variables, are in Appendix B. The chapter is organized in the following manner: results of a traditional OLS analysis are presented first, followed by results of a first order spatial lag model. Next, the results of the two stage least squares Spatial Durbin model are presented.

\subsection{Results for Model One}

The goal of the first model is to establish a relationship between a prime indicator of health status and outcomes of poor health by investigating the relationship between levels of physical inactivity and per capita hospital charges for diseases and disorders of the circulatory system. A traditional OLS analysis is followed by a first order spatial lag analysis. It is important to notice that the traditional OLS estimations do not take into account any spatiality within the data set and thus, the results are probably biased and inconsistent. Therefore, although the results provide an idea about the interrelations between the variables, they should be interpreted cautiously. In order to overcome these problems and gain efficiency, a first order spatial lag model is specified and presented.

\subsubsection{Traditional OLS Analysis}

The first step of the analysis is performing traditional OLS estimations. All variables are as defined in the previous chapter.

Mathematically, the first model is presented as:

PCHOCH99 $_{\mathbf{i}}=\beta_{0}+\beta_{1}$ PHINAC97 $_{\mathbf{i}}+\beta_{2}$ POPOV65 $_{\mathbf{i}}+\beta_{3}$ CVDPHY90 $_{\mathbf{i}}+\beta_{4}$ REHAB93 $_{\mathbf{i}}+$ $\beta_{5}$ EDU $2_{\mathbf{i}}+\beta_{6}$ METRO $_{\mathbf{i}}+\varepsilon_{\mathrm{i}},(\mathrm{i}=1,2 \ldots 55)$. 
A summary of results of a traditional OLS analysis is shown in table 4.1. This table presents a LIMDEP OLS output of the first model.

\begin{tabular}{|c|c|c|}
\hline \multicolumn{3}{|c|}{ TABLE 4.1: TRADITIONAL OLS ANALYSIS } \\
\hline \multicolumn{2}{|c|}{ Dependent variable: PCHOCH99, Number of observations $=\mathbf{5 5}$} \\
\hline VARIABLE & COEFFICIENT & P-VALUE \\
\hline CONSTANT & -209.4 & 0.487 \\
\hline PHINAC97 & 5.4 & 0.028 \\
\hline POPOV65 & 20.9 & 0.014 \\
\hline CVDPHY90 & 55.3 & 0.16 \\
\hline REHAB93 & 111.6 & 0.01 \\
\hline EDU2 & -2 & 0.505 \\
\hline METRO & -33.7 & 0.38 \\
\hline R $^{2}$ & & \\
\hline
\end{tabular}

The results show that the coefficient on PHINAC97 is highly significant indicating a solid relationship between the two variables. Moreover, the coefficient of the variable PHINAC97 is positive $(+)$, indicating that physical inactivity levels are positively related with higher healthcare expenditures. More specifically, the results suggest that a one percent increase in the level of physical inactivity will result in more than a $\$ 5$ increase in medical expenditures, ceteris paribus. Based on these results, the null hypothesis, $\mathrm{H}_{0}: \beta_{\text {physical inactivity }}=0$, can be rejected at any level of significance smaller than 0.028 . That is, the county-level per capita hospital expenditures are significantly related to the level of physical inactivity.

The results also show that counties with larger proportions of residents over 65 years of age (POPOV65) have higher healthcare expenditures. As previously mentioned, as people become older, they tend to become more sedentary and more vulnerable, and therefore need more medical treatments. Other variables that were found to be positively correlated with hospital charges due to diseases and disorders of the circulatory system are variables that are associated with the availability of cardiac health services. Despite the initial conjecture that links between the availability of specialized health services that are associated with heart diseases (such as cardiac rehabilitation units and the existence of a CVD physicians) and lower medical expenditures, the results show a contrary 
linkage. A possible explanation for this is threefold. First, these cardiac preventive services aren't provided free of charge, and thus patients who visit a CVD physician, or are treated at a cardiac rehabilitation unit pay for these services. These payments are partially captured in the hospital charges. Second, people who can afford to pay for these preventive services are more than likely to have better health insurance coverage. Therefore, these people might be inclined to visit health professionals and spend more on medical care. Third, the existence of these cardiac preventive services is determined, in part, by the demand for such services. Hence, such preventive services will operate in places where people need the services and are able and willing to pay for them.

The results indicate that the variables EDU2 and METRO are inversely correlated with healthcare expenditures. The health literature provides clear evidence that links level of education with the level of leisure-time physical activity. That is, more educated people are more likely to be active and therefore incur less medical expenditures. In addition, Schoenborn and Barnes (2002) found that adults who live in the suburbs are more likely to engage in leisure-time physical activity than adults who live in rural or urban areas. West Virginia is a relatively rural state, and counties that are categorized as $M E T R O$ counties are, for the most part, characterized as suburbs in terms of the national standards. Thus, in METRO counties, people have more opportunities and options to exercise that lead to a higher level of physical activity and lower healthcare costs.

The results of the traditional OLS model did establish a direct relationship between physical inactivity and healthcare expenditures. However, as mentioned previously, OLS estimations may be biased, inconsistent, or inefficient in the presence of spatial relationships within the data set. Evidence of the presence of spatiality in the data set is twofold. First, the variables and residuals from the OLS model are displayable, and thus spatial patterns and clustering may be observable. Second, results of the same model ran by SpaceStat (spatial statistics software) indicate spatial dependence. There are two types of diagnostic tests for establishing spatial dependence in a regression model: tests for spatial error dependence and tests for substantive dependence. The common approaches to test the presence of spatial dependence are Moran's I and Lagrange Multiplier tests to the residuals of an OLS regression. 
Figures 3.3, 3.4, and 3.5, in the preceding chapter, clearly show that there are some spatial patterns in the data set. Both per capita hospital charges due to diseases and disorders of the circulatory system and the behavioral risk factors are not evenly distributed across West Virginia. Rather, there are some pockets of these variables at different parts of the state and the spatial dispersion is observable. In addition, figure 4.1 is a map of the residuals of the traditional OLS model. The map clearly illustrates the spatial distribution of the residuals for this model. With relation to the SpaceStat diagnostics, Table 4.2 presents SpaceStat regression diagnostics for spatial dependence in this model.

\begin{tabular}{|l|c|c|}
\hline \multicolumn{3}{|c|}{ TABLE 4.2: SPACESTAT REGRESSION DIAGNOSTICS } \\
\hline \multicolumn{2}{|c|}{ Dependent variable: PCHOCH99, Number of observations $=\mathbf{5 5}$} \\
\hline DIAGNOSTIC & VALUE & P-VALUE \\
\hline MORANS I (error) & 3.81 & 0.000136 \\
\hline LAGRANGE MULTIPLIER (error) & 8.71 & 0.003152 \\
\hline LAGRANGE MULTIPLIER (lag) & 17.57 & 0.000028 \\
\hline LOG -LIKELIHOOD & & -330.559 \\
\hline
\end{tabular}

Table 4.2 presents highly significant Moran's I and Lagrange Multiplier scores, indicating spatial error and spatial lag dependence. Since the Lagrange Multiplier diagnostic for spatial lag dependence is more significant than the diagnostic for spatial error, a spatial lag approach prevails (Anselin, 1993). Therefore, in order to reduce spatial dependence and bias, and increase consistency and efficiency, the model is re-specified and spatial lag analysis is conducted. 


\section{OLS MODEL 1 RESIDUALS}

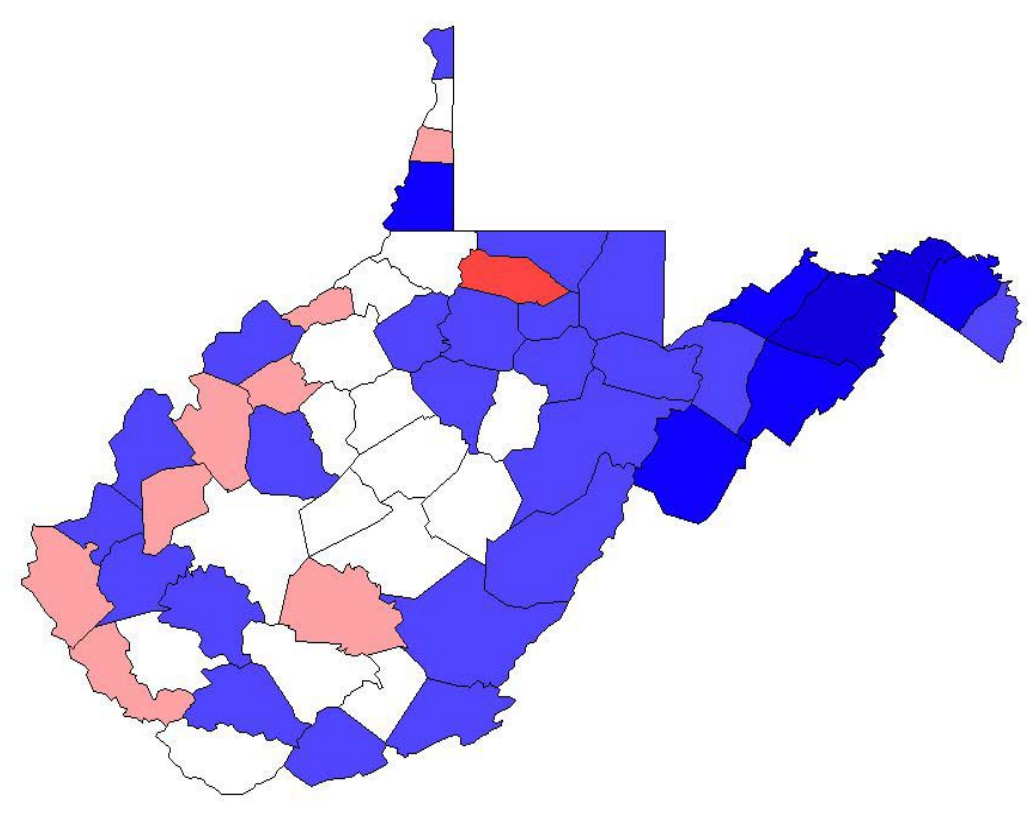

R_PCHOCH

$-3--2$ Std. Dev.

$-2--1$ Std. Dev.

-1 - 0 Std. Dev.

Mean

0 - 1 Std. Dev.

1 - 2 Std. Dev.

2 - 3 Std. Dev.

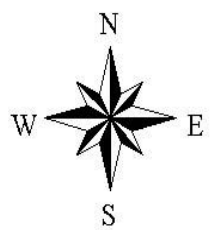

Figure 4.1: Distribution of the Residuals of an OLS Model.

\subsubsection{Spatial Lag Analysis}

Once spatial dependence was established, the second step of the analysis is performing spatial lag estimations. In order to take spatiality into account, a new variable, WPCH99A, is introduced into the OLS model. This variable is essentially a product of the spatial weight matrix of first-order county continuity multiplied by the dependent variable, as explained in chapter three. Mathematically, this model is presented as:

PCHOCH99 $_{\mathbf{i}}=\beta_{0}+\beta_{1}$ WPCH99A $+\beta_{2}$ PHINAC97 $_{\mathbf{i}}+\beta_{3}$ POPOV65 $_{\mathbf{i}}+\beta_{4}$ CVDPHY90 $_{\mathbf{i}}+$ $\beta_{5}$ REHAB93 $_{\mathbf{i}}+\beta_{6}$ EDU $_{\mathbf{i}}+\beta_{7}$ METRO $_{\mathbf{i}}+\varepsilon_{\mathbf{i}},(i \mathrm{i}=1,2 \ldots 55)$. All variables are as defined in the previous chapter. 
A summary of results of a first order spatial lag analysis for the first model is shown in table 4.3. This table presents the outputs of two statistical packages, LIMDEP and SpaceStat. LIMDEP employs OLS method and SpaceStat employs Maximum Likelihood Estimation (MLE) method to estimate the model. Both methods take spatiality into account and therefore a comparison between the spatial lag OLS estimates and MLE estimates is valid.

\begin{tabular}{|c|c|c|c|c|}
\hline \multicolumn{5}{|c|}{ Dependent variable: PCHOCH99, Number of observations $=55$} \\
\hline & \multicolumn{2}{|c|}{ LIMDEP OUTPUT } & \multicolumn{2}{|c|}{ SPACESTAT OUTPUT } \\
\hline VARIABLE & COEFFICIENT & P-VALUE & COEFFICIENT & P-VALUE \\
\hline CONSTANT & -247.9 & 0.34 & -193.9 & 0.4 \\
\hline WPCH99A & 0.6 & 0.0001 & 0.47 & 0.0001 \\
\hline PHINAC97 & 3 & 0.172 & 3.17 & 0.093 \\
\hline POPOV65 & 17.8 & 0.016 & 18.48 & 0.005 \\
\hline CVDPHY90 & 31 & 0.36 & 40.06 & 0.19 \\
\hline REHAB93 & 90.85 & 0.016 & 93.7 & 0.004 \\
\hline EDU2 & -1.43 & 0.57 & -2 & 0.38 \\
\hline METRO & -21.38 & 0.57 & -22.56 & 0.52 \\
\hline LOG -LIKELIHOOD & \multicolumn{2}{|c|}{ NA } & \multicolumn{2}{|c|}{-323.7} \\
\hline$\overline{\mathbf{R}^{2}}$ & \multicolumn{2}{|c|}{0.55} & \multicolumn{2}{|c|}{0.49} \\
\hline
\end{tabular}

Table 4.3 displays the results of a first order spatial lag analysis. The traditional OLS model was expanded and improved by introducing the variable $W P C H 99 A$, which is a first-order weighted variable of PCHOCH99. By placing WPCH99A in the model, spatiality is accounted for, and therefore the results are less biased and more efficient.

A review of the results indicates that the outputs of the two different statistical software packages are similar both in the magnitude and the signs of the coefficients. Yet, the outputs are not identical and there are differences in the magnitudes of the P-values. The differences between the two outputs are due to two reasons. First, SpaceStat is software that is designed to analyze spatial data sets and usually runs in conjunction with ArcView GIS. LIMDEP is a statistical software package that is not specifically designed to analyze spatial data. In other words, SpaceStat created the variable WPCH99A by 
using an internal, commonly used queen first-order contiguity procedure, while for the LIMDEP analysis, the same variable was created externally, by using the queen firstorder contiguity procedure, and then imported to the model. Second, SpaceStat analyzes the spatial data set by using the method of MLE, which finds the parameters' values that would have most likely produced the observed data. LIMDEP, however, analyzes the data set by using the method of OLS. OLS is the most commonly used regression estimation technique and is readily available in most statistical software packages (Studenmund, 2001). OLS is a method of calculating the estimated coefficients that minimize the sum of the squared residuals between the actual observations $(Y)$ and the predicted $\mathrm{Ys}_{\mathrm{s}}\left(\mathrm{Y}^{\wedge}\right)$ produced by the regression.

This spatial lag analysis yielded a significant relationship between physical inactivity rates and healthcare expenditures. This relationship is similar to the one established in the OLS model, indicating a solid relationship between physical inactivity rates and recreation supply. More specifically, the results of the spatial lag analysis suggest that the variable WPCH99A is highly significant. That is, the variation of the dependent variable $\mathrm{PCHOCH} 99$ is explained in part by spatial issues that involve the geographic location of a county and its adjacent counties. The relationship between these two variables is by all means not a cause-effect relationship. Yet, the inclusion of WPCH99A in the model increases the model's efficiency as shown by the likelihood values. The results also show that the coefficients of the variables REHAB93 and POPOV65 are highly significant and are positively correlated with medical expenditures. The variable CVDPHY9O is also positively correlated with medical expenditures. However, the coefficient of CVDPHY90 is not as significant as the previously mentioned variables. Similarly to the results of the OLS model, EDU2 and METRO are inversely correlated with healthcare expenditures. The p-values of both variables indicate that they are not highly significant. Yet, as previous studies have shown, these variables are associated with better health status and less medical expenditures.

The coefficient of the variable PHINAC97 is positive as expected, indicating a positive relationship between physical inactivity rates and healthcare expenditures. However, LIMDEP assigns PHINAC97 a p-value of 0.172 while SpaceStat assigns PHINAC97 a p-value of 0.093. Based on these results, the null hypothesis, 
$\mathrm{H}_{0}: \beta_{\text {physical inactivity }}=0$, can be rejected at a level of significance of 0.18 or 0.1 for the LIMDEP and SpaceStat respectively. Had a level of significance of 0.1 chosen to evaluate the null hypothesis, $\mathrm{H}_{0}: \beta_{\text {physical inactivity }}=0$ would not be rejected using the OLS model, but would be rejected using the MLE model. Thus, despite the similarities in the coefficients' signs and magnitudes as estimated by the two methods, the hypothesis testing results in different conclusions at a significance level of 0.1 . The results of the MLE analysis performed by SpaceStat are more reliable, though, due to the greater efficiency of the MLE estimators, and the spatial functions that are integral procedures of SpaceStat.

As mentioned, analysis of this data set without accounting for spatiality is biased and inconsistent. To illustrate how the spatial model is superior to the traditional OLS model, figure 4.2 is a map of the residuals of the first-order spatial lag model. The map clearly shows that although spatiality wasn't eliminated from the model, it has been reduced (compared to figure 4.1).

\section{SLAG1 RESIDUAL MAP}

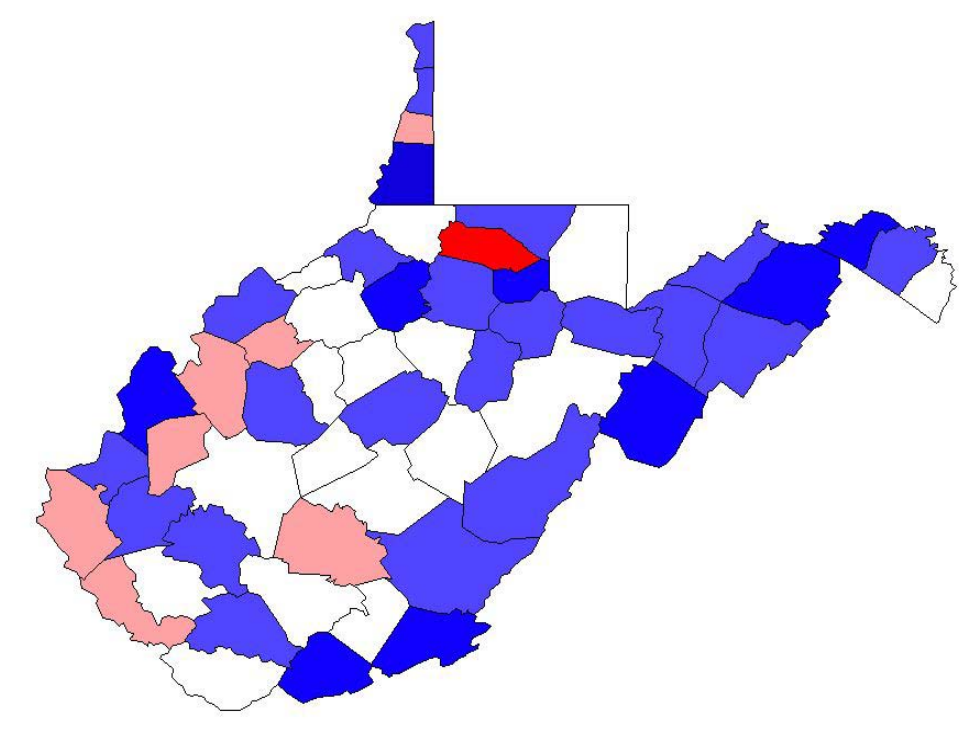

\section{R_PCHOCH}

$-3--2$ Std. Dev.

-2 - -1 Std. Dev. $-1-0$ Std. Dev.

Mean

0 - 1 Std. Dev.

1 - 2 Std. Dev.

2 - 3 Std. Dev.

$>3$ Std. Dev.

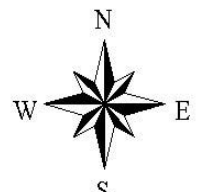

Figure 4.2: Distribution of the Residuals of a Spatial Lag Model 
Further, the log-likelihood estimate of the SpaceStat spatial lag model is -323.7 compared to a SpaceStat non-spatial OLS log-likelihood of -330.559. This highly significant increase (based on a $\chi^{2}$ distribution with one degree of freedom) indicates that the likelihood of the spatial lag model is greater than the likelihood of the traditional OLS model.

A cross comparison of the results of the two models (tables 4.1 and 4.3) reveals the bias inherent in a traditional OLS model in the presence of spatiality within the data set. The biased coefficient for physical inactivity in the traditional OLS model is 5.4 compared to unbiased coefficients of 3 and 3.17 in the spatial lag LIMDEP and SpaceStat models respectively. Thus, a one percent increase in the level of physical inactivity will result in an increase of $\$ 5.4$ compared to $\$ 3$ and $\$ 3.17$ in per capita hospital charges for diseases and disorders of the circulatory system according to the results of the traditional OLS and the spatial lag models respectively. This difference would result in overestimating the effect of physical activity on hospital expenditures when non-spatial OLS estimators are employed. Similarly, the biased coefficient for the percentage of a population in a county that is over the age of 65 is 20.9 in the traditional OLS model compared to unbiased coefficients of 17.8 and 18.48 in the spatial lag models. OLS estimates for the coefficients for variables that indicate availability and accessibility of heart disease related healthcare professional and facilities are overestimated as well $($ CVDPHY90 $=55.3$, REHAB93 $=111.6$ in the traditional OLS model compared to $C V D P H Y 90=31$ and 40.06, REHAB93 = 90.85 and 93.7 in the spatial lag models). However, with regard to the coefficients for the variables that point out an inverse relationship with medical expenditures (EDU2 and METRO), the traditional OLS model bias goes the other way around and the coefficients for these variables are underestimated. For instance, the traditional OLS model coefficient for the variable EDU2 is -2 , suggesting that as the percentage of county's residents, age 25 and over who are at least high school graduates increases by one percent, the per capita healthcare expenditures will be reduced by $\$ 2$ compared to $\$ 1.43$ and $\$-2$ reduction suggested by the spatial lag model. Likewise, the traditional OLS coefficient for the dummy variable METRO is -33.7 , suggesting that people who live in urban counties will spend $\$ 33.7$ less 
on medical expenditures than those who live in rural counties compared to a difference of $\$ 21.38$ and $\$ 22.56$ as suggested by the spatial lag models.

In summary, the first model dealt with the question of whether or not more physically active counties have lower healthcare burdens. The results of both traditional OLS and spatial lag models indicate a significant relationship between the two variables and suggest that physical inactivity levels are positively correlated with higher hospital charges due to diseases and disorders of the circulatory system. The null hypothesis, $\mathrm{H}_{0}$ : $\beta_{\text {physical inactivity }}=0$, was rejected for the traditional OLS model and for the SpaceStat spatial lag model at a level of significance of 0.1, and for the LIMDEP spatial lag model at a level of significance of 0.18 . At these levels of significance the alternative hypothesis, $\mathrm{H}_{1}$ : $\beta_{\text {physical inactivity }} \neq 0$ is accepted.

\subsection{Results for Model Two}

Model two is geared toward investigating the relationship between rates of physical inactivity and the provision of recreational opportunities in West Virginia counties. Due to the absence of previous research in this field, this model is exploratory. Consequently, preliminary research and analysis of the variables provided a fair direction for specifying the model. In other words, variables that intuitively and empirically explained the variation of the dependent variable, PHINAC97, were retained in the model while other variables that neither had theoretical justification to be included in the model nor were individually significant in preliminary specifications of the model, were excluded from the final analysis.

Based on the results of the first model and the figures presented in chapter three, a spatial approach is employed to specify model two. Those maps clearly show that both physical inactivity and obesity are not evenly distributed across West Virginia, and spatial patterns for both risk factors are observable. In addition, a special consideration is given in the second model to the potential simultaneity and endogeneity of these behavioral risk factors because physical activity tends to promote obesity, and obesity tends to promote physical inactivity. Thus, simultaneous equations for the model are specified and evaluated, and a two stage least squares spatial Durbin model is employed.

The primary difference between a Spatial Autoregressive model as used in model one, 
and a Spatial Durbin model is that the latter introduces additional spatially lagged exogenous variables. These additional spatially lagged variables are important in that residents of a county can participate in, or consume recreation activities outside of their county of residence. Therefore, recreation supply is taken into account in a spatial fashion by applying the same spatial weight matrix, $w$, which was used in model one. That is, recreation supply is restricted to first-order contiguity.

\subsubsection{Specification of Simultaneous Equations for Model Two}

As described in chapter three, the simultaneous equations for model two are of the form of: $P I=f\left(O B, S D_{l}, R S_{1}\right) ; O B=f\left(P I, S D_{2}, R S_{2}\right)$, where $P I$ and $O B$ are the proportions of the adult population considered being physically inactive and obese in 1997, respectively. $R S$ are measures of recreational supply, and $S D$ are sociodemographic characteristics associated with the dependent variables as explained before. More specifically, the simultaneous equations model is defined as follows:

i. PHINAC97 $_{\mathbf{i}}=\beta_{0}+\beta_{1}$ OBES97 $_{\mathbf{i}}+\beta_{2}$ WPHYSA $_{\mathbf{i}}+\beta_{3}$ POPOV65 $_{\mathbf{i}}+\beta_{4}$ EDU2 $_{\mathbf{i}}+$ $\beta_{5}$ POPDENO0 $_{\mathbf{i}}+\beta_{6}$ PUBLANP $_{\mathbf{i}}+\beta_{7}$ WPULANPA $_{\mathbf{i}}+\beta_{8}$ FURB1 $_{\mathbf{i}}+\beta_{9}$ FLD2 $_{\mathbf{i}}+$ $\beta_{10} \mathbf{F W T 2}_{\mathbf{i}}+\varepsilon_{\mathrm{i}},(\mathrm{i}=1,2 \ldots 55)$. The variables are as defined in chapter three.

ii. OBES97 $_{\mathbf{i}}=\beta_{0}+\beta_{1}$ PHINAC97 $_{\mathbf{i}}+\beta_{2}$ WOBES97 $_{\mathbf{i}}+\beta_{3}$ EDU $_{\mathbf{i}}+\beta_{4}$ POPDEN00 $_{\mathbf{i}}+\varepsilon_{\mathbf{i}}$, $(i=1,2 \ldots 55)$. The variables are as defined in the chapter three.

Both of these simultaneous equations are identified according to the "order condition" that states that in order for an equation to be identified, the number of predetermined variables in the system has to be greater than or equal to the number of slope coefficients in the equation of interest. Since both equations are identified, two stage least squares technique can be applied to the model (Studenmund, 2001).

\subsubsection{Testing for Simultaneity}

The Hausman specification test is used to test for simultaneity between PHINAC97 and OBES97. This test is commonly used in cases where there is uncertainty about which of the endogenous variables drives an equations system. The Hausman test determines if two endogenous variables are simultaneously determined according to the following procedure: first, reduced-form equations are formed and the estimated 
endogenous variables and residuals are obtained. Then, one endogenous variable is regressed on both its exogenous variables, and the estimated values and residuals of the other endogenous variable. Finally, a t-test is performed on the coefficient of the estimated residuals. If it is not statistically significant then simultaneity is rejected and the two variables can be considered as mutually independent. However, if the t-test score is statistically significant then simultaneity between the two endogenous variables is established (Gujarati, 2003).

A summary of results for the Hausman specification tests for simultaneity between OBES97 and PHINAC97 is presented in table 4.4.

\section{TABLE 4.4: RESULTS OF HAUSMAN SPECIFICATON TEST FOR SIMULTANIETY}

\begin{tabular}{|c|c|c|c|c|c|}
\hline \multicolumn{3}{|c|}{ ENDOGENOUS VARIABLE: PHINAC97 } & \multicolumn{3}{|c|}{ ENDOGENOUS VARIABLE: OBES97 } \\
\hline VARIABLE & COEFFICIENT & P-VALUE & VARIABLE & COEFFICIENT & P-VALUE \\
\hline $\begin{array}{l}\text { ESTIMATED } \\
\text { OBES97 } \\
\text { RESIDUALS }\end{array}$ & 0.6 & 0.013 & $\begin{array}{l}\text { ESTIMATED } \\
\text { PHINAC97 } \\
\text { RESIDUALS }\end{array}$ & 0.22 & 0.012 \\
\hline
\end{tabular}

Table 4.4 clearly shows that the p-values for the estimated residuals are highly significant, indicating that the variables OBES97 and PHINAC97 change simultaneously. Once simultaneity is established, model two is estimated by a two stage least squares spatial Durbin model. This model takes into account the simultaneity between the endogenous variables as well as the spatiality within the data set. 


\subsubsection{Two Stage Least Squares Spatial Durbin Model}

A summary of results of a two stage least squares spatial Durbin analysis for the second model is shown in table 4.5. This model was ran by using OLS, which could lead to inefficiency and biased estimates. However, given the results from the previous model presented in table 4.3 , this bias is expected to be relatively small with these data.

\begin{tabular}{|l|c|c|c|c|}
\hline & \multicolumn{4}{|c|}{ PHINLE 4.5: TWO STAGE LEAST SQUARES SPATIAL DURBIN MODELS } \\
\hline & COEFFICIENT & P-VALUE & COEFFICIENT & P-VALUE \\
\hline VARIABLE & 55.12 & 0.025 & 11.3 & 0.25 \\
\hline CONSTANT & 0.18 & 0.68 & NA & NA \\
\hline OBES97 & NA & NA & 0.68 & 0.0001 \\
\hline WOBES97A & NA & NA & 0.04 & 0.73 \\
\hline PHINAC97 & 0.45 & 0.098 & NA & NA \\
\hline WPHYSA & 0.15 & 0.73 & NA & NA \\
\hline POP0V65 & -0.53 & 0.001 & -0.098 & 0.32 \\
\hline EDU2 & -0.01 & 0.25 & -0.002 & 0.7 \\
\hline POPDEN00 & -0.13 & 0.13 & NA & NA \\
\hline PUBLANP & -0.19 & 0.27 & NA & NA \\
\hline WPULANPA & -0.74 & 0.43 & NA & NA \\
\hline FURB1 & -0.58 & 0.51 & NA & NA \\
\hline FLD2 & -1.1 & 0.11 & NA & NA \\
\hline FWT2 & $11(10,44)$ & 0.00 & $9.26(4,50)$ & 9.26 \\
\hline F-STAT & \multicolumn{1}{|l|}{0.65} & & 0.38 \\
\hline ADJUSTED R & & &
\end{tabular}

Table 4.5 shows that all the explanatory variables are of the expected sign but some of them are insignificant. In the PHINAC97 model, the coefficient of WPHYSA, the spatial lag variable of PHINAC97 is 0.45 and significant, at the 0.1 level. A positive sign on $O B E S 97$ means physical inactivity increases with increases in obesity. However, the coefficient for $O B E S 97$ is insignificant in this model. A significant and positive estimate for $E D U 2$ supports the convention that higher education levels lead to lower physical inactivity rates. All the other explanatory variables are not significant at the 0.1 level. 
Consequently, the null hypothesis, $\mathrm{H}_{0}: \beta_{\text {recreation supply }}=0$, is not rejected. Nevertheless, the appropriate signs on all recreation supply variables coupled with the evidence that both PUBLANP and FWT2 are just shy of statistical significance indicate that greater supplies of recreation opportunities are inversely related to physical inactivity rates.

In the OBES97 model, only one explanatory variable, WOBES97A, is statistically significant. This variable is the spatial lag variable for OBES97 that represents the influence of contiguous counties on the level of obesity in a county. Although insignificant in the model, the coefficients of PHINAC97 and EDU2 are of expected signs. Obesity increases with increases in physical inactivity, and higher education levels tend to be associated with lower rates of obesity.

The OBES97 model has less good of a fit (adjusted $\mathrm{R}^{2}=0.38$ ) than the PHINAC97 model (adjusted $\mathrm{R}^{2}=0.65$ ), implying that its explanatory variables do not adequately account for the distribution of $O B E S 97$, as well as the explanatory variables of PHINAC97 do.

None of the recreation supply variables was significant in the OBES97 model, so they were subsequently dropped. These supply variables directly affect the level of physical inactivity and since physical inactivity and obesity are simultaneous, they indirectly affect the levels of obesity. Thus, the PHINAC97 model is more expansive, and better reflects the linkage between recreational opportunities, risk factors, and health status. This result is supported from the literature. An article that reviews the literature on defining relationships between physical inactivity and obesity presents a threefold conclusion. First, physical activity clearly reduces the health risks associated with obesity or overweight. Second, physically active obese people have lower morbidity and mortality than normal weight but sedentary people. Third, the importance of physical inactivity as a mortality predictor is as important as obesity (Blair and Brodney, 1999). Another article concludes that physical activity aids health regardless of Body Mass Index (Johansson and Sundquist, 1999). That is, physical inactivity is the primary cause of morbidity and mortality rates as compared with obesity, and is the driver of their simultaneous equation system presented above. 


\section{CHAPTER FIVE: SUMMARY OF RESULTS, CONCLUSIONS AND POLICY IMPLICATIONS, AND SUGGESTIONS FOR FUTURE STUDY}

\subsection{Summary of Results}

The objective of this thesis was to test a set of hypotheses concerning the linkage between recreation supply, physical activity levels, and health status. This objective was met by constructing two models.

The first model tested whether more physically active counties have lower healthcare burdens measured as expenditures on healthcare. Two methods of analysis were employed to examine the relationship between physical inactivity levels and healthcare costs due to diseases and disorders of the circulatory system. Both methods of analysis, traditional OLS and first order spatial lag, showed that physical inactivity levels are positively related with higher healthcare expenditures. Nevertheless, since there are some clear noticeable patterns within the data set, the first order spatial lag model was found as a superior method to employ. The first order spatial lag model takes into account the spatial dependence within the data set and therefore is less biased, and more consistent and efficient than the traditional OLS specification.

The second model tested whether or not lower levels of physical inactivity are related to the supply of recreational opportunities and options in West Virginia counties. A version of Hausman's specification test was implemented to test for simultaneity between physical inactivity levels and obesity levels. Once simultaneity between these two behavioral risk factors was established, model two was estimated by a two stage least squares spatial Durbin model. This model takes into account the simultaneity between the endogenous variables as well as the spatiality within the data set. The results of the second model show an inverse relationship between variables that are associated with recreation supply and levels of physical inactivity. Yet, this inverse relationship was weakly statistically significant.

In summary, the results of the models presented in this research show a direct relationship between physical inactivity levels and higher healthcare expenditures. The results also show that physical inactivity levels are inversely associated with recreation supply indicators. Although the latter relationship is not statistically significant, there is 
clear evidence that counties with more recreational opportunities have lower levels of physical inactivity. Thus, the two models establish a direct relationship between physical inactivity levels and an indicator of health status, a direct relationship between recreation supply and physical inactivity rates, and indirect relationships between recreational opportunities and healthcare expenditures and obesity. In all models causation is not proven. Instead, associations amongst the data are identified. Causality would only be established from individual behavior data. These individual data would include people's health endowments, physical activity choices, and responses to a wide array of recreational opportunities.

\subsection{Conclusions and Policy Implications}

The major conclusion that can be drawn from the models presented in this research is that there is a relationship between the availability of recreational opportunities and health status in West Virginia counties. The underlying mechanism of this relationship is that a greater supply and variety of recreational opportunities and options might encourage more people to become more active. Accordingly, more physically active people have less risk to suffer from adverse health outcomes. Health professionals praise physical activity for its ability to prevent or reduce morbidity and mortality due to chronic diseases. Communities that provide greater opportunities for people to engage in recreational activities might enhance the overall level of physical activity among the community members who as a result gain health benefits.

The models presented in this thesis show the direct relationship between lack of physical activity and higher healthcare expenditures due to diseases and disorders of the circulatory system. They also showed a positive relationship between variables that are associated with recreation supply and levels of physical activity. Thus, physical activity is a key driver in making our society healthier. Yet, most Americans don't engage regularly in physical activities due to perceptual and physical barriers such as lack of time, lack of facilities, poor accessibility to recreational facilities, feeling that physical activity is difficult and boring, and lack of enjoyment. These barriers to participate discourage people of engaging regularly in physical activities. 
The prime challenge policy makers are facing, with regard to this research, is how to overcome these aforementioned barriers to participate in physical activities. Life in the $21^{\text {st }}$ century encourages more sedentary lifestyles because fewer people work in physically demanding jobs, more people have vehicles, communication is transferred online, and so forth. On the other hand, it is easier today, more than ever, to engage in physical activities because people are more mobile, have more leisure time, and understand the importance of an active lifestyle and its impact on their health. If people start engaging in physical activities and developing more active lifestyle, then both individuals and society will benefit.

The traditionally recommended active lifestyle is perceptually misleading. People wrongly associate active lifestyles with regimented, vigorous exercise programs. However, according to health and exercise professionals, it turns out that regular, lowmoderate intensity physical activity provides substantial health benefits. A more physically active lifestyle reduces the risk of chronic diseases down the road and contributes significantly to overall well being and quality of life.

A significant step in the process of inducing a predominantly sedentary society to engage in physical activities is the creation and provision of a variety of recreational opportunities. Recreational activities can serve as driving factors to overcome both the physical and perceptual barriers to participate. With regard to perceptual barriers, recreational activities are perceived as fun and enjoyable activities that provide versatility in terms of type, location, number of participants etc. Therefore, recreational activities can appeal to people with diverse preferences. If people are happy with the activities they engage in, they will find the time and make the effort to incorporate these activities in their daily routine. Thus, in order to overcome the perceptual barriers a well-designed marketing plan that emphasizes the fun and enjoyment and benefits that are associated with recreational activities should be implemented. Additionally, in order to overcome the physical barriers to participate, some actions have to be taken. Recreational facilities have to be available, affordable, accessible, functional, and well maintained.

Obviously, policy makers have a key impact on the issue of barriers to participate. Policy makers control and influence (directly and indirectly) the supply and condition of 
most recreational facilities, and thus it is the role of policy makers to provide people with the opportunity to become more active at accessible, safe, and convenient sites.

The goal of turning a sedentary society into an active one is not easy to achieve. Despite broad recognition of the health benefits of physical activity, only one out of five American adults is active at the recommended level and about 50 percent of people who decide to participate in physical activities, quit within six months. These statistics reveal a significant problem. The efforts of trying to narrow the gap, between high awareness of healthier active lifestyle and low rates of implementing such a lifestyle, should be focused on delivering the right message to the right audience in a proper way.

Policy makers can take a leading role in making the American society less sedentary. This involvement can include increasing the supply and expanding the infrastructure of recreational facilities, investing in physical activity oriented projects, improving the accessibility, functionality, and maintenance of existing recreational facilities, and promoting and marketing the importance of physical activity and the benefits associated with it. Policy makers have the means to prioritize the importance of turning our society to a more active and healthy society. Yet, to succeed in this mission cooperation and collaboration on the side of public health agencies, health professionals, educators, parents, employers, community groups, and the insurance industry is essential.

Policy interventions in the forms of laws, regulations, programs etc. influence the public's attitudes and actions. A study conducted in rural Missouri found that the majority of the population favored zoning regulations and the use of local government funds to support physical activity. The study concluded that "programs that increase awareness and knowledge of physical activity or that increase skills among those with low self-efficacy and out-come efficacy may also increase support for community-based policy measures" (Brownson et al., 1998). Similarly, a cross-sectional study conducted between the years 1999 to 2000 among American adults concludes that "there was high support for health policy related measures to enhance physical activity". This study also found that the majority of Americans believe that employers should provide their employees time to exercise during the working day, and that there is massive support for requiring physical education in schools. Furthermore, this study also found compelling evidence supporting the "use of government funds to provide areas to engage in physical 
activity and for zoning requirements that would include walking and biking paths" (Brownson et al., 2001).

To date, there is little data that show how policy interventions actually affect levels of physical activity. For instance, Linenger et al. provide evidence that environmental changes (bike paths, extended hours at gyms) have increased the level of physical activity within a community (Linenger et al., 1991). However, studies that involve actual influence of policy interventions should become more prevalent in the near future.

Policy makers deal with tradeoffs when they make decisions. They are subjected to budget and time constraints and need ultimately to please their supporters. Decisions regarding investments in recreational oriented projects usually require an economic analysis. The notion that people who engage in physical activity are more healthy, live longer, and enjoy a better quality of life than their sedentary counterparts, has already been established. However, the monetary values of these improvements are yet to be determined. There are some methods to evaluate health. These methods are described in appendix A. All these methods, though, have their own pros and cons and thus, the inability to precisely determine the dollar value of incremental health benefits presents a problem in the face of policy makers as they discuss funding of physical activity related projects. The belief that a project, which is associated with physical activity, is beneficial to the community, along with the inability to precisely estimate the benefits derived from the project may lead policy makers to adopt the "field of dream" philosophy. The "field of dream" philosophy states that "...if we build it, they will come". However, reality shows that this philosophy is flawed and that the fear of illness, premature death, or a poor quality of life has not led to an increase of physical activity levels better than other attempts to motivate people to exercise have (Kaman, 2000). Therefore, I argue that if policy makers want to effectively promote physical activity, investing in physical activity oriented projects is essential but will not be sufficient in itself. Indeed, providing resources to support physical activity and recreational activities is necessary. Nevertheless, in order to successfully promoting a healthier, more active society, a major emphasis should be on investigating the actual reasons that hold people back from exercising regularly. The barriers to participate have to be further investigated, and 
appropriate actions should be taken to minimize the effects these barriers impose. Every suggested project has to be fully planned and evaluated, and once a project is undertaken it has to be marketed and promoted. Effective marketing campaign and public relations can make the difference between successful outcomes or failures. If policy makers do not stop at providing recreational opportunities, but in addition promote all of the benefits associated with recreational activities and incorporate recreational activities with other events, these activities may be perceived as fun, trendy and enjoyable. Consequently, people will have an opportunity, which they consider to be fun, to enhance their lifestyle and health. I assume that once policy makers embark on an effort to promote healthier lifestyle, the provision of recreation supply will increase. As a result, there will be more opportunities to engage in physical activities. Combining this with effective marketing plan and promotion has good chances to raise the level of physical activity. If that happens, than the favorable outcomes of better health status, well being, and quality of life will benefit both individuals and the public.

\subsection{Suggestions for Future Study}

This research is exploratory in nature and its main goal was to set a framework for the relationship between recreational opportunities and health status. The study was based on pre-existing secondary data that were compiled, organized, and analyzed. Given the constraints and scope of this research, the results are pleasing. However, following are a few suggestions for expanding and improving this research.

- The recreation indices developed in this research are based on the NORSIS 1997 data set. As explained in chapter three, NORSIS is an extensive national data set. Thus, in order to fit these recreation indices to West Virginia, these recreation indices were reproduced, and as a result some efficiency may have been lost. In addition, the NORSIS data set contains mainly information about outdoor facilities. All my attempts to incorporate additional information about indoor facilities were statistically insignificant. A similar approach to research a larger area (e.g. multiple states, the nation) would be able to exploit the NORSIS data set more effectively and incorporate information about indoor facilities as well as businesses associated with recreation more successfully. 
- The hospital charges data used in this research are aggregated and for all coronary and cardiovascular procedures. Some of these procedures are due to factors other than physical inactivity such as age and genetic endowments, among other things, while others are merely preventative or screening factors. I accounted for age effects in my models, but genetic endowments are not controllable without individual specific data. Additionally, the hospital charges data set contains information merely on West Virginia hospitals. Therefore, information on West Virginia residents that receive their healthcare outside of West Virginia is not accounted for in this research. In fact, this phenomenon comes into play as a "border counties effect". The residuals per capita hospital charges map, presented in chapter four, depicts that the models overpredict healthcare expenditures of counties along the West Virginia border, especially the eastern panhandle. Many people who live in these counties, work in the DC area, and thus, if their health insurance doesn't restrict them to consume healthcare at their place of residence, they may consume healthcare outside of West Virginia. In that case, the models don't capture their healthcare expenditures.

- An effective extension to this research would be to collect individual behavior data. Collection of individual behavior data might enable the establishment of causation between physical inactivity, healthcare expenditures, and recreation supply. The desired data should be restricted to health conditions and expenditures linked specifically to physical inactivity.

- Data on physical inactivity and obesity rates were retrieved from the West Virginia Behavioral Risk Factor Survey. This survey has several limitations. For example, the survey is based on self-reported data and therefore results may be biased. Furthermore, the survey neither takes into account non-leisure time physical activities as occupational activities and so forth nor does it distinguish whether or not physical inactivity is due to a disability or is a choice of the individual. Thus, estimates of physical inactivity may be misleading and most likely overestimated. Additional limitation of the West Virginia's survey is that several counties had too small a sample size to stand-alone and therefore, these counties were combined and regrouped to allow valid calculation. A collection of individual behavior data through a survey customized to obtain information on people's actual behaviors, risk factors, 
and medical expenditures could dramatically improve the results of this study as well as establish a cause-effect relationship between behaviors and health outcomes.

○ This research is a cross-sectional study. A time series analysis aiming to investigate the same issues could shed more light on temporal patterns, or dose-response relationship between increasing the supply of recreational opportunities and options and health status responses both for individual and communities.

- Analyzing and estimating the two stage least squares model by utilizing MLE technique and SpaceStat software could enhance this study and not only make the results more efficient and robust, but it will potentially also reduce the level of bias.

- An extension of this research to include a larger area and multiple year data will reduce the "border line effect" and make use of the NORSIS data set more effectively.

In closing, the goal of this study was accomplished. The results of the models were pleasing and showed that there is a relationship between supply of recreational opportunities, levels of physical activity, and health status. Policy and decision makers, who aim to promote issues of healthier society, and better well being and quality of life, may relate to this study and pursue further research of the subject matter.

A more active, less sedentary society is a healthier society. A healthier society means that individuals, families, communities, and the general public as a whole enjoy a better quality of life. A healthier society is a goal we as a society should strive for. 


\section{REFERENCES CITED}

1) American Heart Association, 2001 Heart and Stroke Statistical Update (n.d.). Retrieved October $1^{\text {st }}, 2001$ from http://www.americanheart.org/statistics/economic.html

2) Anselin, L. (1989) Spatial Econometrics: Methods and Models. NY: Kluwer Academic Publishers.

3) Anselin, L. (1993) Discrete Space Autoregressive Models in Environmental Modeling with GIS. Oxford: Oxford University Press.

4) Barnett, E.; Elmes, G.A.; Braham, V.E.; Halverson, J.A.; Lee, J.Y. \& Loftus, S. (1998)

Heart Disease in Appalachia: An Atlas of County Economic Conditions, Mortality, and Medical Care Resources. Prevention Research Center, West Virginia University, Morgantown WV.

5) Batrik, T.J. (1988) “Evaluating the Non-Marginal Reduction in Pollution Using Information on Defensive Expenditures." Journal of Environmental Economics and Management. 15: 111-127.

6) Blair, S.N.; Kohl, H.W. III; Barlow, C.E.; Paffenbarger, R.S. Jr.; Gibbons, L.W. \& Macera, C.A. (1995) “Changes in Physical Fitness and All-Cause Mortality.” JAMA. 273(14): 1093-1098.

7) Blair, S.N. \& Brodney, S. (1999)“Effects of Physical Inactivity and Obesity on Morbidity and Mortality: Current Evidence and Research Issues. Medicine and Science in Sports and Exercise. 31(11): S646-S662.

8) Brownson, R.C.; Baker, E.A.; Housemann, R.A.; Brennan, L.K. \& Bacak, S.J. (2001)

"Environmental and Policy Determinants of Physical Activity in the United States." American journal of public health. 91(12): 1995-2003.

9) Brownson, R.C.; Schmid, T.L.; King, A.C.; Eyler, A.A.; Pratt, M.; Murrayi, T.; Mayer, J.P. \& Brown, D.R. (1998) "Support for Policy Interventions to Increase Physical Activity in Rural Missouri.” American Journal of Health Promotion. 12(4): 263-266.

10) Bundy, J. (2002). “W.Va. Can’t Afford Cost of its Unhealthy Residents.” The Dominion Post. (Jan. 26). Morgantown, WV.

11) Carlin, S. (2001) “Community Breast Cancer Mapping-Huntington, Long Island." Retrieved December 11 $11^{\text {th }}, 2001$ from www.esri.com

12) Centers for Disease Control and Prevention. (1993). "Prevalence of Sedentary LifestyleBehavioral Risk Factor Surveillance System, United States, 1991.” MMWR-Morbidity and Mortality Weekly Report. 42(29): 576-579. 
13) Centers for Disease Control and Prevention. (1993). "Public Health Focus: Physical Activity and the Prevention of Coronary Heart Disease." MMWR-Morbidity and Mortality Weekly Report. 42(35): 669-672.

14) Centers for Disease Control and Prevention. (2001). "Prevalence of Healthy Lifestyle Characteristics-Michigan, 1998 and 2000." MMWR-Morbidity and Mortality Weekly Report. 50(35): 758-761.

15) Chenoweth, D. \& Pfohl, S. (2000). “The High Cost of Couch Potatoes.” Business \& Health. 18(1): 20-22.

16) Colditz, G.A. (1999). "Economic Costs of Obesity and Inactivity." Medicine and Science in Sports and Exercise. 31(11) supplement: S663-S667.

17) Deller, S.C.; Tsai, T.H.; Marcouiller, D.W. \& English, D.B.K. (2001) “The Role of Amenities and Quality of Life in Rural Economic Growth. American Journal of Agricultural Economics. 83(2): 352-365.

18) Diamond, P.A.; Hausman, J.A.; Leonard, G.K. \& Denning, M.A. (1993) "Does Contingent Valuation Measure Preferences? Experimental Evidence.” In Hausman, J., ed., Contingent Valuation: A Critical Assessment. Amsterdam: North Holland Press. 41-89.

19) Dickie, M. \& Gerking, S. (2000) "Valuing Public Health Damages Arising from War.” In Austin, J.E. \& Bruch, C.E., ed., The Environmental Consequences of War: Cambridge University Press, Cambridge, UK.501-529.

20) Dickie, M \& Gerking, S. (1991). "Willingness to Pay for Ozone Control: Inferences from the Demand for Medical Care.” Journal of Environmental Economics and Management. 21(1): 1-16.

21) Dickie, M \& Gerking, S. (1996). "Formation of Risk Beliefs, Joint Production and Willingness to Pay to Avoid Skin Cancer." Review of Economics and Statistics. 78 (3): 451463.

22) Dishman, R.K.; Sallis, J.F. \& Orenstein, D.R. (1985) “The Determinants of Physical Activity and Exercise.” Public Health Reports. 100(2): 158-171.

23) English, D.B.K.; Marcouiller, D.W. \& Cordell, H.K. (2000) "Tourism Dependence in Rural America: Estimates and Effects. Society \& Natural Resources. 13(3): 185-202.

24) Fletcher, G.F.; Balady, G; Blair, S.N.; Blumenthal, J.; Caspersen, C.; Chaitman, B.; Epstein, S.; Froelicher, E.S.S.; Froelicher, V. F.; Pina, I.L.\& Pollock, M.L. (1996) "Statement on Exercise: Benefits and Recommendations for Physical Activity Programs for All Americans." Circulation. 94: 857-862. 
Freeman, A.M. III. (1993) The Measurement of Environmental and Resource Values:

Theory and Methods. Washington, DC: Resource for the Future.

26) Goddin, G.; Valois, P.; Shephard, R.G. \& Desharnais, R. (1987) "Prediction of Leisure-

Time Exercise Behavior: A Path Analysis (LISREL V) Model.” Journal of Behavioral

Medicine. 10 (2): 145-158.

27) Gujarati, D.N. (2003) Basic Econometrics $4^{\text {th }}$ Edition. New York: McGraw-Hill.

28) Hanemann, W.M. (1994) "Valuing the Environment through Contingent Valuation."

Journal of Economic Perspectives 8(4): 19-43.

29) Harrington, W. \& Portney, P.R. (1987) "Valuing the Benefits of Health and Safety

Regulation.” Journal of Urban Economics 22: 101-112.

30) Harris, S.S.; Caspersen, C.J.; DeFriese, G.H. \& Estes, Jr., E.H. (1989) "Physical Activity Counseling for Healthy Adults as a Primary Preventive Intervention in the Clinical Setting." JAMA. 261(24): 3590-3598.

31) Hatziandreu, E.I.; Koplan, J.P.; Weinstein, M.C.; Casperten, C.J. \& Warner, K.E. (1988)

"A Cost-Effectiveness Analysis of Exercise as a Health Promotion Activity." AJPH. 78(11): 1417-1421.

32) Healthy People 2000. (n.d.). Retrieved November $25^{\text {th }}, 2001$ from http://odphp.osophs.dhhs.gov/pubs/hp2000/Default.htm

33) Healthy People 2000, Progress Review. (1998). Retrieved November, $25^{\text {th }}, 2001$ from http://odphp.osophs.dhhs.gov/pubs/hp2000/PROGRVW/phys/dec-98physactivity.htm

34) Healthy People 2010. (n.d.). Retrieved November $25^{\text {th }}, 2001$ from http://www.health.gov/healthypeople/

35) Hill, A.B. (1965) "The Environment and Disease: Association or Causation?" Proceedings of the Royal Society of Medicine. 58: 295-300.

36) Jones, T.F. \& Eaton, C.B. (1994) “Cost-Benefit Analysis of Walking To Prevent Coronary Heart Disease." Arch Fam Med. 3(8): 703-710.

37) Johansson, S.E. \& Sundquist, J. (1999) "Change in Lifestyle and their Influence on Health Status and All-Cause Mortality." International Journal of Epidemiology. 28: 10731080.

38) Kaman, R.L. (2000) "Will Increasing Fiscal Resources Promote Physical Fitness?" Canadian Medical Association Journal. 163 (11): 1467.

39) Keith, B. \& Althouse, R. (1999). Inside West Virginia: Public Policy Perspectives for the $21^{\text {st }}$ Century. West Virginia University Press, Morgantown, WV: 27-39. 
40) Kesaniemi, Y.A.; Danforth, E.; Jensen, M.D. Jr.; Kopelman, P.G.; Lefebvre, P. \& Reeder, B.A. (2001) “Dose-Response Issues Concerning Physical Activity and Health: An Evidence-Based Symposium." Medicine and Science in Sports and Exercise 33(6) supplement: S351-S358.

41) King, A.C.; Blair, S.N.; Bild, D.E.; Dishman, R.K.; Dubbert, P.M.; Marcus, B.H.;

Oldridge, N.B.; Paffenbarger, R.S. Jr.; Powell, K.E. \& Yeager, K.K. (1992) “Determinants of Physical Activity and Interventions in Adults.” Medicine and Science in Sports and Exercise. 24(6) S221-S236.

42) Kuchler, F. \& Golan, E. (1999). Assigning Values to Life: Comparing Methods for Valuing Health Risks. Washington DC: Agricultural Economic Report; no.784.

43) Levy, M.R.; Dignan, M. \& Shirreffs, J.H. (1988) Essentials of Life \& Health $5^{\text {th }}$ Edition. New York: Random House.

44) LeSage, J.P. (1999). Spatial Econometrics. The Web Book of Regional Science. Morgantown, WV: Regional Research Institute. Available at: http://rri.wvu.edu.

45) Linenger, J.M.; Chesson, C.V. \& Nice, D.S. (1991) "Physical Activity Gains Following Simple Environmental Change.” American Journal of Preventive Medicine. 7: 298-310.

46) National Center for Health Statistics (NCHS), Highlights of the Healthy people 2000 Final Review. (2001). Retrieved November, $25^{\text {th }}, 2001$ from http://www.cdc.gov/nchs/products/pubs/pubd/hp2k/review/highlightshp2000.htm

47) Myers, J.; Prakash, M.; Froelicher, V.; Do, D.; Partington, S. \& Atwood, J. E. (2002) "Exercise Capacity and Mortality among Men Referred for Exercise Testing." The New England Journal Of Medicine. 346(11): 793-801.

48) Nicholl, J.P.; Coleman, P. \& Braizer, J.E. (1994) "Health and Healthcare Costs and Benefits of Exercise.” PharmacoEconomics. 5(2): 109-122.

49) Pratt, M.; Macera, C.A.\& Wang, G. (2000) "Higher Direct Medical Costs Associated with Physical Inactivity.” The Physician and Sportsmedicine. 28(10): 63-70.

50) Rowe, R.D. \& Chestnut, L.G. (1985) Oxidants and Asthmatics in Los Angeles: A Benefits Analysis. Report to the Office of Policy Analysis, US Environmental Protection Agency.

Energy and Resource Consultants, Inc., Boulder, Co.

51) Ruskin, H (1999) “Leisure, Health, and Wellness: A Macro Approach.” Retrieved from ELRA website on 28, June 2001.

52) Russell, R.P.; Pratt, M.; Blair, S.N.; Haskell, W.L.; Macera, C.A.; Bouchard, C.;

Buchner, D.; Ettinger, W.; Heath, G.W.; King, A.C.; Kriska, A.;

Leon, A.S.; Marcus, B.H.; Morris, J.; Paffenbarger, Jr., R.S.; Patrick, K.; Pollock, M.L.; 
Rippe, J.M.; Sallis, J. \& Wilmore, J.H. (1995) "Physical Activity and Public Health-A

Recommendation from the Center for Disease Control and Prevention and the American

College of Sports Medicine.” JAMA. 273: 402-407.

53) Schoenborn, C.A. \& Barnes, P.M. (2002) "Leisure-Time Physical Activity among

Adults: United States, 1977-1998." Advanced Data from Vital and Health Statistics. 325.

Hyattsville, Maryland: National Center for Health Statistics.

54) Shephard, R.G. (1989) "Current Perspectives on the Economics of Fitness and Sport with Particular Reference to Worksite Programs.” Sports Medicine. 7: 286-309.

55) Shephard, R.G. (1992) "Twelve Years Experience of a Fitness Program for the Salaried Employees of a Toronto Life Assurance Company." American Journal of Health Promotion. 6(4): 292-301.

56) Studenmund, A.H. (2001) Using Econometrics: A Practical Guide $4^{\text {th }}$ Edition. Addison Wesley.

57) The Burden of Cardiovascular Disease in West Virginia: A Report By The West Virginia Department of Health and Human Resources, Bureau for Public Health, Office of Epidemiology and Health Promotion \& Health Statistics Center. In Collaboration With The Division of Health Promotion \& The Cardiovascular Health Program. Retrieved on June 22nd 2002 from http://www.wvdhhr.org/bph/oehp/hsc/burdencvd/default.htm

58) U.S. Forest Service. (1997). National Outdoor Recreation Supply Information System (NORSIS). Athens, GA: Southern Research Station, US Forest Service. (Compiled database)

59) World health organization (n.d.) retrieved August, $15^{\text {th }} 2002$ from http://www.who.int/about/definition/en/ 


\section{APPENDIX A \\ HEALTH VALUATION METHODS}

This appendix provides a discussion of the most frequently used economic methods for measuring values for health and life. This section relies heavily on the discussion of the most frequently employed methods for valuing public health damages arising from war by Dickie and Gerking (2000).

Despite extensive use over the past few decades, methods for valuing health and estimating values for morbidity and mortality are still highly controversial. Not only is health evaluation subject to difficulties associated with non-market goods valuation, but also some people believe that life and health are unlike other commodities. Assigning monetary values to them is perceived to be totally inappropriate. Additional problems in evaluating health are that, in practice, no method can capture all the aspects and effects of changes in health status. This is because assigning values to pains and suffering, level of well being, and other health related feelings would differ between different individuals. Further, because health problems may develop over time, manifest themselves in different ways, cause various complexities, and appear regardless of other health problems, it is very difficult to establish a precise reference point for a comparison between health status of different individuals, and determining precisely the attributes of a particular health state. Consequently, there isn't a single, universally accepted method for computing monetary values of changes in health status.

Since health is an intangible, non-market good, the unit it is measured by is not straightforward. The methods presented in this discussion use dollars as their metric. The use of a monetary scale is appealing not only because it allows comparing and ranking behaviors and outcomes, but also due to the fact that money is a common tool for conveying value. However, the use of monetary units as a measurement tool has some disadvantages. For example, assigning finite values to life and health is criticized for being inappropriate and for being subject to flaws based on the uneven distribution of money across the population.

When economists evaluate benefits or impairments associated with changes in health status, they basically examine for changes in well being, which depends, according to economic theory, on consumption of goods and services, health status, and other 
characteristics. To facilitate the valuation process, economists prefer to assign dollar equivalents for changes in individual well being. Theoretically, these changes can be measured by either willingness to pay (WTP) for health improvements or willingness to accept (WTA) compensation for health level reductions. Both WTP and WTA are contingent upon individual preferences and therefore vary across individuals.

The WTP measure of health is the maximum amount of money an individual is willing and able to pay in order to obtain an improvement or avoid a decrement in his health status. Thus, the WTP approach is concerned with measuring ex ante valuations; which means that the valuations are at the same time that choices are made. The WTA measure of health is the smallest amount of money that an individual would accept as a compensation to endure a decrement or forego an improvement in his health status.

Both WTP and WTA, when using a monetary metric, assign monetary terms to changes in well being. However, these concepts are not identical due to the fact that they adopt different reference points. Although both measures capture changes in well being, WTP, is easier to quantify, and thus used more frequently in health valuations.

Generally, WTP depends on preferences and opportunities. Preferences represent the individual's perceptions about how his health, market and non-market goods and services, and other factors affect his well being. In other words, these preferences generate the individual's indifference curves. Opportunities refer to the means available to satisfy preferences and are determined by prices, income, and time. Thus, opportunities form the constraints an individual is subject to when trying to maximize his preferences.

WTP for health also depends on socio-demographics characteristics such as age, income, and education, prior health status, genetics, and the context in which the health effects occurred. The latter refers to the degree and extent that an individual has been voluntarily exposed to adverse health effects.

The foundation of the WTP approach is the belief that individuals are the best judges for their own well being (consumer sovereignty). Accordingly, people reveal their preferences through observed behavior and stated preferences. There are two basic approaches for assessing people's health preferences. The first is called "revealed preference". It relies on observed behavior and indirectly measures preferences and infers WTP by linking changes in health to related market good. For example, if a certain dose 
relieves a specific ache without providing any other benefit, then any one who purchase this dose at its market price, values his ache's relief at least at the price of this dose. The second approach is called "stated preference" because it confronts individuals with a hypothetical situation and relies on their statements of how they value a change in their health status. For example, a questionnaire may include questions that ask respondents how much they will be willing to pay to avoid a flu episode, toothache, or cancer. Regardless of the approach used, several problems arise when measuring WTP for health:

i. A change in health status is usually followed by several health-related impacts on one's well being. Therefore, some impacts may be overestimated while others may be underestimated.

ii. Health effects include pains, anxiety, suffering, and other aspects that are difficult to measure precisely.

iii. An individual's health status may affect the well being of others, therefore WTP for an individual's own health may be too narrow and be underestimated in many cases.

iv. A timing problem is possible because health effects of certain situations may be immediate or delayed. For example, bad eating habits as a youngster enhance the chances for being an obese adult, which may lead to various diseases.

v. There is a problem with discounting health problems. WTP today to avoid a specific future health effect would be lower the further into the future it is expected to occur.

vi. Health status is a function of many parameters, and is not driven merely by cause and effect. For instance, health professionals preach that smoking increases the risk of poor health. Yet, every once in a while you find an exception: a 90 year old person who smokes, drinks alcohol, and has never been sick.

WTP for better health can be measured by several methods and its magnitude differs according to health outcomes and degree of health effects. Morbidity and mortality have different forms. Morbidity can be either acute or chronic. Mortality can occur at any point of time and there is a certainty about its occurrence at some point. Obviously, one will be willing to pay more to avoid a severe, long lasting impairment than to avoid mild, short-term symptoms. This insight is supported by both common sense and economic theory. 
To date, WTP provides the best estimate of individual welfare known to economists. The foundations of the concept are logical, sound, and well supported by welfare economic theory. Therefore, estimating WTP is basically the essence of all health evaluation methods. Yet, due to its theoretical nature and its reliance on individual's utility functions, empirically calculating WTP is a challenging task that usually yields a range of values and proxies (Kuchler \& Golan, 1999).

Based on the WTP concept, economists have developed methods to capture, bound, or provide proxies for evaluating health and life. What follows is a discussion of the most prevalent methods for valuing health outcomes: Cost of Illness (COI), averting behavior, and contingent valuation. Indeed, there are additional, more complex, methods for valuing health such as: hedonic wage, risk-risk trade-offs, and health state indices. However, these methods are beyond the scope of this discussion.

\section{Cost of Illness}

Cost of Illness (COI) estimates provide an accounting of the dollars spent on medical goods and services and dollars of employment compensation that are foregone as a result of illness or premature death (Colditz, 1999; Jones \& Eaton, 1994; AHA 2001 Heart and Stroke Statistical Update). Total COI is composed of the sum of direct and indirect costs of morbidity and premature mortality. Direct costs include all of the out-ofthe-pocket- money invested in treating an impaired or ill individual. More specifically, direct costs are usually associated with costs for hospitalization, doctors appointments, medical goods and services, and so forth. Indirect costs, also called human capital costs, reflect the present value of foregone labor earnings due to illness or premature mortality. Generally, the relative sizes of direct and indirect costs vary across different diseases, and are dependent on the characteristics of the illness and the technologies associated with preventing the illness. Typically, over time, due to biomedical research and technology improvements, the relative size of direct costs increases and the relative size of indirect costs decreases. However, if an illness results in extensive morbidity or premature mortality, then indirect costs will outweigh direct costs (Kuchler \& Golan).

Theoretically, the COI approach measures ex post costs associated with a health impairment or premature death. In other words, COI retrospectively measures the flow of direct and indirect costs associated with an illness rather than the individual's WTP to 
prevent it. Yet, most health economists agree that COI establishes a lower bound on WTP (Harrington \& Portney, 1987; Kuchler \& Golan, 1999).

The reasons COI is considered as a lower bound for WTP, and the main critiques against it are that it doesn't account for elements such as pain and suffering, it neglects the value associated with better well being, it doesn't consider savings resulting from defensive and preventive expenditures, and it doesn't account for lost leisure time and other potential benefits derived from improved health.

Methodologically, the COI method has some drawbacks.

i. COI doesn't account for the value of intangibles such as pain, anxiety, and suffering.

ii. There are different problems associated with measuring the value of lost production for calculating indirect costs. The major problems are: accounting for the full impact of chronic illness on earnings, selecting the right wage rate to apply to lost work time, and valuing time spent in unpaid work. Adverse health conditions influence an individual's work schedule in different ways: it can cause a person to miss regularly scheduled work time, it may limit his job options and restrict a person to choose a job with fewer scheduled hours and requirements, and it even may result in a withdrawal from the workforce. In addition, evaluating missed hours due to illness on an hourly wage basis suffers from the following flaws: it doesn't capture long-term effects of chronic illness on the selection of a position, it may be influenced by labor market volatility, employee's compensation typically includes more than wages (e.g. bonus, flexible hours, pension plans, etc.), and most importantly, it doesn't account for foregone productivity of individuals who are not employed in paid work nor does it account for loss of leisure time.

iii. The distribution of an illness does not always match with the distribution of sociodemographic characteristics. For instance, more educated people tend to earn higher salaries and to be healthier than less educated people. Accordingly, the human capital estimation will yield lower values to minorities and unskilled (Kuchler \& Golan). This flaw is of a major importance if trying to rank severity of diseases according to their total COI because in extreme cases, mild diseases that affect a wealthy class might yield a higher COI than a severe disease that affect a lower class due to differences in the wage rates. 
iv. Direct costs are influenced by the distribution of income. Since health is a normal good, an illness that strikes low-income individuals would cause smaller direct health expenditures than a disease that strikes randomly throughout the population.

v. Direct costs reflect the ability to pay for medical services to treat the illness. Thus, severe diseases with almost no remedies will generate fewer costs than mild diseases such as the common cold, and as a result may be underrated based on total COI.

Empirically, COI components are considered as relatively easy to estimate and analyze. However, there aren't strict COI guidelines to follow and data are for the most part insufficient and inaccurate. Usually, COI is measured on a prevalence or incidence basis. Prevalence-based measurements assign costs of all existing cases of an illness to the year in which these costs are incurred. Incidence-based measurements assign the present value of all costs associated with an illness to the year of onset. The difference between prevalence-based and incidence-based is contingent on the duration of the disease. Generally, the difference is little for an acute illness, and as duration increases prevalence-based costs exceed incidence-based costs.

Prevalence-based and incidence-based approaches have different data requirements. Prevalence direct costs are usually computed from aggregate data, where total health care expenditures are broken down to categories such as hospital care, nursing home care, medical drugs, etc. Then, expenditures from each category are allocated to specific diseases, and by a summation of all categories for a specific disease, direct costs are calculated. Indirect costs are usually estimated by applying monetary value to the duration of restricted activities. Alternatively, the incidence-based approach estimates the COI for each year of illness, weighted by the probability an individual would survive each year, and then computing the discount value of the stream of costs. Direct costs will be based upon actual costs incurred by patients, and in cases when data do not exist, on literature reviews. Indirect costs are measured by using estimations of the duration of the impairment and the effect the impairment has on the individual's income. A few specific problems associated with the incidence-based approach are: little data for computing direct costs and earning losses, choosing the appropriate discount rate, estimating the correct individual's surviving probability, and forecasting future costs. 
In summary, despite the appeal of the COI method, humans' well being goes beyond direct and indirect costs of illness. Therefore, COI fails to capture the complete WTP for an individual's well being. If a change in welfare with respect to adverse health outcomes is the summation of lost working compensation, medical expenses, the monetary value of the disutility of illness, and the impact of preventive expenditures, then the COI method measures only the first two elements and neglect the latter two. Consequently, the COI method is not considered as a good measurement of WTP, and at most, COI can be a proxy or a lower bound of WTP (Kuchler \& Golan). Nevertheless, despite its shortcomings, the COI method is still an important tool because it provides economist and policymakers useful information on the impact and the magnitude of the economic flows resulting from adverse health outcomes.

\section{Averting Behavior}

The averting behavior method is used to infer individual's WTP from actions taken to prevent adverse health outcomes. Since this method takes into account actions taken by an individual to either avoid a certain illness or to reduce its effects, this method is a variation of the revealed preference approach. Averting behavior can come into play in several forms: purchase of a durable good, purchase of a nondurable good, and changes in lifestyle and daily activities (Hatziandreu et al., 1988; Jones \& Eaton, 1994).

The bulk of research with respect to the averting behavior method has been about capturing the WTP for avoiding exposure to environmental hazards and mitigating their health effects. However, this method can be stretched beyond environmental health effects because individuals are able to choose courses of actions to avoid or reduce illnesses in general.

The averting behavior method incorporates the WTP concept since individuals possess the right to choose their course of action, and thus, this method reflects individual's own will.

The averting behavior method accounts for all the effects of health on people's well being. Consistent with economic theory, the averting behavior method implies that a person would pursue protective actions as long as the perceived marginal benefit from the last unit of protection exceeds its costs. Hence, assuming a continuous relationship between defensive actions and health improvements, an individual will avert until cost of 
averting is equal to the maximum WTP for health improvements. For example, if there was a pill with no related side effects that reduces the risk of developing a heart disease by one in a million at a cost of $\$ 5$, then an individual will consume these pills until the point where his WTP for an additional reduction in risk of heart disease is just equal to $\$ 5$. Interestingly, for large changes in health conditions, averting behavior can establish a lower bound on non-marginal WTP (Batrik, 1988). For example, a person who installs a \$25 shock absorber on his mountain bike to avoid or reduce the chance for subsequent back problems is willing to pay at least $\$ 25$, as revealed by his actions, although his actual WTP to prevent back problems may be higher. This example shows that the averting behavior method enables the comparison of marginal health benefits to marginal costs for continuous goods and establishes lower bounds for more discrete or large changes in health status.

A few downsides of the averting behavior method are:

i. Not all goods are broadly accepted to have a favorable effect on health. For example, energy supplements such as isotonic drinks or energy bars are still controversial with respect to their effect on the average person's health.

ii. Price instability can cause fluctuations when calculating averting behavior.

iii. Most goods include other benefits other than health benefits. Thus, segregating the WTP for health improvement from other values that are provided by the good is a complicated process. For instance, if a person is willing to pay $\$ 100$ for a pair of name-brand running shoes, his willingness to pay consists of other intangible benefits he receives from the shoes.

iv. Several averting actions do not have a market price to use in computing their costs. For example, if a person prefers to stay indoors to avoid exposure to air pollution, there isn't any monetary price to attach to his action. Wage rate will not fit because this person can be either productive or deriving additional benefits from staying indoors.

v. In actuality, averting behavior usually reflects a discrete choice of whether or not to take an action, rather than a decision about the level of a continuous variable. Consequently, these discrete choices do not reveal WTP, rather they bound it from 
beneath. Estimating WTP based on discrete behaviors is possible only by using complex methods (Dickie \& Gerking, 1991).

vi. Usually, surveys are used to collect data on the actions taken, their costs, and perceived health effects. Thus, the averting behavior method is not only subject to problems associated with survey design but also to problems associated with capturing and documenting individuals perceptions.

vii. A person's choice of averting behavior is based on his perception of the associated health improvements. However, these perceptions may be biased and not fit assessments made by experts.

\section{Contingent Valuation}

The contingent valuation (CV) approach is a "stated preference" method for directly establishing an individual's WTP for a hypothetical commodity, typically using survey research methods. This tool was designed to help economists estimate demand for non-market goods based on respondents' stated preferences in a hypothetical market. Although contingent valuation methods have been used primarily for valuing recreation benefits and environmental conditions in the past, there is a recent increase in the use of CV methods to assess values for avoiding morbidity and mortality. For example, contingent valuation methods have been used to value reductions in skin cancer risk (Dickie \& Gerking, 1996), avoidance of asthma-related illness (Rowe \& Chestnut, 1985), and so forth.

Data for $\mathrm{CV}$ studies are usually collected through surveys. A questionnaire is designed to collect data on symptoms' properties (e.g. frequency, severity, etc.), and the respondent's maximum WTP to avoid these symptoms. Then, a statistical analysis is conducted. Despite the theoretical evidence that CV methods are consistent with welfare economic theory because they can measure either WTP or WTA depending on the survey design and the research objectives, and their capability to capture the full effects of illness on an individual's well being, CV methods are controversial. The nature of CV methods (eliciting an individual's WTP or WTA by using surveys that describe a hypothetical situation) may result in inaccuracies, flawed estimations, and disputed results. Several criticisms of the $\mathrm{CV}$ method can include the following: 
- Structural bias: CV methods don't require real cash transactions. Accordingly, individuals may not be able to convey their real demand for the good on hand. In addition, WTP as a concept is limited to the amount of money a person is not only willing but also able to pay for a good. When money doesn't change hands, results might be biased.

- Information bias: respondents have to understand the good (e.g. illness) to be valued, its side effects and its associated long and short term implications. Consequently, mild, prevalent illnesses may be more applicable for $\mathrm{CV}$ than rare, unique diseases. Thus, assessing the value of non-market goods such as relief from illness, especially from rare diseases that most respondents are not familiar with, is subject to errors.

- Strategic bias: the hypothetical nature of CV methods may yield over or under estimations by the respondent due to either lack of incentive to answer the questionnaire thoroughly and carefully, or the desire of respondents to influence the results in order to reach personal goals.

- Perception bias: respondents will assign different WTP values to an illness that is perceived to be hypothetical than to an illness that is perceived real. For example, a basketball player will assign a higher WTP value to avoid a sprained ankle than a sedentary person who has never experienced the pain associated with such impairment.

- Timing bias: usually people will state a higher WTP to prevent impairments or pains as long as it is a hypothetical payment. In actuality, people may be willing to suffer more or pay less for preventing it. For instance, people who suffer a toothache would often say that they would pay the dentist a fortune for relief. After the treatment, when the pain is gone they would often complain about the costs of the treatment.

- Survey design: there are two major techniques to elicit valuations. One is using "open-ended" questions, in which the respondent has to state a maximum value he would be willing to pay for a certain good. Principally, this technique elicits each individual's maximum WTP. However, often respondents have difficulty with this approach evidenced by high rates of non-responses or extremely inconceivable results (Freeman, 1993). The other technique is called a "referendum" approach, in which respondents are asked if they would be willing to pay a stated amount of money for a 
certain good. This technique reveals boundaries for the respondents WTP. Researches often use a "bidding game" to define more precisely what the actual WTP of an individual is by offering increasing or decreasing bids to the individual until an upper bound for WTP is established. However, this technique introduces "bidding system bias" because responses associated with dollar values are dependent upon the design of the survey. Responses, thus, are affected by the extent of the scale, the initial value asked, and the magnitude of the increments. Other factors concerning surveys are: sampling technique and size, survey technique (e.g. telephone survey, in-person interview, mail), order of the questions, length and complexity of the survey, the attitudes of the surveyor and respondent towards the valued good, and so forth.

- "Insensitivity to scope": CV methods are based on economic theory but results occasionally are not consistent and are not sensitive to scope. In other words, in contrast to economic theory, which is based on the assumption that more is better, some studies have shown that people are not consistent and their WTP to prevent some symptoms of a disease is no larger then their WTP to prevent only one symptom (Diamond et al., 1993). Economists attribute this inconsistency to a lack of understanding the nature of the good on hand, and people's inability to precisely rank their preferences.

In summary, the $\mathrm{CV}$ method is a controversial tool for empirically estimating WTP in monetary units. Its main shortcomings are that it is based on survey responses to hypothetical situations and the lack of real money transactions. However, proponents of CV claim that by careful survey design and data analysis, most biases can be eliminated, minimized, or controlled. In that case, most responses would reflect stable preferences in accordance to economic theory, and often yield results that correspond closely to value measures inferred from actual behavior (Hanemann, 1994).

\section{Summary}

The three most frequently methods for assigning values to health: COI, averting behavior, and $\mathrm{CV}$ have been introduced, and their advantages and disadvantages have been discussed. The objective of all these methods is to capture an individual's WTP for an improved health status. Yet, neither of the methods is ideal, nor fit all circumstances; and they all are controversial and have different drawbacks. 
The COI method is frequently applied due to its straightforward interpretation. However, COI doesn't take into account critical factors associated with impaired health such as pain and suffering. The averting behavior has a theoretical economic support, but data needed for implementation are difficult to obtain and thus, often times this method uses proxies instead of actual data. The CV method provides, theoretically, a broad conceptual measurement of an individual's WTP for improved health. Alas, this method is very controversial due to the hypothetic nature of its data collecting process.

In terms of capturing the WTP for improved health, COI does account for actual money spent and loss of productivity due to morbidity and mortality. However, due to its shortcomings it is considered, at most, as a lower bound of WTP. CV and averting behavior are theoretically better measurements for well being. Nevertheless, in practice these methods are subject to many inaccuracies and data associated problems and tend to either bound the WTP or to under or over estimate it.

In any case, its important to stress that there are more sophisticated methods to evaluate health and, yet, there isn't a single method that is considered as best to use in all situations. 


\section{APPENDIX B \\ REGRESSION RESULTS (LIMDEP AND SPACESTAT OUTPUT)}

\section{Traditional OLS Analysis (LIMDEP)}

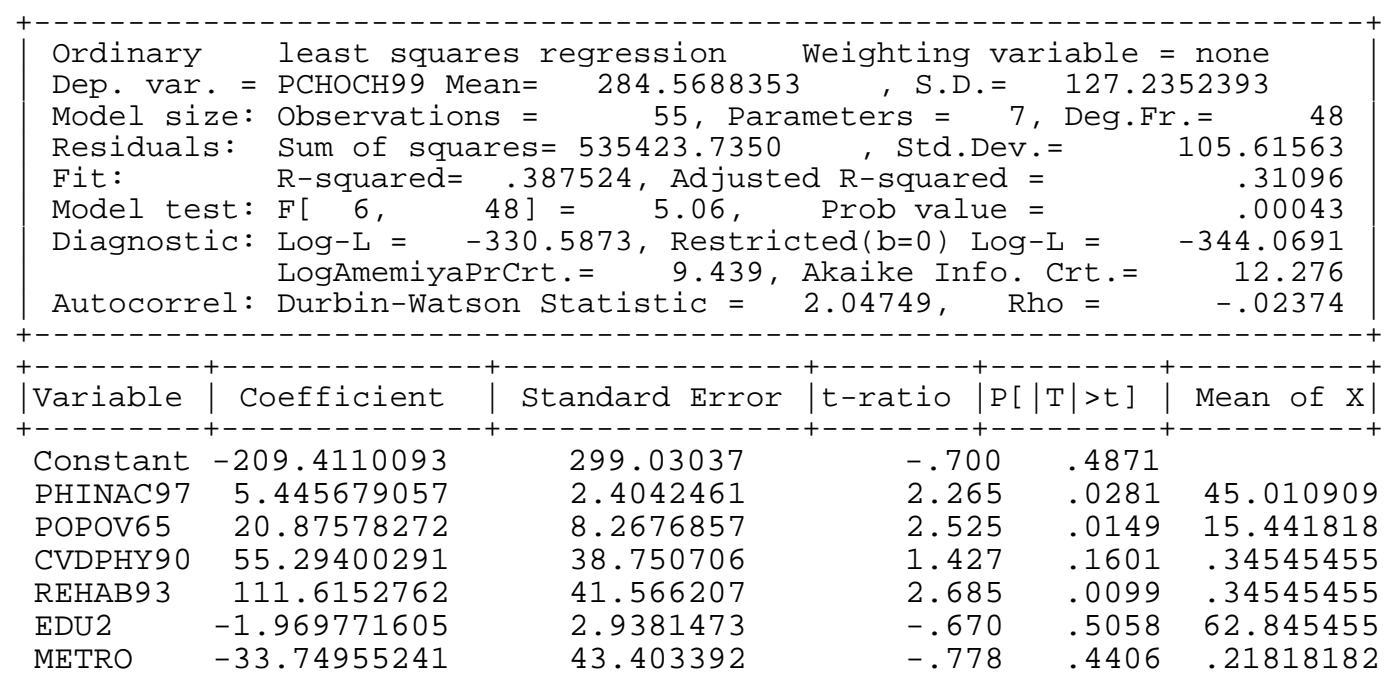

\section{SPACESTAT Regression Diagnostics for the Non-Spatial OLS Model}

\section{TEST}

Moran's I (error)

Lagrange Multiplier (error)

Robust LM (error)

Kelejian-Robinson (error)

Lagrange Multiplier (lag)

Robust LM (lag)

Lagrange Multiplier (SARMA)

MI/DF
0.283179
1
1
7
1
1
2

VALUE

PROB

$3.815851 \quad 0.000136$

$\begin{array}{ll}8.717139 & 0.003152\end{array}$

$2.552637 \quad 0.110110$

$23.503252 \quad 0.001392$

$17.576319 \quad 0.000028$

$11.411817 \quad 0.000730$

$20.128956 \quad 0.000043$ 


\section{First Order Spatial Lag Analysis (LIMDEP)}

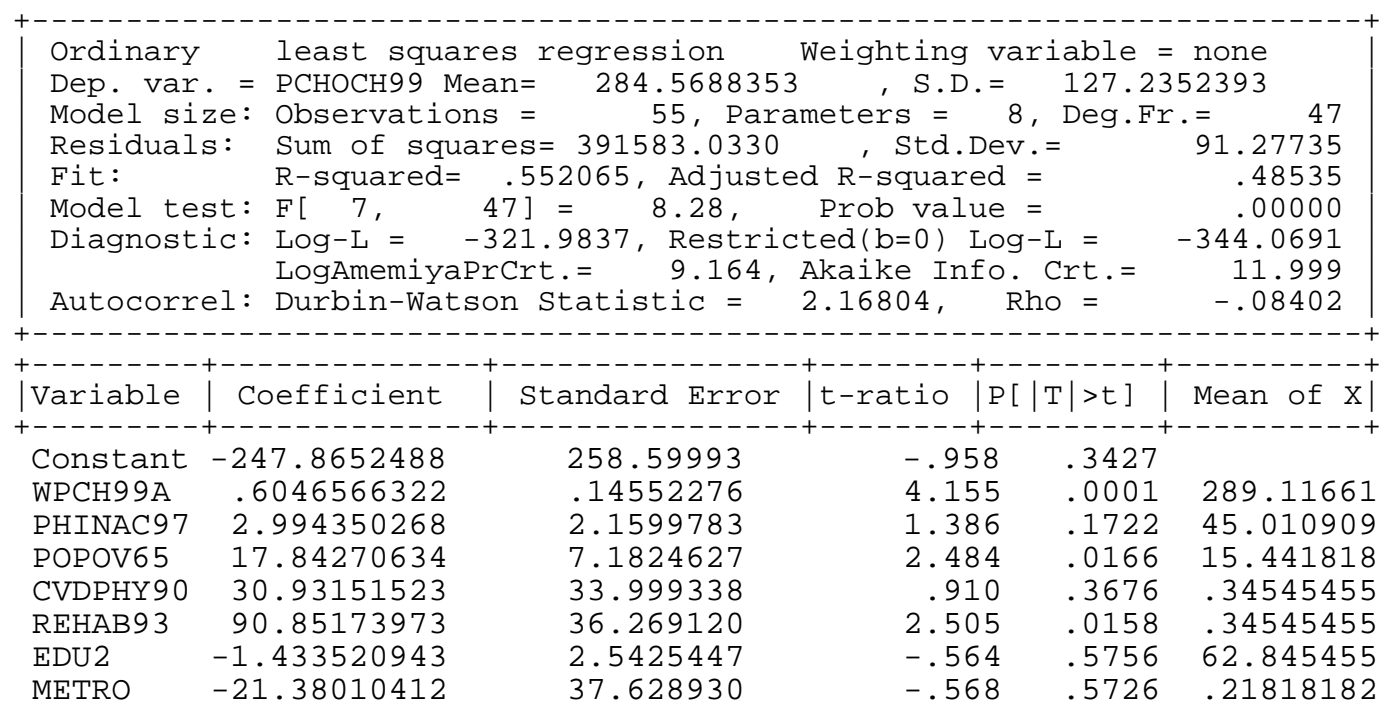

\section{First Order Spatial Lag Analysis (SPACESTAT)}

\begin{tabular}{|c|c|c|c|c|c|c|c|}
\hline DATA S & SET YOA & AV2 & TIAL & WEIGHTS & MATRIX & WM & \\
\hline DEPENI & DENT VA & RIABLE PCHOCH & & OBS 55 & VARS 8 & DF & \\
\hline $\mathrm{R} 2$ & 0.4885 & Sq. Corr. 0.5539 & & & & & \\
\hline LIK & -323.707 & AIC $\quad 663.414$ & $\mathrm{SC}$ & 679.47 & & & \\
\hline SIG-SQ & 7116.6 & $9(84.3605)$ & & & & & \\
\hline VARIA & ABLE & COEFF & S.D & & Z-VAI & $\mathrm{UE}$ & PROB \\
\hline W_PCH & $\mathrm{OCH}$ & 0.47551 & 0.1 & 25511 & 3.788 & 88 & 0.000152 \\
\hline $\mathrm{CO} N S T$ & ANT & -193.894 & & 3.573 & -0.830 & 19 & 0.406471 \\
\hline PHINA & C97 & 3.16899 & & 88821 & 1.678 & 05 & 0.093288 \\
\hline POPOV & 65 & 18.4762 & & 54137 & 2.824 & 07 & 0.004735 \\
\hline CVDPH & $Y 9 \overline{0}$ & 40.0677 & & .7453 & 1.3032 & 16 & 0.192501 \\
\hline REHAB & 93 & 93.6813 & & .0367 & 2.835 & 73 & 0.004573 \\
\hline EDU2 & & -2.04672 & & 31981 & -0.8822 & 81 & 0.377625 \\
\hline METRO & & -22.5652 & 34 & .9458 & $-0.645^{\circ}$ & & 0.518460 \\
\hline
\end{tabular}

REGRESSION DIAGNOSTICS

DIAGNOSTICS FOR HETEROSKEDASTICITY

RANDOM COEFFICIENTS

TEST DF VALUE PROB

Breusch-Pagan test $\quad 6 \quad 9.951773 \quad 0.126698$

Spatial B-P test $6 \quad 9.952462 \quad 0.126668$

DIAGNOSTICS FOR SPATIAL DEPENDENCE

SPATIAL LAG DEPENDENCE FOR WEIGHTS MATRIX WMS (row-standardized weights)

TEST DF VALUE PROB

$\begin{array}{lll}\text { Likelihood Ratio Test } \quad 1 \quad 13.702898 & 0.000214\end{array}$

LAGRANGE MULTIPLIER TEST ON SPATIAL ERROR DEPENDENCE

WEIGHT STAND ZERO DF VALUE PROB

$\begin{array}{llllll}\text { WMS } & \text { yes } & \text { no } & 1 & 4.144905 & 0.041760\end{array}$ 
Two Stage Least Squares Spatial Durbin Model: PHINAC97 (LIMDEP)

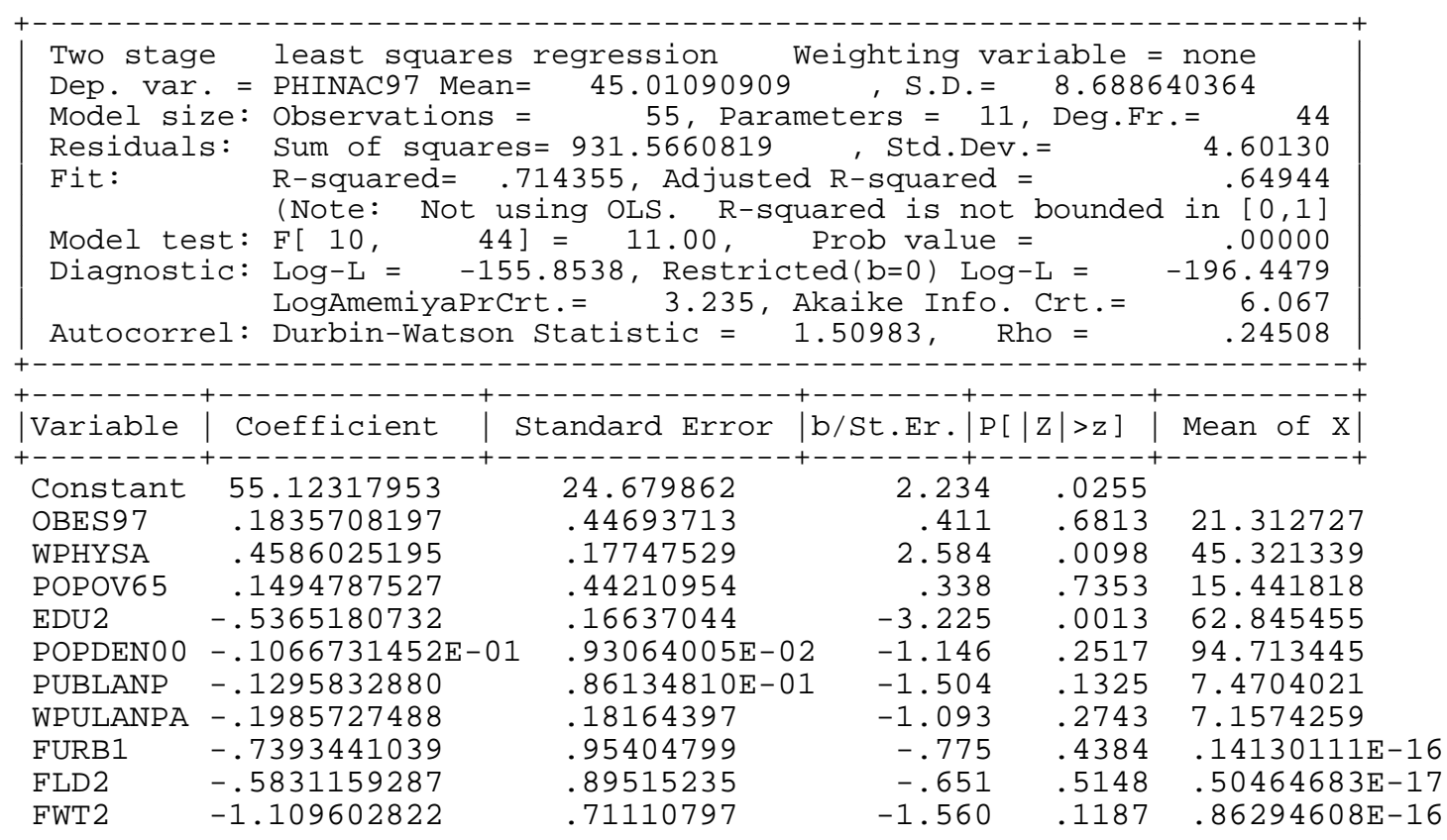

\section{Two Stage Least Squares Spatial Durbin Model: OBES97 (LIMDEP)}

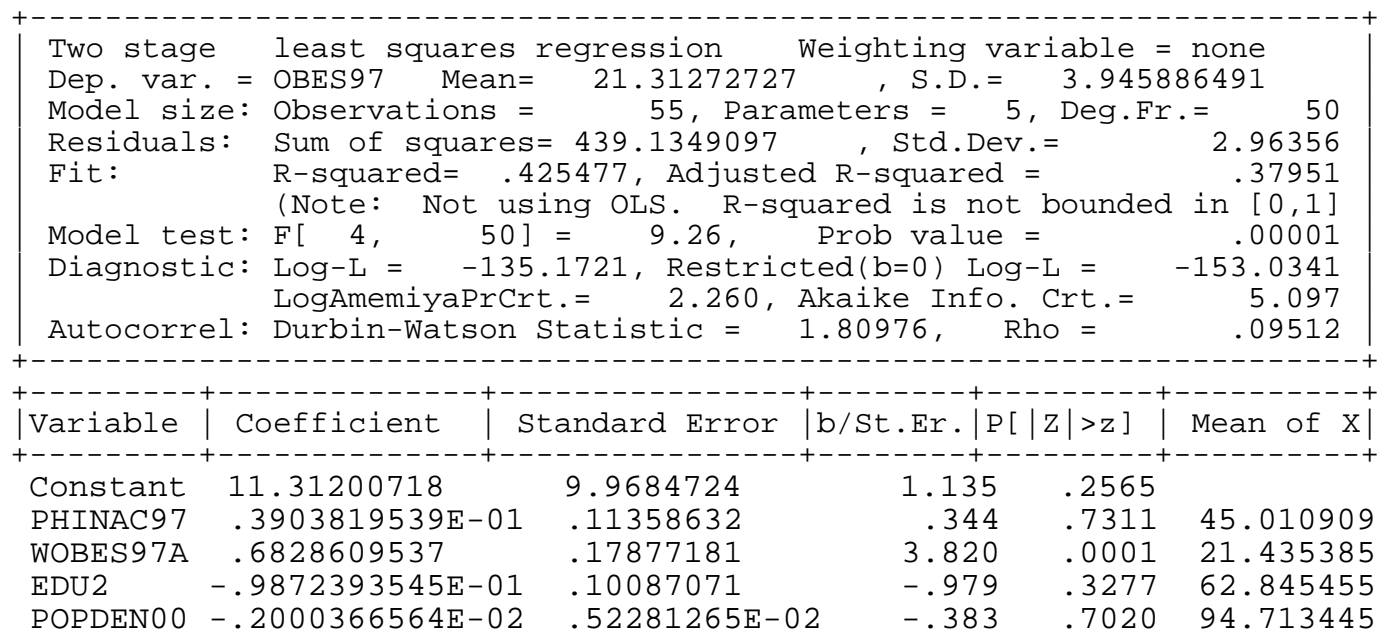


DESCRIPTIVE STATISTICS

\begin{tabular}{|c|c|c|c|c|}
\hline \multicolumn{5}{|c|}{ DESCRIPTIVE STATISTICS $(\mathbf{N}=\mathbf{5 5})$} \\
\hline VARIABLE & MEAN & STD. DEV & MINIMUM & MAXIMUM \\
\hline РСHOCH99 & 284.56 & 127.23 & 50.8 & 663.13 \\
\hline PHINAC97 & 45 & 8.68 & 22.4 & 63.2 \\
\hline OBES97 & 21.31 & 3.94 & 14.1 & 30.3 \\
\hline WPCH99A & 289.11 & 96.11 & 62.54 & 426.59 \\
\hline WPHYSA & 45.32 & 5.78 & 31.6 & 61 \\
\hline WOBES97A & 21.43 & 2.74 & 15.5 & 28.57 \\
\hline POPOV65 & 15.44 & 1.9 & 10.7 & 19.9 \\
\hline CVDPHY90 & 0.34 & 0.47 & 0 & 1 \\
\hline REHAB93 & 0.345 & 0.479 & 0 & 1 \\
\hline EDU2 & 62.8 & 7.7 & 42.3 & 75.4 \\
\hline METRO & 0.21 & 0.416 & 0 & 1 \\
\hline POPDEN00 & 94.7 & 100.1 & 9.7 & 446.58 \\
\hline PUBLANP & 7.47 & 10.6 & 0 & 57.2 \\
\hline WPULANPA & 7.15 & 6.32 & 0.35 & 28.2 \\
\hline FURB1 & 0 & 1 & -0.76 & 6.17 \\
\hline FLD2 & 0 & 1 & -1.86 & 2.74 \\
\hline FWT2 & 0 & 1 & -1.4 & 6.22 \\
\hline
\end{tabular}

